\title{
System Definition and Analysis Gas-Fired Industrial Advanced Turbine Systems
}

\author{
Topical Report \\ May 1997 \\ By: \\ Gary M. Holloway
}

RECEIVED

JAN 131998

OSTI

Work Performed Under Contract No.: DE-AC21-93MC30244

By

GE Power Generation Engineering

Power Generation Systems

Building 53, Room 425

1 River Road

Schenectady, New York 12345 


\section{Disclaimer}

This report was prepared as an account of work sponsored by an agency of the United States Government. Neither the United States Government nor any agency thereof, nor any of their employees, makes any warranty, express or implied, or assumes any legal liability or responsibility for the accuracy, completeness, or usefulness of any information, apparatus, product, or process disclosed, or represents that its use would not infringe privately owned rights. Reference herein to any specific commercial product, process, or service by trade name, trademark, manufacturer, or otherwise does not necessarily constitute or imply its endorsement, recommendation, or favoring by the United States Government or any agency thereof. The views and opinions of authors expressed herein do not necessarily state or reflect those of the United States Government or any agency thereof. 


\section{DISCLAIMER}

Portions of this document may be illegible electronic image products. Images are produced from the best available original document. 


\section{TASK 6-SYSTEM DEFINTION AND ANALYSIS}

\subsection{TASK OBJECTIVE}

Define and analyze an engine system based on the gas fuel Advanced Turbine from Task 3.

Using the cycle results of Task 3, a technical effort was started for Task 6 which would establish the definition of the engine flowpath and the key engine component systems.

The key engine systems are:

- Gas Turbine Engine Overall Flowpath

- Booster (Low Pressure Compressor)

- Intercooler

- High Pressure Compressor

- Combustor

- High Pressure Turbine

- Low Pressure Turbine \& Materials

- Engine System Packaging

- Power Plant Configurations

As noted earlier in Task 3, the design objective is to use the GE90 engine as the platform for the GE Industrial Advanced Turbine System. This objective sets the bounds for the engine flowpath and component sytems.

\subsection{ADVANCED TURBINE SYSTEM ENGINE FLOWPATH, BOOSTER AND POWER TURBINE DESIGN}

The flowpath for the Advanced Turbine System (ATS) for the Task 6 cycle has been completed and incorporates as much hardware from the GE90 as possible. This unit is an intercooled and turbocooled design which pushes the core compressor to a high exit pressure, but limits high pressure turbine inlet temperature due to NOx emissions. The intercooler allows the high-pressure compressor to pass increased mass flow of air, which results in a larger power output. This unit uses the GE90 core compressor, the GE90 high pressure turbine, and the GE90 turbine mid frame. The power turbine is a GE90 type turbine, and the booster is a new design. Using General Electric's developed software called Flowpath, which uses engine cycle data and key mechnical design algorithms, an engine cross section was developed for the General Electric's Industrial Advanced Turbine System. The resulting Flowpath developed cross section of the engine is shown in Figure 6.1.1. 


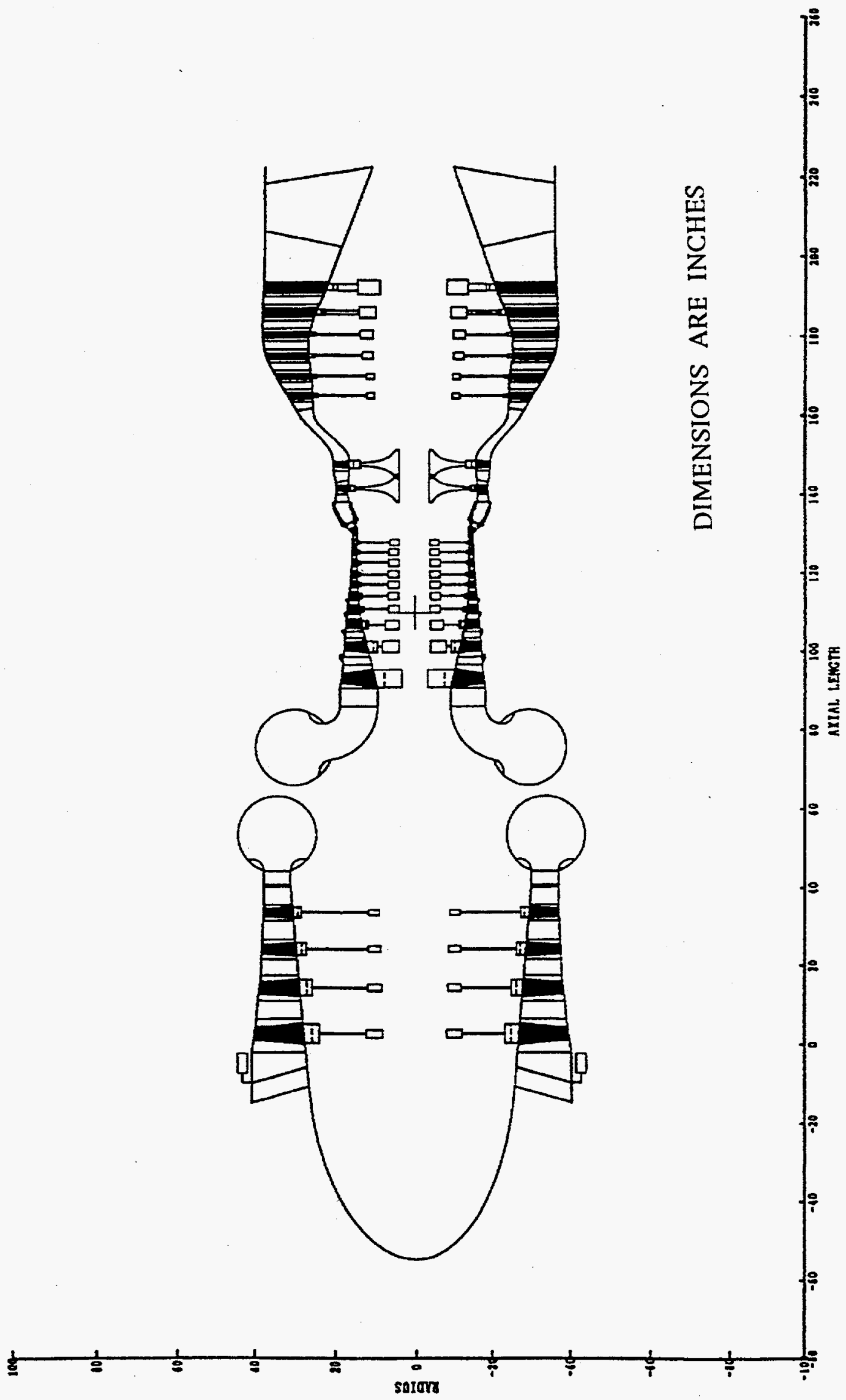

Figure 6.1.1. Industrial ATS Flowpath 
The booster is a 4 stage design which is sized for a pressure ratio of 3.1 and an inlet corrected flow of $613 \mathrm{lbs} / \mathrm{sec}$ with fixed inlet guide vanes. Figure 6.1.2 shows the flowpath cross section of the booster. The booster sized in this fashion will allow operation at $3,000 \mathrm{rpm}$ with fixed IGVs to produce the cycle pressure ratio of 2.4 and cycle inlet corrected flow of $496 \mathrm{lbs} / \mathrm{sec}$. The booster operation at $3,000 \mathrm{rpm}$ is shown on the map given in Figure 6.1.3. The map indicates that the booster is expected to operate at about $90.5 \%$ adiabatic efficiency. The booster operation at 3,600 rpm with IGVs closed is shown on the map given in Figure 6.1.4. This map indicates that at 3,600 $\mathrm{rpm}$ the booster is expected to operate at about $89.0 \%$ adiabatic efficiency. Since the majority of the cycle pressure rise occurs in the core, this should not result in a big loss in simple and combined cycle performance. The performance implied by the maps should be considered as preliminary.

The intercooler produces an increased core mass flow (compared to the GE90), which causes the high pressure turbine to operate at about a $17 \%$ larger flow function and at about a $4 \%$ slower speed than the GE90. The increased flow function can possibly be accommodated by either designing all new turbine airfoils or by rotation of the existing turbine airfoils. A preliminary look was taken at rotating the first stage vane and blade airfoils open in order to match the cycle flow function. The estimated performance agreed well with the cycle deck. An initial estimate shows that the HPT efficiency increases about $0.8 \%$ points if all new airfoils are designed. It is felt that the performance level of the HPT in the cycle deck can be obtained.

The power turbine uses a GE90 type flowpath as can be seen in Figure 6.1.5. The inlet to the power turbine has been sized so that the GE90 mid turbine frame can be used. The power turbine exit flow area has been sized to give a maximum value of annulus area times rotor rpm ( $\mathrm{AN}^{2)}$ of 45 $\times 10^{9}$ which results in an exit Mach number of 0.56 at the design point. A preliminary trade study was done to determine the number of power turbine stages needed to give high efficiency. It can be seen, in Figure 6.1.6, that only a small insignificant gain in efficiency is possible in going from 7 stages to 8 stages, and that a marginal gain of about $0.35 \%$ points occurs in going from a 6 stage to a 7 stage design. It was decided to pick a 6 stage design at this time. However, a more detailed trade study in the future might show that a 7 stage design would make sense from an economic point of view.

The power turbine design point was taken at $3,285 \mathrm{rpm}$ to minimize the increase in loading when the power turbine is operated at $3,000 \mathrm{rpm}$. The power turbine efficiency at $3,285 \mathrm{rpm}$ was estimated at $94.6 \%$. The off-design power turbine efficiency at $3,600 \mathrm{rpm}$ is estimated to be $94.5 \%$, with a $1 \%$ drop in flow function from the design point. There is essentially no loss in performance between the design point and 3,600 rpm. The off-design power turbine efficiency at 3,000 rpm is estimated to be $93.9 \%$, with about a $1 \%$ increasing flow function from the design point. The power turbine efficiency can be expected to drop about $0.6 \%$ points when operating at $3,000 \mathrm{rpm}$ in comparison to performance at $3,600 \mathrm{rpm}$. The power turbine was assumed to have an exhaust diffuser with a 2:1 area ratio and a recovery factor of 0.7 , which implies either a cold end or hot end drive. A diffuser with a recovery factor of 0.8 , which implies only a cold end drive, would result in another $0.7 \mathrm{MW}$ in output. A 15 -in. $\mathrm{H}_{2} \mathrm{O}$ stack loss in static pressure was assumed to occur after the exhaust diffuser. The power turbine efficiency estimate should be reevaluated later in the detail design process. 


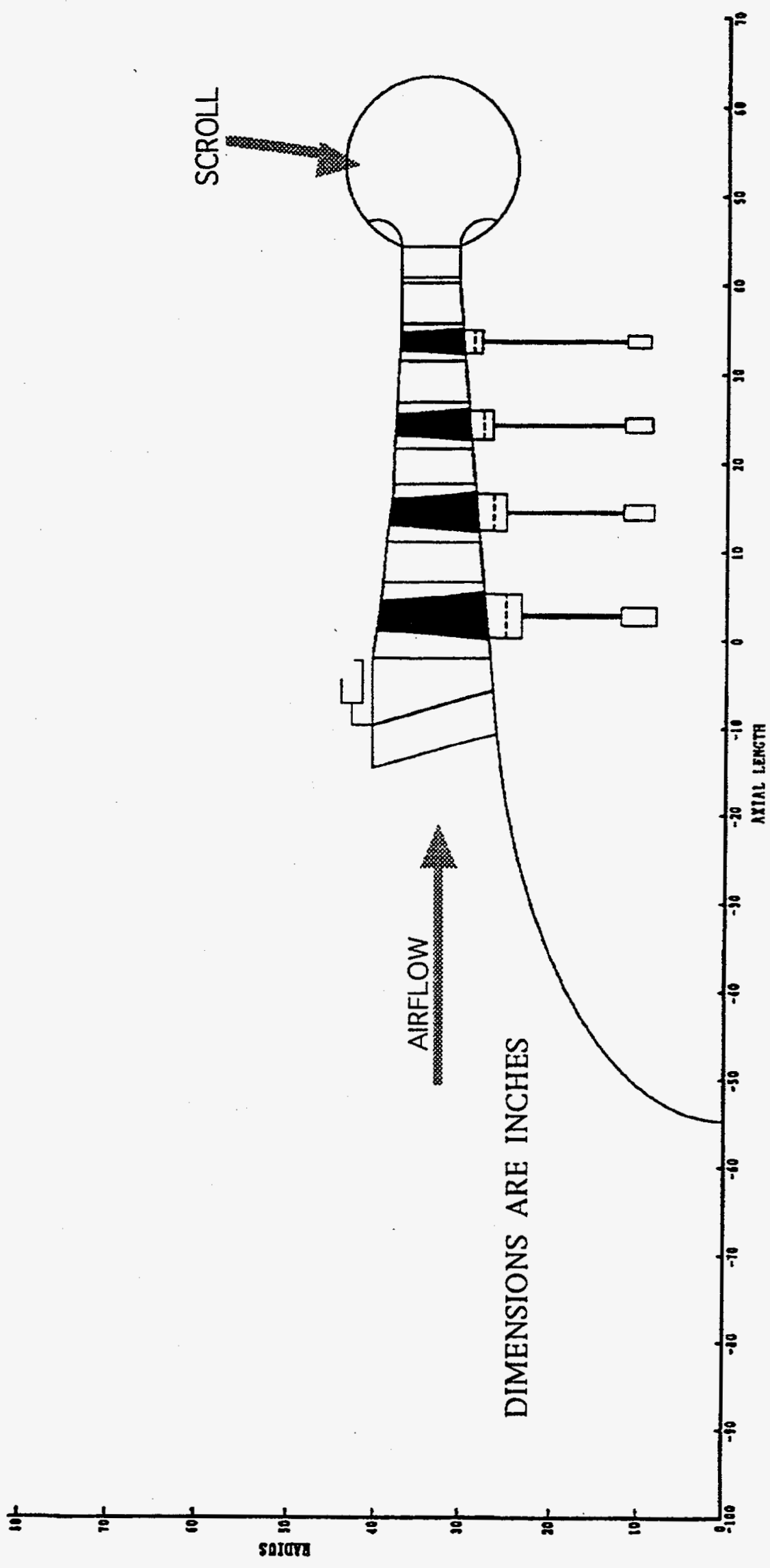

Figure 6.1.2. Industrial ATS Booster Stages 


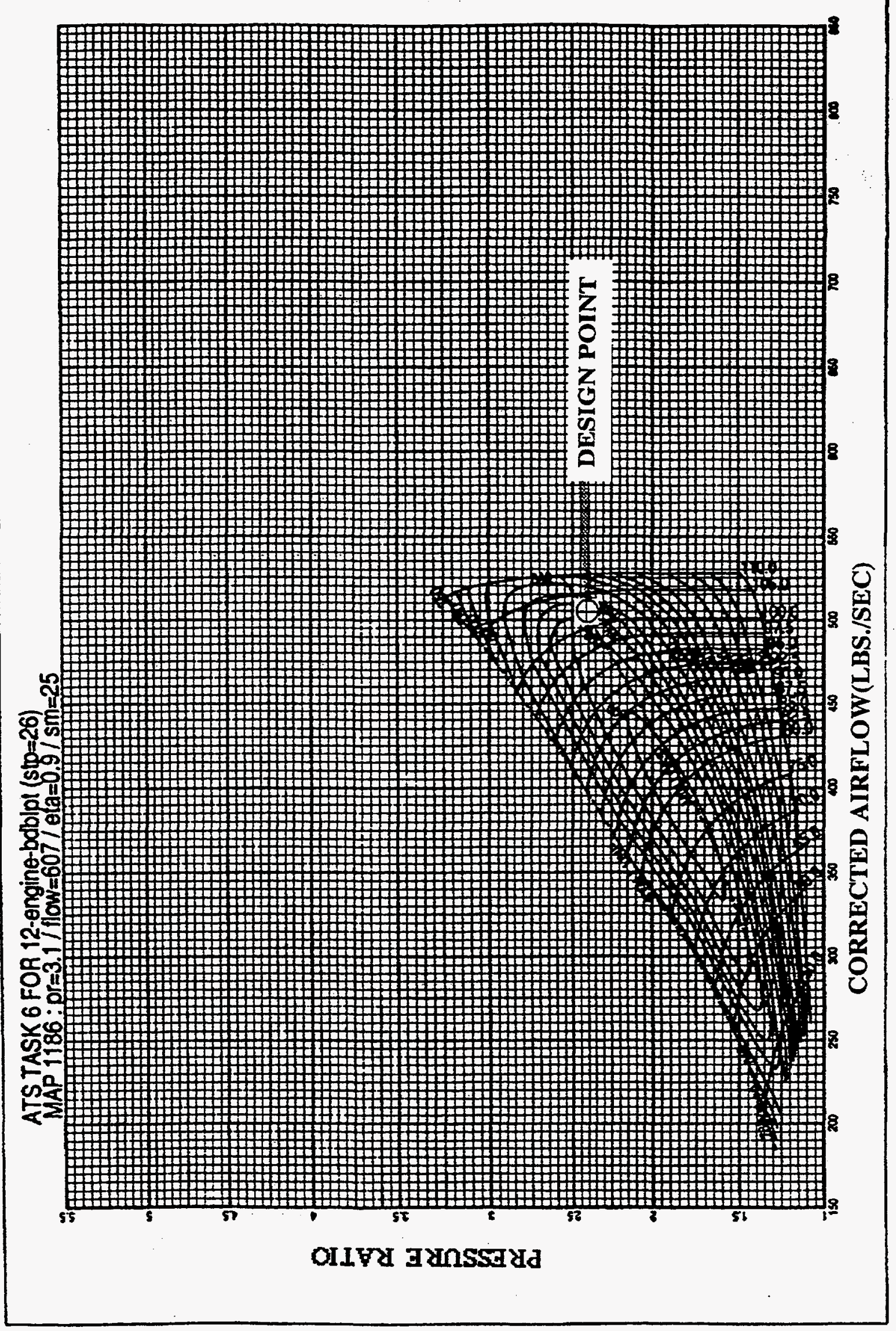

Figure 6.1.4. Booster Performance Map (3,600 rpm) 


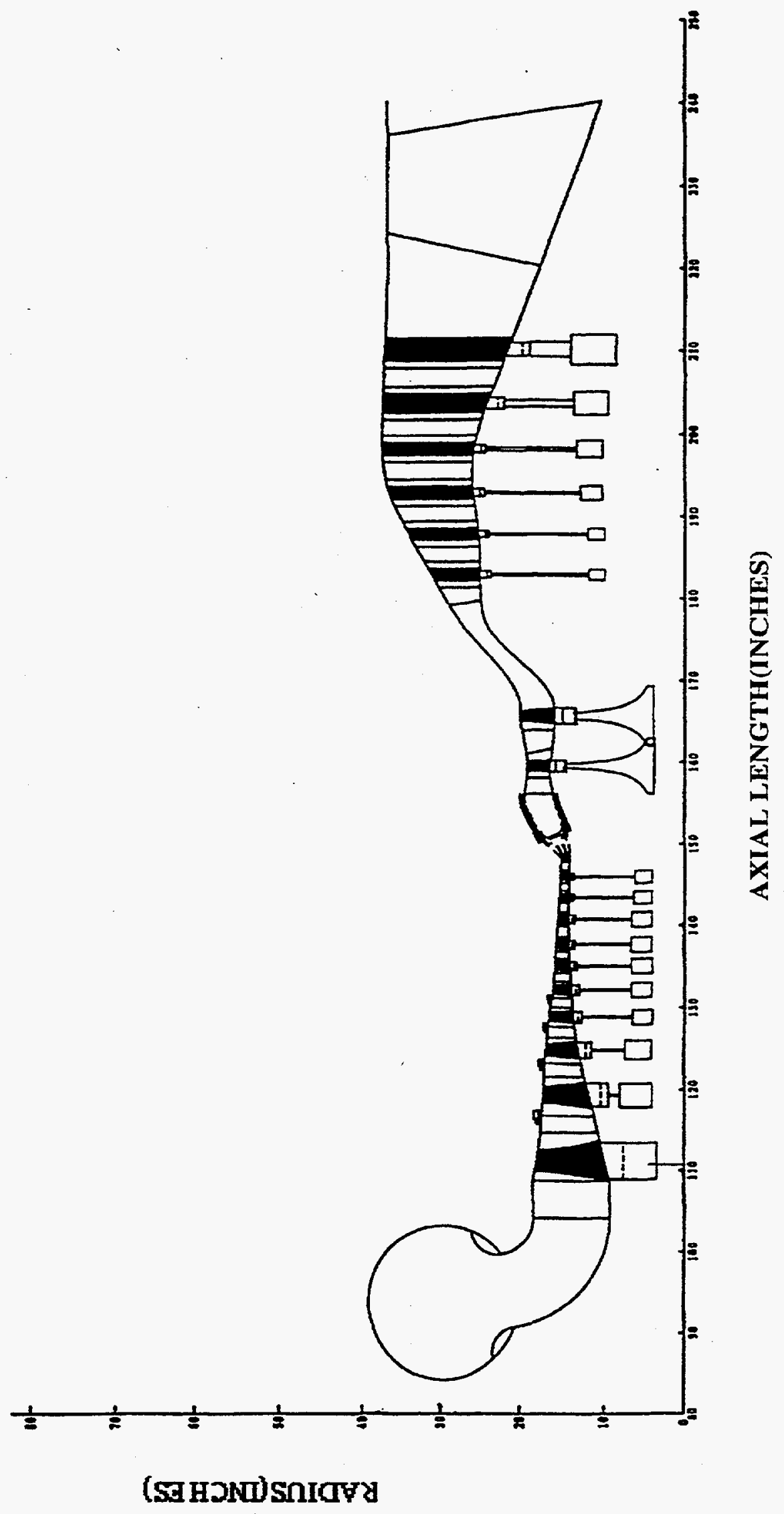

Figure 6.1.5. Industrial ATS High-Pressure Core and Power Turbine 


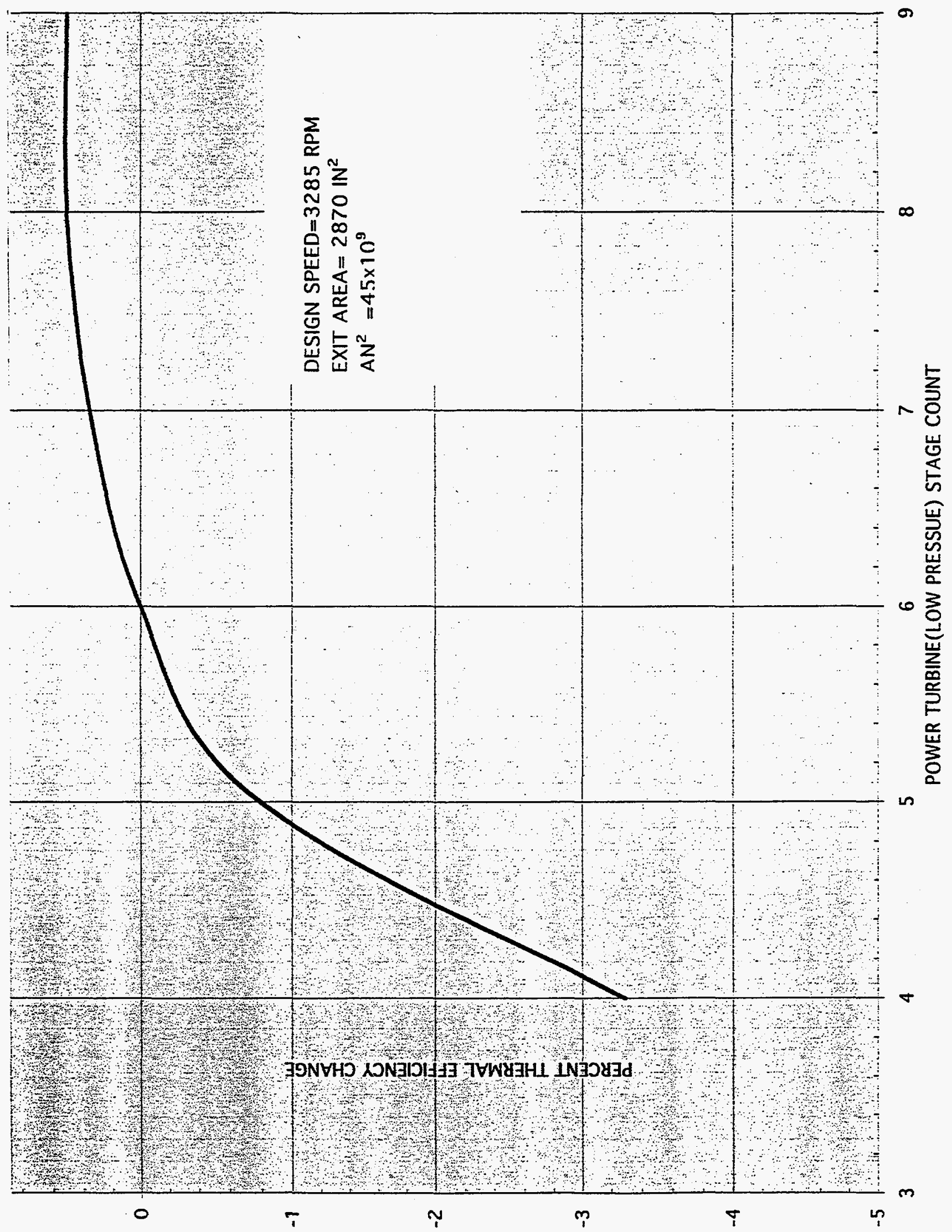

Figure 6.1.6. Power Turbine Efficiency Change vs. Number of Stages 
The cycle deck has assumed a $95 \%$ power turbine efficiency at 3,600 rpm, which is 0.5 point higher than the current estimate using a 6 stage turbine. It might be possible to attain the $95.0 \%$ level with further optimization and/or adding an additional stage. The current estimate shows that a power turbine with a high level of performance should be attainable.

The net change in simple cycle efficiency between $3,600 \mathrm{rpm}$ and $3,000 \mathrm{rpm}$ is that the $3,000 \mathrm{rpm}$ operation is estimated to be about $0.3 \%$ poorer. The performance loss for combined cycle operation is estimated to be only about $0.1 \%$ lower. These estimates are based on cycle derivatives for the booster and the power turbine and their estimated change in efficiencies from $3,600 \mathrm{rpm}$ to $3,000 \mathrm{rpm}$. The small difference in performance between $3,600 \mathrm{rpm}$ and $3,000 \mathrm{rpm}$ are well worth being able to use the same booster hardware and use the same power turbine hardware for both $3,600 \mathrm{rpm}$ and 3,000 rpm operation. The core is the same for both 3,600 rpm and 3,000 rpm. Designing the power turbine at $3,285 \mathrm{rpm}$ and designing the booster at $3,600 \mathrm{rpm}$ at a higher pressure ratio and larger corrected flow than in the cycle resulted in a versatile ATS design.

\subsection{INTERCOOLER DESIGN}

Two vendors were surveyed about the intercooler design performance. Both vendors, Allied Signal and General Atomics, indicated that the desired performance could be met. The indicated size of the intercooler was estimated to be 9 feet in diameter and 10 feet in length. Figure 6.2.1 shows the performance and shape of the intercooler. 


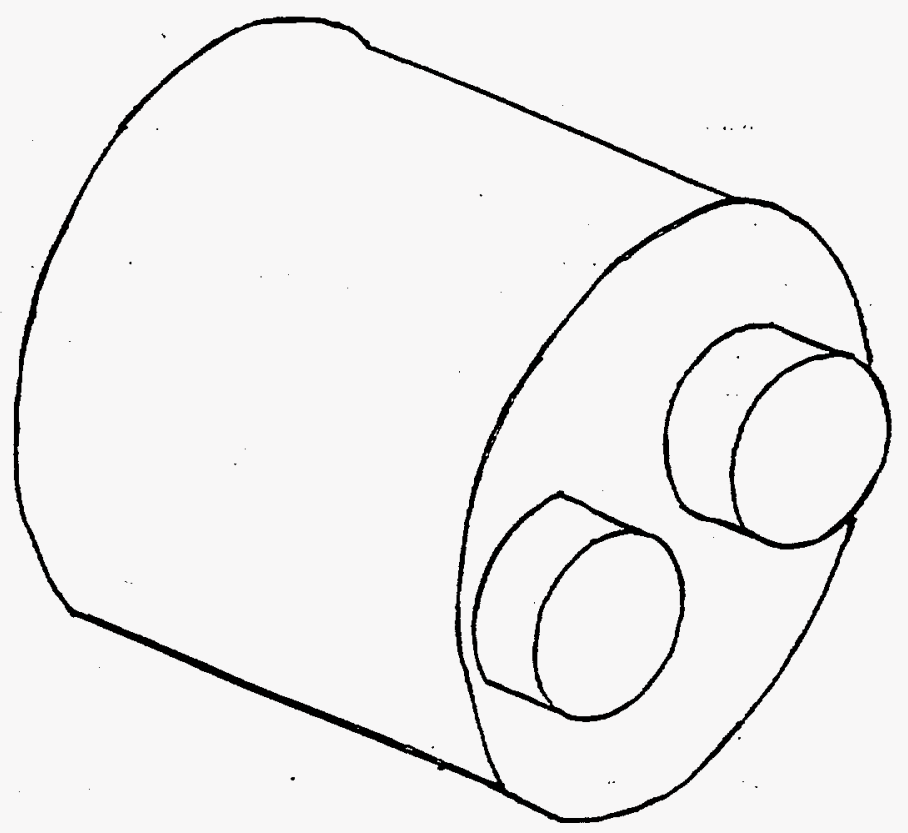

INTERCOOLER

INTERCOOLER DESIGN

\begin{tabular}{|c|c|c|}
\hline PARAMETERS & DESIGN GOALS & $\begin{array}{c}\text { VENDOR } \\
\text { PROJECTIONS }\end{array}$ \\
\hline AMBIENT TEMP( ${ }^{\circ}$ F) & & 59 \\
\hline ALTITUDE & 59 & SEA LEVEL \\
\hline $\begin{array}{c}\text { INLET AIR } \\
\text { FLOW(LBS/SEC) }\end{array}$ & 485 & 485 \\
\hline INLET AIR TEMP( ${ }^{\circ}$ F) & 220 & 220 \\
\hline INLET PRESSURE(PSIA) & 35 & 35 \\
\hline INLET MACH NUMBER & 0.15 & 0.15 \\
\hline WATER INLET TEMP( ${ }^{\circ}$ F) & 84 & 84 \\
\hline EXIT AIR TEMP( ${ }^{\circ}$ F) & 90 & 90 \\
\hline $\begin{array}{c}\text { AIR SIDE PRESSURE } \\
\text { DROP(\%) }\end{array}$ & 2 & 1.6 \\
\hline (FLANGE TO FLANGE) & & 1251 \\
\hline $\begin{array}{c}\text { WATER FLOW } \\
\text { (LBS/SEC) }\end{array}$ & & 96 \\
\hline WATER OUTLET & & \\
\hline TEMP( ${ }^{\circ}$ F) & & \\
\hline
\end{tabular}

Figure 6.2.1. Intercooler Shape and Performance 


\subsection{ATS DLE COMBUSTOR PRELIMINARY DESIGN}

The ATS combustor design is based on the use of Lean Premix Combustion technology developed on the LM6000 DLE engine, which was introduced to field service in December 1994. The ATS combustor utilizes a scaled triple dome configuration of the LM6000 design. The DACRS III premixers developed for the LM6000 are scaled up to the ATS design point.

The preliminary design process included the steps of (1) determining the design point, (2) determining the combustor fuel air ratio needed to satisfy the NOx goals set in the program, (3) sizing the triple annular combustor in accordance with the design methodology developed on the LM6000 DLE program, (4) sizing the premixers in accordance with above methodology, (5) adjusting the diffuser design, and (6) performing trade studies.

\section{GOALS}

The design goals for the combustor include the emissions requirements set by DOE, which are $8 \mathrm{ppm}$ NOx emissions and $20 \mathrm{ppm} \mathrm{CO}$ emissions. Other design goals include the profile and pattern factor, as well as combustion system pressure drop. These are shown in Table 6.3.1. The design intent is to meet the above emissions goals from $60 \%$ power to $100 \%$ power

TABLE 6.3.1

Emissions Goals

\begin{tabular}{|c|c|c|}
\hline & Initial goal & Ultimate goal \\
\hline NOx & $<9 \mathrm{ppm}$ & $<8 \mathrm{ppm}$ \\
\hline $\mathrm{CO}$ & $<20 \mathrm{ppm}$ & $<20 \mathrm{ppm}$ \\
\hline
\end{tabular}

\subsubsection{DOUBLE ANNULAR COUNTER-ROTATING SWIRLER (DACRS) PREMIXER DESIGN}

The DACRS series of premixers was developed for application to lean premixed combustion systems for the LM series of gas turbines. DACRS stands for Double Annular Counter Rotating Swirler. Figure 6.3.1.1 shows a cross section through a DACRS III premixer. These compact premixers utilize two counter-rotating swirlers followed by a mixing duct. The inner swirler has a centerbody to keep the air/fuel mixture from separating. This centerbody also allowed the injection of a small quantity of air at its tip to help avoid separated flows. The mixing duct is conical, with the smaller diameter at the exit plane. The conical shape of the duct continuously accelerates the mixture, avoiding buildup of boundary layers on the duct surface. These features of the DACRS family of premixers make the design flashback-resistant. The small residence time of these devices $(<1 \mathrm{msec})$ and the avoidance of any recirculation within them ensures that autoignition will not occur within the mixing duct at any operating 
conditions. The DACRS-I design utilized radial fuel injection from the centerbody, the DACRS-II design utilized fuel injection through spokes located on the centerbody, and the DACRS III design utilizes hollow outer swirl vanes through which fuel is injected into the air stream.

For the determination of the fuel air ratios at design point, the NOx emissions obtained by Leonard and Correa were utilized. This assumes that the DACRS-III premixer performance will be improved from the published data of Joshi et.al. (1994) to achieve the level of mixing achieved by Leonard and Correa (1990). Figure 6.3.1.2 shows the NOx correlations used for these studies. 


\section{DESIGN}

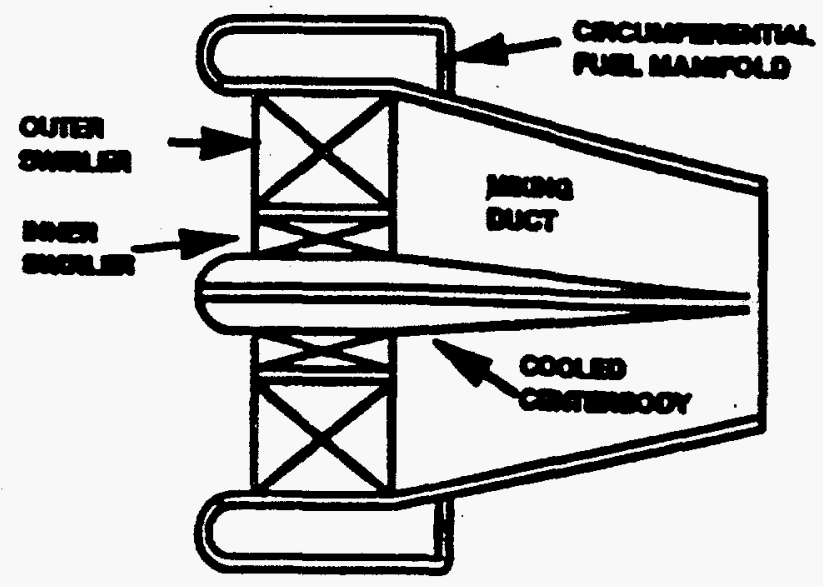

\section{VELOCITY PROFILES}

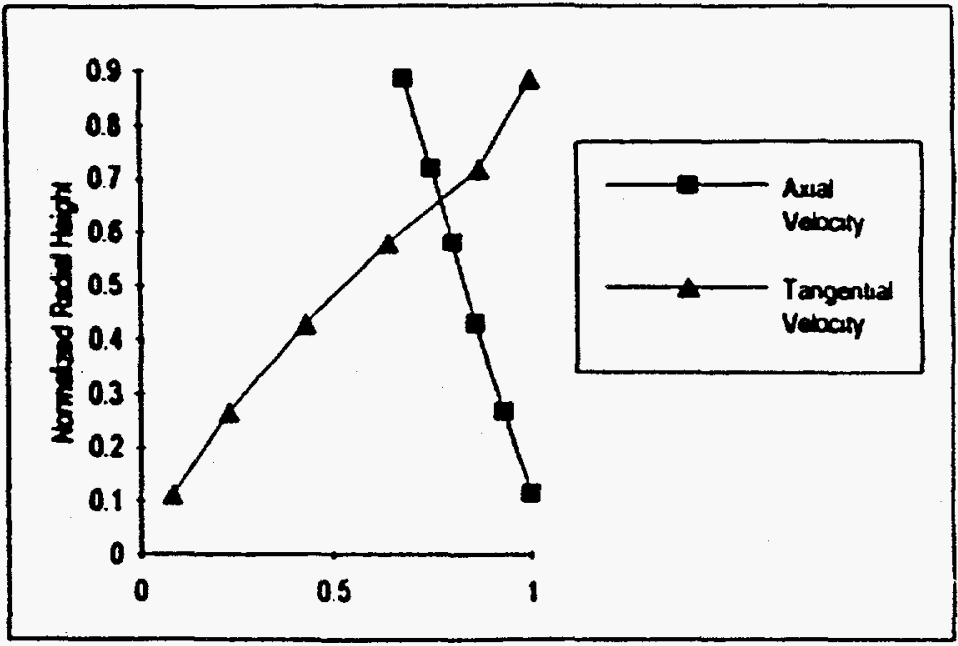

Figure 6.3.1.1. Double Annular Counter-Rotating Swirler (DACRS) 


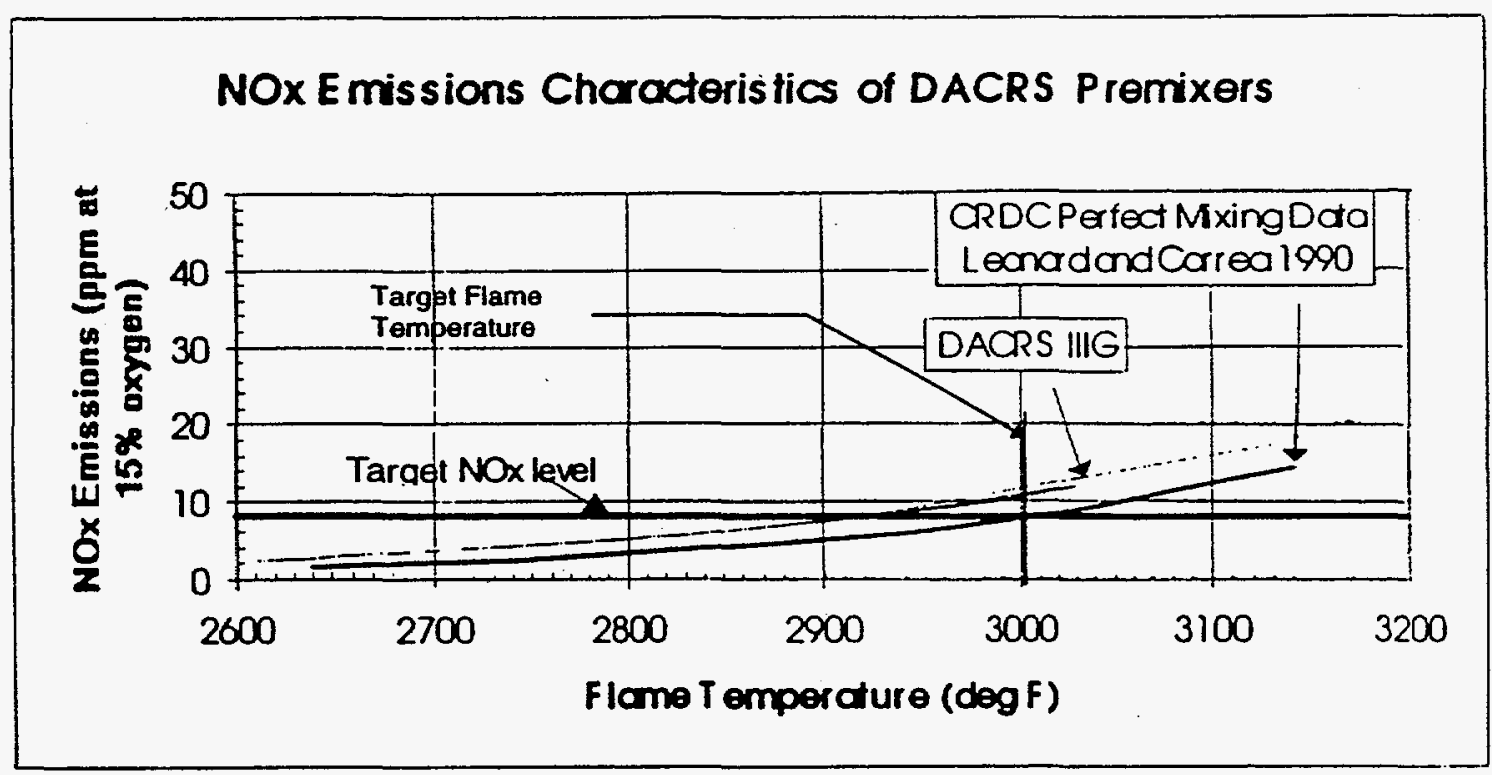

NOx Emissions from Premixer to be reduced to CRDC Line

Combustor design to be modified to dump heat shield cooling air into the premixers to reduce flame temperature.

Figure 6.3.1.2. DACRS NOx Emissions vs. Flame Temperature 


\subsubsection{SIZING STUDY BASED ON LM6000 DLE COMBUSTOR DESIGN}

The LM6000 DLE combustor design, shown in Figure 6.3.2.1, utilizes lean premixed combustion from ignition to full power. The original LM6000 diffuser and compressor rearframe (which houses the combustor) were modified to accommodate the larger DLE combustor. The DLE combustor is configured as a triple-dome combustor. Most of the combustor air passes through the premixers, with only a small fraction of air being used for liner cooling at the aft ends and for heat shield cooling in the dome. The heat shield cooling air is introduced into the dome downstream of the primary combustion zone, avoiding dilution of the primary zone in any way, which permits the combustor to operate at lower flame temperatures. The inner dome has 15 premixers; the middle and the outer each have 30 . The premixers are designed to be removable to permit ease of replacement and repair. The combustor itself is mounted from the front end, unlike the non-DLE combustor, which is mounted from the aft end. The combustor utilizes a set of igniters on the outer liner. Ignition is achieved by fueling a set of 3 outer dome premixers in line with the igniters, in addition to the middle dome. These 3 premixers are switched off as soon as ignition is detected in the middle dome. The middle dome is the pilot dome that stays lit at all times. As engine power is increased, the inner and the outer domes are lit in sequence. Additional operability is obtained by modulating combustion air flow by bleeding air flow from the engine. 


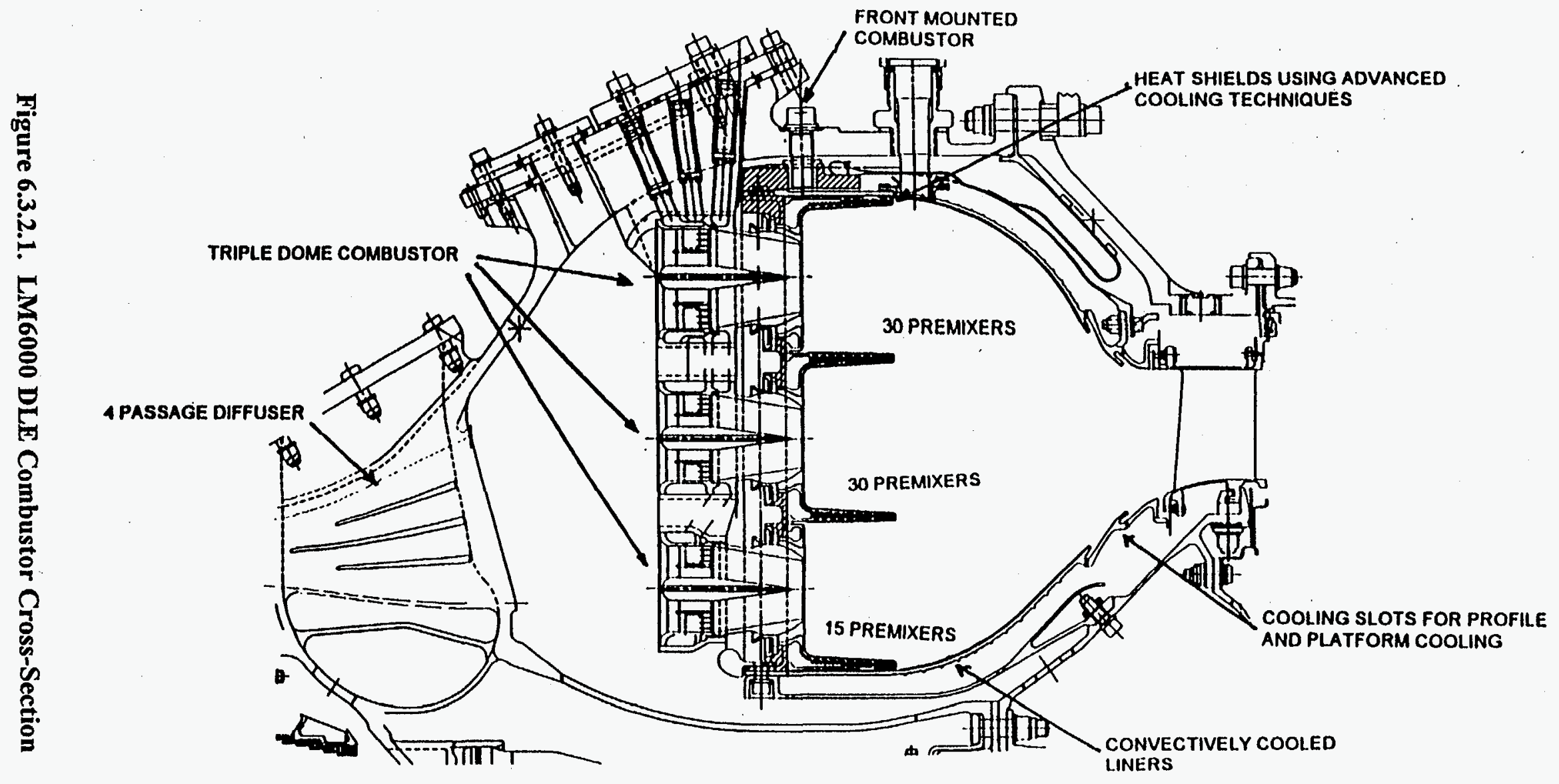




\subsubsection{DESIGN POINT CONDITIONS}

The design point conditions used for the preliminary design of the ATS DLE combustor are shown in Table 6.3.3.1.

TABLE 6.3.3.1

ATS DLE Combustor Design Conditions

\begin{tabular}{|c|c|c|}
\hline Parameter & Units & \\
\hline T2 & $\operatorname{deg}$ F & 59 \\
\hline P3 & psia & 760 \\
\hline T3 & $\operatorname{deg~F}$ & 955 \\
\hline W3 & PPS & 463 \\
\hline W36 & PPS & 391 \\
\hline Wf36 & pph & 47249 \\
\hline LHV of fuel & Btu/lb & 19000 \\
\hline W41 & PPS & 453.24 \\
\hline T41 & deg F & 2684 \\
\hline & & \\
\hline
\end{tabular}

\subsubsection{COMBUSTOR AIRFLOWS}

The air flow diagram and design point cycle conditions are shown in Figure 6.3.4.1. The air flow from the diffuser, which is about $94 \%$ of W25, is split into several streams. One of the streams is diverted to the turbocooler, where the air is cooled and compressed further for cooling of the turbine nozzle and combustor. The rest of the air is passed into the combustor. The cooling air returning from the turbocooler is used to cool the turbine nozzle diaphragm, as shown Figure 6.3.6.4, as well as the combustor liners and dome. Details of the preliminary cooling design is described in Section 6.3.6. 


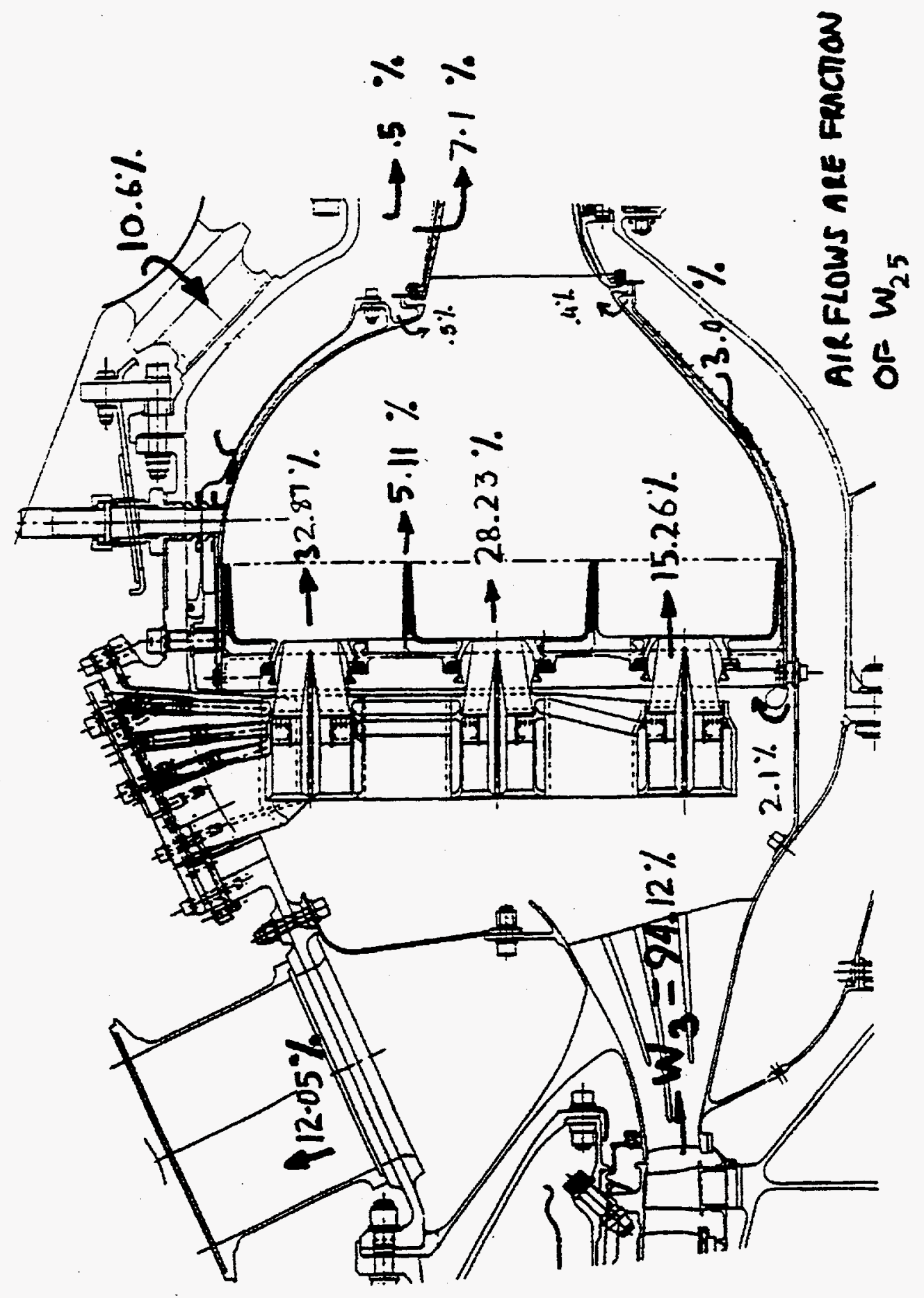

Figure 6.3.4.1. ATS DLE Combustor Air Flow 


\subsubsection{DESIGN DESCRIPTION}

The air flow split between the combustion air (burning) and cooling air for the heat shield and liners is determined by cycle conditions. The combustor utilizes the maximum air available to decrease the combustion flame temperatures and thereby minimize NOx emissions. The threedome air flow splits were set by assuming that the dome heights were of similar dimensions, and that the dome reference velocity was equal in each dome. This design methodology is similar to that used on the LM6000 DLE combustor design. The inner diameter of the liner is determined by geometric and fit-up requirements, and was set at 25 " to give sufficient space for the design of an impingement baffle for the liner. A heat shield thickness of 0.375 in. was assumed for the heat shield in order to calculate the flowpath inner diameter. A dome reference velocity of 40 fps (cold) was assumed, and the outer diameter was calculated for the inner dome, based on the cycle parameters shown in Table 6.3.3.1, and the air flow split, shown in Figure 6.3.4.1. A heat shield thickness of 0.375 in. was again assumed to calculated the inner flow path diameter for the middle dome, and the method outlined above was repeated to calculate the outer diameter of the middle dome. The methodology was repeated to calculate the outer liner diameter. A summary of the dome sizing study is shown in Table 6.3.5.1. Once the dome diameters were obtained, a trade study was done to evaluate the number of premixers that will be required in each dome. A summary of the trade study is shown in Table 6.3.5.2. One of the design considerations is the ease and simplicity of premixer removal from the engine. This consideration, and the requirements for case integrity, increases with the number of premixers. Although beneficial from an emissions point of view (increased fuel sources), this has to be traded with cost (more premixers increase cost) and the integrity of the case (thinner web between premixer windows leads to softer case ). For the preliminary design, shown in Figure 6.3.5.1, 36 premixers were chosen for the middle and outer domes and 18 were picked for the inner dome. This is similar to the LM6000 DLE design, as shown in Figure 6.3.2.1, where each dome has, respectively, 30/30/15 premixers. 
TABLE 6.3.5.1

Combustor Dome Sizing Study Summary.

\begin{tabular}{|c|c|c|c|}
\hline \multicolumn{4}{|c|}{ INNER DOME DESIGN } \\
\hline Heat shield thickness & $0.009525 \mathrm{~m}$ & & 0.375 in \\
\hline Inner liner radius $=$ & $0.327025 \mathrm{~m}$ & & $12.5 \mathrm{in}$ \\
\hline Dome outer radius & $0.400790075 \mathrm{~m}$ & $=$ & 15.779137 in. \\
\hline Dome height $=$ & $0.073765075 \mathrm{~m}$ & $=$ & $2.9041368 \mathrm{in}$. \\
\hline \multicolumn{4}{|c|}{ MIDDLE DOME DESIGN } \\
\hline Inner radius of the middle dome & $0.410315075 \mathrm{~m}$ & & $16.154137 \mathrm{in}$. \\
\hline Dome outer radius & $0.492797763 \mathrm{~m}$ & $=$ & 19.401487 in. \\
\hline Dome height $=$ & $0.082482689 \mathrm{~m}$ & $=$ & $3.2473499 \mathrm{in}$. \\
\hline \multicolumn{4}{|c|}{ OUTER DOME DESIGN } \\
\hline Inner radius of the outer dome & $0.502322763 \mathrm{~m}$ & & 19.77649in \\
\hline Dome outer radius & $0.58215031 \mathrm{~m}$ & & 22.919304 in. \\
\hline Outer liner radius & $0.59167531 \mathrm{~m}$ & & 23.294304 in. \\
\hline Case radius & $0.61707531 \mathrm{~m}$ & & 24.294304 in. \\
\hline
\end{tabular}


TABLE 6.3.5.2

Summary of Premixer Number Trade Study

\begin{tabular}{|c|c|c|}
\hline Outer Engine C & Circumference $=$ & $3.87719 \mathrm{~m}$ \\
\hline \multicolumn{3}{|c|}{ Outer Case Circumference Spacing per Number of Premixers } \\
\hline \multicolumn{3}{|c|}{ \# of Pre Mixers } \\
\hline & 20 & $0.19385 \mathrm{~m}=$ \\
\hline & 30 & $0.12924 \mathrm{~m}=$ \\
\hline & 36 & $0.1077 \mathrm{~m}=$ \\
\hline & 40 & $0.09693 \mathrm{~m}=$ \\
\hline & 45 & $0.08616 \mathrm{~m}=$ \\
\hline \multicolumn{3}{|r|}{ Dome Premixer Spacing } \\
\hline Dome Location & \#of Premixers & Dome Circumferential Spacing \\
\hline \multirow[t]{6}{*}{ Inner } & 18 & $0.12702 \mathrm{~m}=5.00109$ in. \\
\hline & 20 & $0.11432 \mathrm{~m}=4.50098$ in. \\
\hline & 30 & $0.07621 \mathrm{~m}=3.00065$ in. \\
\hline & 36 & $0.06351 \mathrm{~m}=2.50054$ in. \\
\hline & 40 & $0.05716 \mathrm{~m}=2.25049 \mathrm{in}$ \\
\hline & 45 & $0.05081 \mathrm{~m}=2.00043$ in. \\
\hline \multirow[t]{4}{*}{ Middle } & 30 & $0.09457 \mathrm{~m}=3.72337 \mathrm{in}$ \\
\hline & 36 & $0.07881 \mathrm{~m}=3.10281$ in. \\
\hline & 40 & $0.07093 \mathrm{~m}=2.79253$ in. \\
\hline & 45 & $0.06304 m=2.48225$ in. \\
\hline \multirow[t]{4}{*}{ Outer } & 30 & $0.11356 \mathrm{~m}=4.47109$ in. \\
\hline & 36 & $0.09463 \mathrm{~m}=3.72591$ in. \\
\hline & 40 & $0.08517 \mathrm{~m}=3.35331 \mathrm{in}$ \\
\hline & 45 & $0.07571 \mathrm{~m}=2.98072 \mathrm{in}$ \\
\hline
\end{tabular}




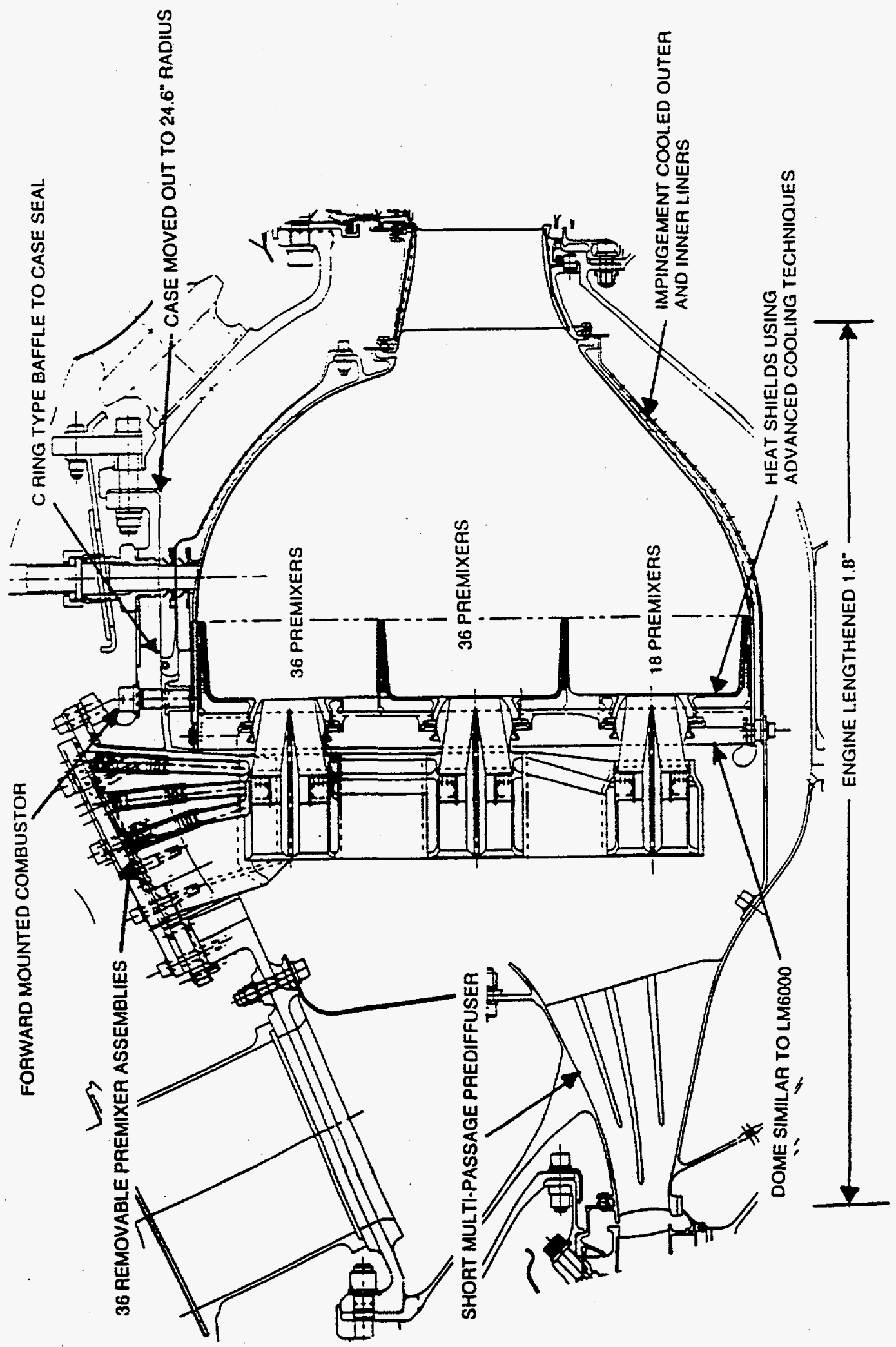

Figure 6.3.5.1. Preliminary ATS Combustor Layout 
Having picked $36 / 36 / 18$ premixers in the outer, middle, and inner domes the premixer diameters were determined by scaling the DACRS-III premixer design from the LM6000 DLE combustor design. The premixer design parameters are summarized in Table 6.3.5.3. The mixing length of the premixer was reduced from the LM6000 value of 2 in. in order to limit exposure to autoignition in the premixers due to the increased severity of the cycle. A dimensional check was performed to make sure that the premixers did not interfere with each other in the combustor and were removable through an appropriately sized window in the case.

TABLE 6.3.5.3

Premixer Diameters Scaled From LM6000 DLE Combustor

$\begin{array}{lccc}\text { Dome } & \begin{array}{c}\text { Swirler Diameter } \\ \text { (inches) }\end{array} & \begin{array}{c}\text { Exit Diameter } \\ \text { (inches) }\end{array} & \begin{array}{c}\text { Mixing Length } \\ \text { (inches) }\end{array} \\ \text { Inner } & 2.62 & 1.298 & 1.56 \\ \text { Middle } & 2.55 & 1.298 & 1.56 \\ \text { Outer } & 2.7 & 1.4 & 1.56\end{array}$

The combustor length was set at 7.0 in. in order to generate sufficient residence time at temperature to oxidize $\mathrm{CO}$ formed in the primary combustor zone. This combustor length, coupled with the need to pull the premixers forward for disassembly, required the diffuser to be extremely short, so that the overall increase in the diffuser/combustor length could be minimized. Based on the LM6000 DLE design, a diffuser length of 5 in. is carried in this design.

\subsubsection{COMBUSTOR COOLING SYSTEM DESIGN}

The combustor cooling system is designed to enable the combustor to operate for 50,000 hours (with repair) on natural gas while using a minimum of cooling air consistent with the stated emission goals. The cooling system has been sized for baseload operation at a flame temperature of $2853 \mathrm{~F}$ and compressor discharge pressure of 760 psia. Cooling design assumptions include uniform flame temperature, negligible liner film cooling benefit from the outer and inner heatshield centerbodies, usage of impingement baffles that employ crossflow reductions features, TBC surface temperature capability to $2400 \mathrm{~F}$, and a 100 degree temperature rise in cooling air that passes through the turbine inlet nozzle to the inner liner cooling circuit.

The ATS liners are cooled by a combination of impingement, backside forced convection, and hot side film cooling. Cooling air is supplied from the turbocooler at 300F (baseload condition) and 841.6 psia and delivered to a distribution plenum within the combustor case surrounding the combustor. The liner cooling air is directed to the liners through impingement baffles covering both the outer and inner liners. $1.8 \% \mathrm{~W} 25$ cooling air is impinged to the outer liner and $1.2 \% \mathrm{~W} 25$ to the inner liner. $70 \%$ of the spent impingement air $(1.3 \%$ W25 outer inner and 
$0.8 \%$ W25 inner liner) flows forvard between the baffles and liner to cool the forward portion of the liners via forced convection. This cooling air is then dumped into the plenum upstream of the dome and enters the combustor as heatshield cooling air or premixer combustion air. The remaining 30\% spent impingement air $(0.5 \%$ outer liner and $0.4 \%$ inner liner) flows to the rear of the liners to cool the aft portion by forced convection before discharging through exit slots into the flowpath, approximately 1.5 inches from the end of the liners. Film cooling from the exit slots cool the last 1.5 in. of the liners. The hotside surface of the liners is protected by a layer of 0.035 -in. thick dense microcracked thermal barrier coating (TBC) applied over a 0.007 in. bond coat.

The backside surface of each liner is manufactured with surface enhancement features which multiply the impingement and forced convection heat transfer. The impingement region features a textured surface that effectively multiplies the impingement heat transfer by a factor of 1.5 , while the forced convection region is enhanced by turbulators which multiply the effective heat transfer coefficient by a factor of 1.8 .

Performance of the liner cooling system at baseload conditions results in maximum liner metal temperatures of less than $1475 \mathrm{~F}$ and maximum $\mathrm{TBC}$ surface temperatures slightly lower than $2300 \mathrm{~F}$. The heatshield components protect the dome region of the combustor and effectively divide the combustor into three dome regions with the heatshield centerbodies. The heatshields are mounted to the domeplate and employ the same advanced cooling design as used in the LM6000 DLE. The source of cooling air is a combination of CDP air and the portion of the liner cooling air discharged forward into the compressor discharge plenum. The heatshields require a toal of $5.1 \%$ W 25 cooling air (3\% W25 CDP air and 2. $1 \%$ W 25 spent liner cooling air). The heatshield faceplate is cooled by impingement through the domeplate. The spent impingement cooling air from the faceplate flows through the heatshield centerbodies that are cooled by enhanced forced convection. The centerbody enhanced convection is provided by full-length pin fins that span the channel height of the centerbody. Textured surfaces are employed, on the faceplate and up to the pin bank on the centerbody portion of the heatshield, that effectively multiply the heat transfer coefficient by a factor of 1.5 . The hotside of the heatshields are protected by a layer of 0.035 -in. thick dense microcracked thermal barrier coating (TBC) applied over a 0.005 -in. bond coat.

Maximum heatshield metal temperatures are expected to run at approximately $1600 \mathrm{~F}$ on the faceplate, with a TBC surface temperature less than $2300 \mathrm{~F}$, and at $1550 \mathrm{~F}$ on the centerbodies, with a TBC surface temperature of less than $2300 \mathrm{~F}$.

The design goals and assumptions made for the combustor liner cooling are shown in Figures 6.3.6.1 thru 6.3.6.6. 


\section{COMBUSTOR COOLING SYSTEM}

KEY ASSUMPTIONS:

- $\quad$ T75 $=300.0 \mathrm{~F}$

$\mathrm{P} 75=$ 841.6 PSIA

$\mathrm{T} 405=2853.0 \mathrm{~F}\left(\mathrm{~T}_{\text {flame }}\right)$

P405= $\quad 717.2 \mathrm{PSIA}$
T70 $=955.0 \mathrm{~F}$
P70 $=752.4$ PSIA

- NATURAL GAS

- UNIFORM FLAME TEMPERATURE (NO HOT STREAKS)

- NEGLECT LINER FILM COOLING BENEFIT FROM OUTER AND INNER HEATSHIELD CENTERBODIES

- IMPINGEMENT BAFFLES EMPLOY CROSSFLOW REDUCTION FEATURES

- TBC SURFACE TEMPERATURE CAPABILITY TO $2400 \mathrm{~F}$

- COOLING AIR SUPPLIED TO INNER LINER INCREASES 100 F PASSING THROUGH TURBINE INLET NOZZLE

Figure 6.3.6.1. ATS Combustor Cooling System - Assumptions 


\section{COMBUSTOR COOLING SYSTEM}

LINERS:

- COOLING AIR SUPPLIED BY TURBOCOOLER

- IMPINGEMENT, BACKSIDE FORCED CONVECTION, AND FILM COOLING (AT COMBUSTOR EXIT)

- COOLING SYSTEM FEATURES:

- ENHANCED BACKSIDE CONVECTION

- IMPINGED TEXTURED SURFACES

( $1.5 \times$ IMPINGEMENT FORECED CONVECTION)

- TURBULATED PASSAGES

(1.8 X CHANNEL FORCED CONVECTION)

- THICK TBC (O.O35 INCHES DENSE MICROCRACKED)

- CONVENTIONAL SLOT AT COMBUSTOR EXIT

- $1.8 \%$ W25 OUTER LINER COOLING

- $1.3 \%$ W25 FLOWS TO DOME

- $0.5 \%$ W25 FLOWS TO EXIT SLOT

- $1.2 \%$ W25 INNER LINER COOLING

- $0.8 \%$ W25 FLOWS TO DOME

- $0.4 \%$ W25 FLOWS TO EXIT SLOT

Figure 6.3.6.2. ATS Combustor Cooling System - Liners 


\section{COMBUSTOR COOLING SYSTEM}

HEATSHIELDS:

- THERMAL PROTECTION TO DOME STRUCTURE

- DIVIDES COMBUSTOR INTO THREE DOME REGIONS

- COOLING AIR SUPPLIED FROM COMPRESSOR DISCHARGE PLUS 70\% OF TOTAL SPENT LINER COOLING

- COOLING SYSTEM FEATURES:

- FACEPLATE IMPINGEMENT COOLED

- TEXTURED SURFACE

( $1.5 \times$ IMPINGEMENT FORCED CONVECTION)

- CENTERBODY FORCED CONVECTION COOLED

- SPENT IMPINGEMENT AIR FROM FACEPLATE

- FULL LENGTH PIN FINS

(3.5X SIMPLE FORCED CONVECTION)

- THICK TBC ( 0.035 INCHES DENSE MICROCRACKED)

- $5.1 \%$ W25 TOTAL COOLING

- 3\% W25 CDP AIR

- $2.1 \%$ W25 SPENT LINER COOLING AIR

Figure 6.3.6.3. ATS Combustor Cooling System - Heat Shields 


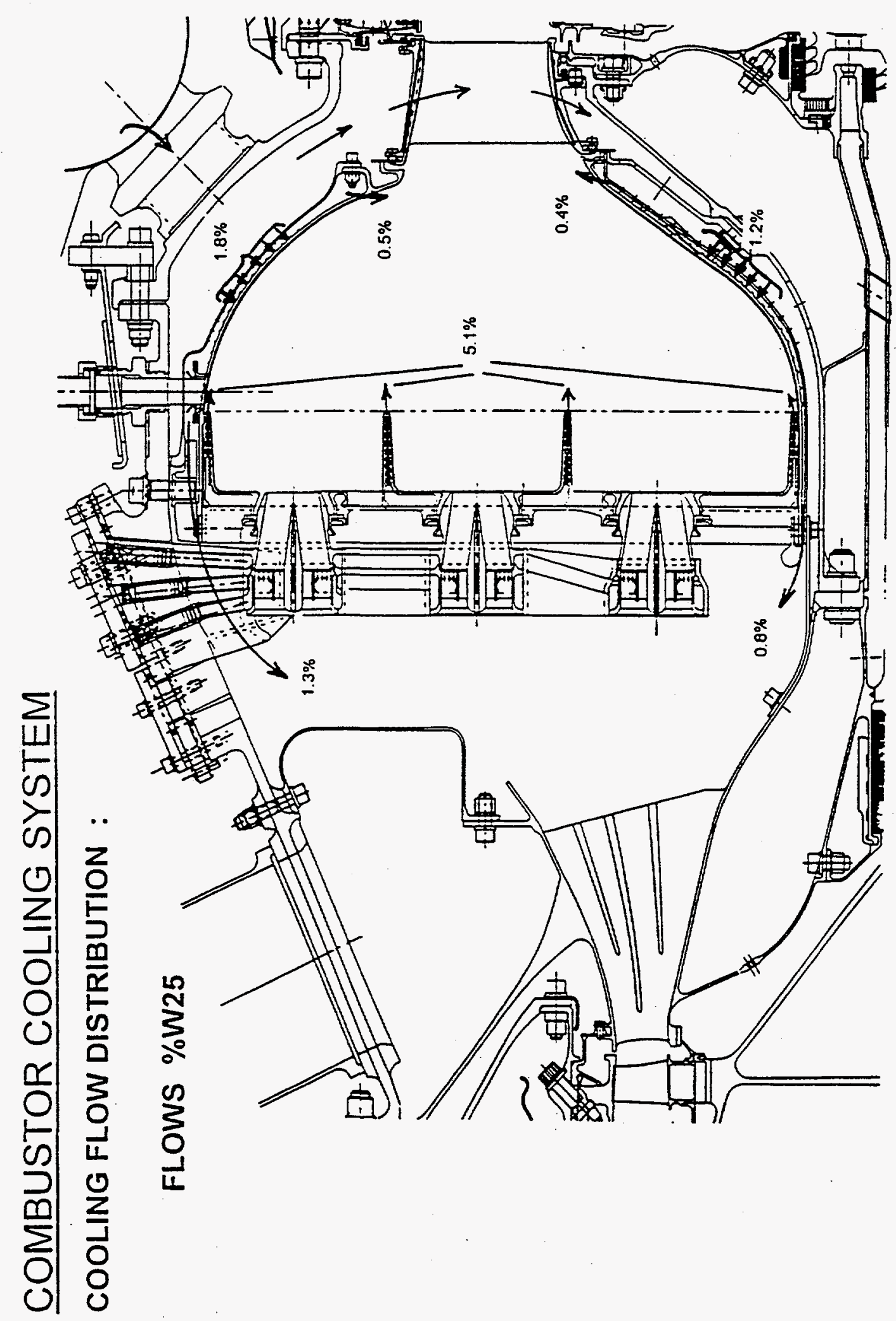

Figure 6.3.6.4. ATS Combustor Cooling System - Cooling Flow Distribution 


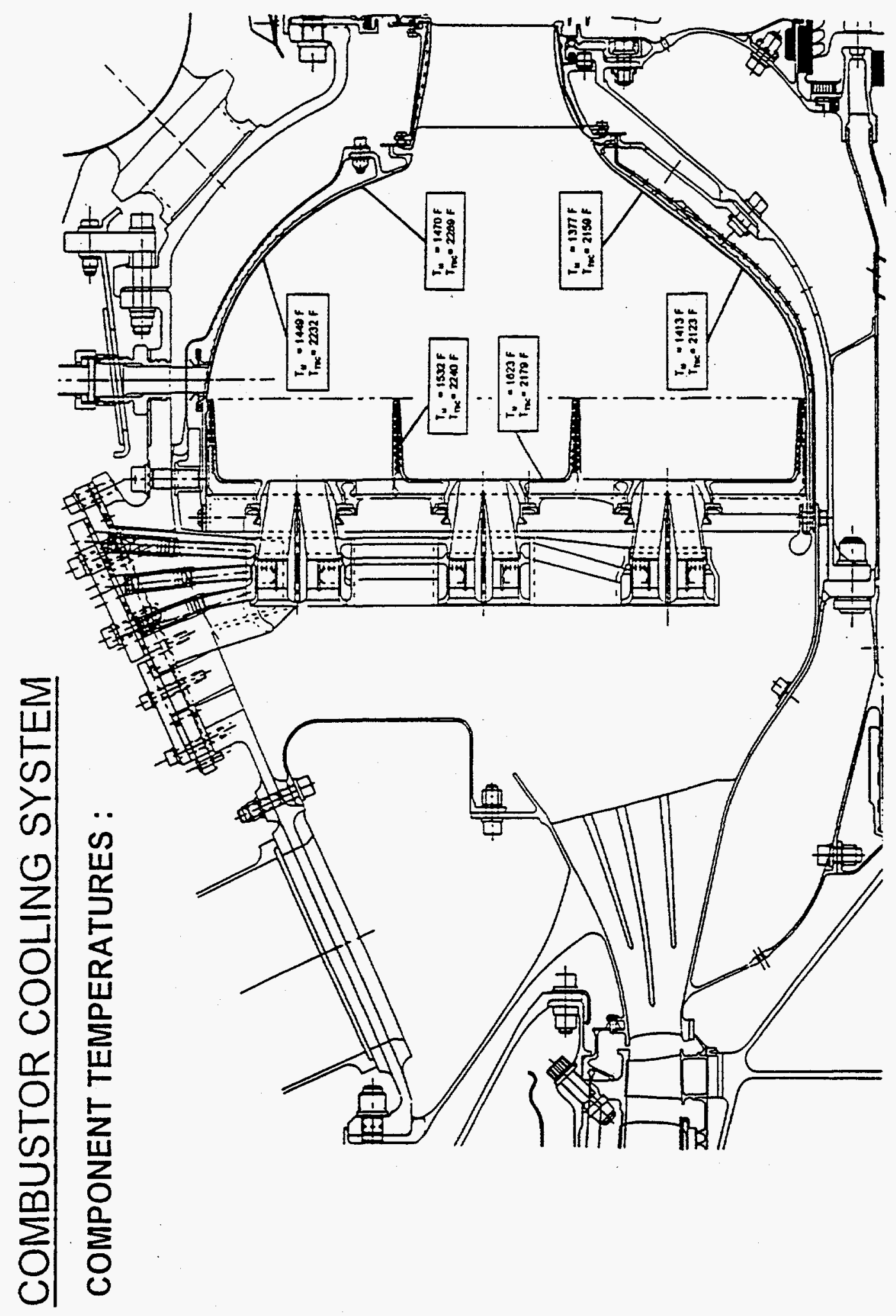

Figure 6.3.6.5. ATS Combustor Cooling System - Temperatures 


\section{COMBUSTOR COOLING SYSTEM:}

SUMMARY:

- LINER IMPINGED WITH TURBOCOOLER AIR

- $70 \%$ OF SPENT LINER COOLING AIR MIXES WITH COMPRESSOR DISHARGE AIR AND INTRODUCED BACK INTO COMBUSTOR

- IMPINGEMENT SYSTEM REQUIRES CROSSFLOW REDUCTION FEATURE

- HEATSHIELDS EMPLOY ADVANCED COOLING USED IN LM6000 DLE APPLICATION

Figure 6.3.6.6. ATS Combustor Cooling System - Summary 


\subsubsection{ADDITIONAL DEVELOPMENTS NEEDED}

\section{Premixers}

The current DACRS III premixers will have to be developed further to improve the emissions performance of these devices. Leonard and Correa NOx emissions correlation (fully premixed Methane/air flames) has been used for predicting NOx emissions from the combustor.

\section{Diffuser}

The ATS combustor design uses a 5 in. long diffuser. In order to limit diffuser dump losses significant development will have to be undertaken to design a low loss ultra short diffuser. Trades between diffuser losses and combustor/engine lengths will have to be made to optimize the design of the diffuser.

\section{Highly Skewed Part Power Profiles}

The LM6000 combustor operates with the middle dome lit at all times. As load on the engine is increased, the staging sequence ignites the inner, and then the outer, as shown in Figure 6.3.7.1. This results in highly skewed temperature profiles entering the turbine nozzle. The nozzle and blade design will have to take the skewed profiles at part power into consideration. 


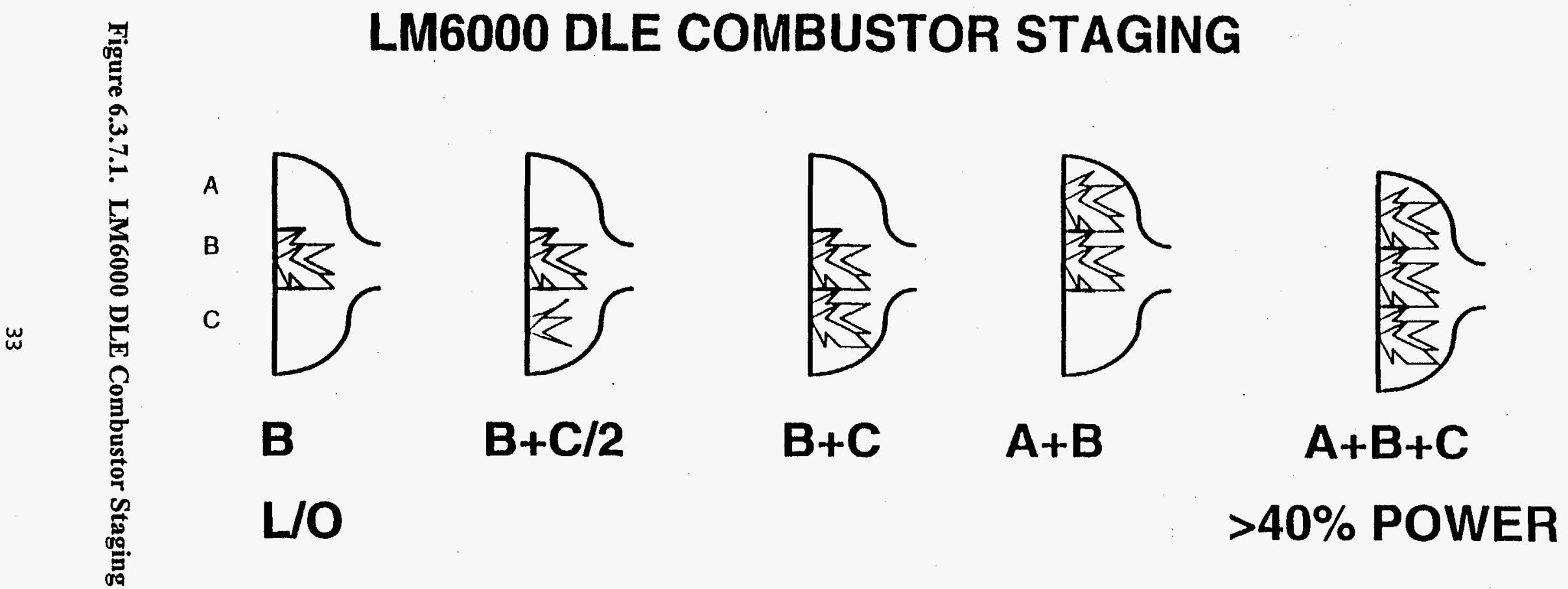




\section{Combustor Acoustics and Operability}

Lean premixed combustors have been shown to have increased dynamic pressures. The ATS combustor is also a lean premixed combustion system and will require on engine development to ensure that dynamic pressures are within design limits. The ATS combustor is designed to operate within a narrow flame temperature window with the use of air flow modulation. The transient dynamics of the turbocooler and the rest of the engine will have to be modeled in the design of the control system for the ATS engine.

\section{Hot Fuel/Coal Gas Capability}

The combustor operates at part power with the inner and outer domes switched off. The control system requires separate shut off valves for each of the domes. The design $f$ the fuel system will have to take into consideration the impacts of heated fuels if the cycle design requires it. Additional analysis will be required to establish the effects of burning coal gas in the compact design of the ATS combustor.

\section{Sealing Technology}

The premixer to dome joint, the outer/inner liner to turbine nozzle joint, and the igniter/flame detector penetrations have been assumed not to leak, so that all air can be used for combustion to minimize NOx emissions. To achieve this goal, current sealing concepts may be need further development.

\subsubsection{CONCLUSIONS}

The preliminary design of the ATS combustor has been completed. The lean premixed natural gas fired combustor design utilizes the concept and operating modes proven on the LM6000 DLE program. However technical challenges in premixer performance, sealing, operability/staging effects, diffuser design, and coal gas capability will be addressed in the follow-on program. The detail design process will address operability, system integration , and mechanical design of the combustor. 


\subsection{HIGH PRESSURE TURBINE COOLING DESIGN}

Preliminary turbine cooling designs were developed for the Stage 1 and Stage 2 high-pressure turbine vanes and blades to support the evolution of the Advanced Turbine System cycle and establish the design constraints necessary for a successful detail design.

The ATS turbocooler provides cooling flow to the combustor liners and high pressure turbine vane and bands at reduced temperatures and increased pressures, as compared to traditional CDP (Compressor Discharge Pressure) air-cooled designs. Flow from the turbocooler cools the combustor liner, the HPT vane outer band, and HPT vane as film as well as non-film impingement cooling. The post-impingement spent cooling air is used to cool the combustor inner liner, vane inner band, and forward seal. Figure 6.4.2 indicates the cooling flow from the turbocooler.

Coolant supply to the remaining HPT components is based upon a more traditional configuration: CDP air cools the HPT Stage 1 blade; 7th Stage Bleed cools the HPT Stage 2 blade; and interstage air cools the HPT Stage 2 vane.

In order to achieve a cost effective design, existing GE90 hardware was used where possible. The ATS design flow function increased $19 \%$ relative to the GE90's. This will require a rotation of the airfoils in the turbine and may require new airfoils.

The gas temperature profile is based upon the ATS profile and pattern factor, which is very flat compared to other DLE (Dry Low Emission) engines. This effect can be seen in Figure 6.4.4.

Figures 6.4.1 thru 6.4.24 outline the critical design areas that have been analyzed for the highpressure turbine. 


\section{Cycle Conditions \& Gas Temperature Profiles}

The design cycle conditions for the ATS follow:

ATS Cycle Conditions

$\begin{array}{lll}\text { T3 } & \text { (F) } & 955.4 \\ \text { P3 } & \text { (psi) } & 760.0 \\ \text { T41 } & \text { (F) } & 2684.3 \\ \text { P4 } & \text { (psi) } & 717.7 \\ & & \\ \text { T42 } & \text { (F) } & 1885.0 \\ \text { W25 } & \text { (pps) } & 491.9 \\ \text { W41 } & \text { (pps) } & 453.2 \\ & & \\ \text { XN25 } & \text { (rpm) } & 9433\end{array}$

Figure 6.4.1. ATS Turbine Design Considerations 


\section{Cooling Flow Status}

Part

Combustor Aft Seal Leakages

Combustor Outer Liner

Combustor Inner Liner

HIP Vane Inner Band

HPT Vane Outer Band

HIPT Vane Film

HP'T Vane Trailing Edge

HPT Shroud

Total

HPT Blade

Forward Combustor

TC Turbine Flow

\section{From \\ $\mathrm{T} / \mathrm{C}$ \\ 1.80 \\ 1.50 \\ 1.50 \\ 0.92 \\ 1.03 \\ 1.38 \\ 0.98 \\ $\underline{0.50}$ \\ 9.61 \\ 0.60}

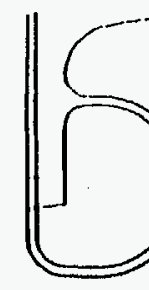

From

CDP

9.61

2.60

1.50
$9.61 \% W 25$

I' $=300^{\prime \prime} \mathrm{f}$

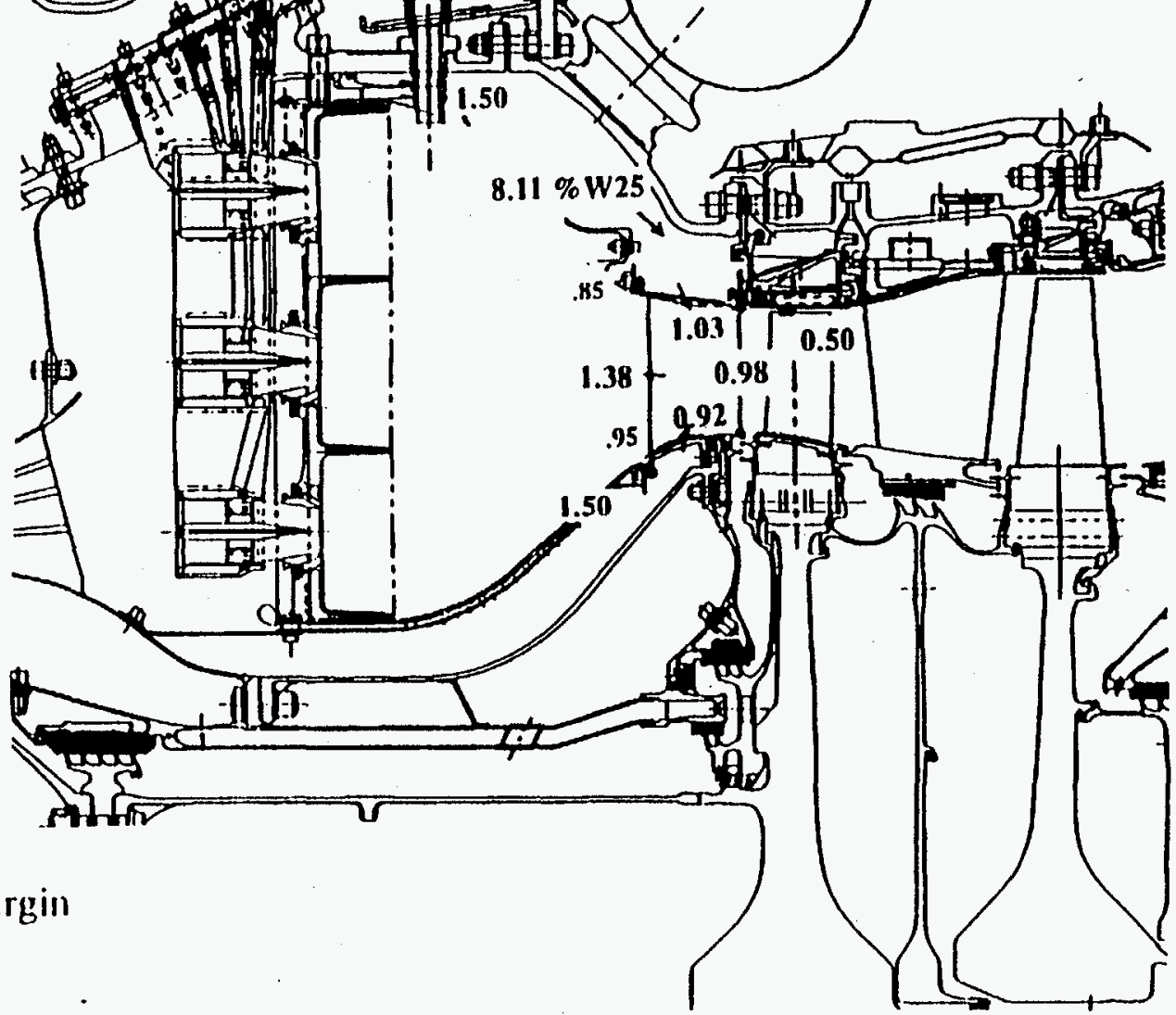




\section{Gas Temperature Profile Impact of Pattern and Profile Factor}

The following is a listing of the pitchline gas temperatures for the HPT Stage 1 \& 2 vanes and blades.

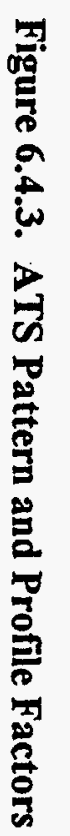
As a comparison, the gas temperatures of the airfoils are shown with pattern and profiles factors similar to the LM6000 Dry Low Emission combustor. As can be seen, the impact of the much lower ATS pattern and profile factors reduces the pitchline gas temperatures approximately $100^{\circ} \mathrm{F}$.

\begin{tabular}{|c|c|c|}
\hline & A'TS & A'TS \\
\hline & ATS PF & LM6000 DLE PF \\
\hline Pattern Factor & 0.070 & 0.132 \\
\hline Profile Factor & 0.030 & 0.092 \\
\hline \multicolumn{3}{|l|}{ HPT Stage I Vane } \\
\hline T Hot Streak & 2966 & 3082 \\
\hline \multicolumn{3}{|l|}{ HPT Stage 1 Blade } \\
\hline Ttb $\quad$ (F) & 2682 & 2794 \\
\hline \multicolumn{3}{|l|}{ HP'T Stage 2 Vane } \\
\hline T Hot Streak & 2308 & 2409 \\
\hline \multicolumn{3}{|l|}{ HPT Stage 2 IBlade } \\
\hline Ttb & 2114 & 2209 \\
\hline
\end{tabular}




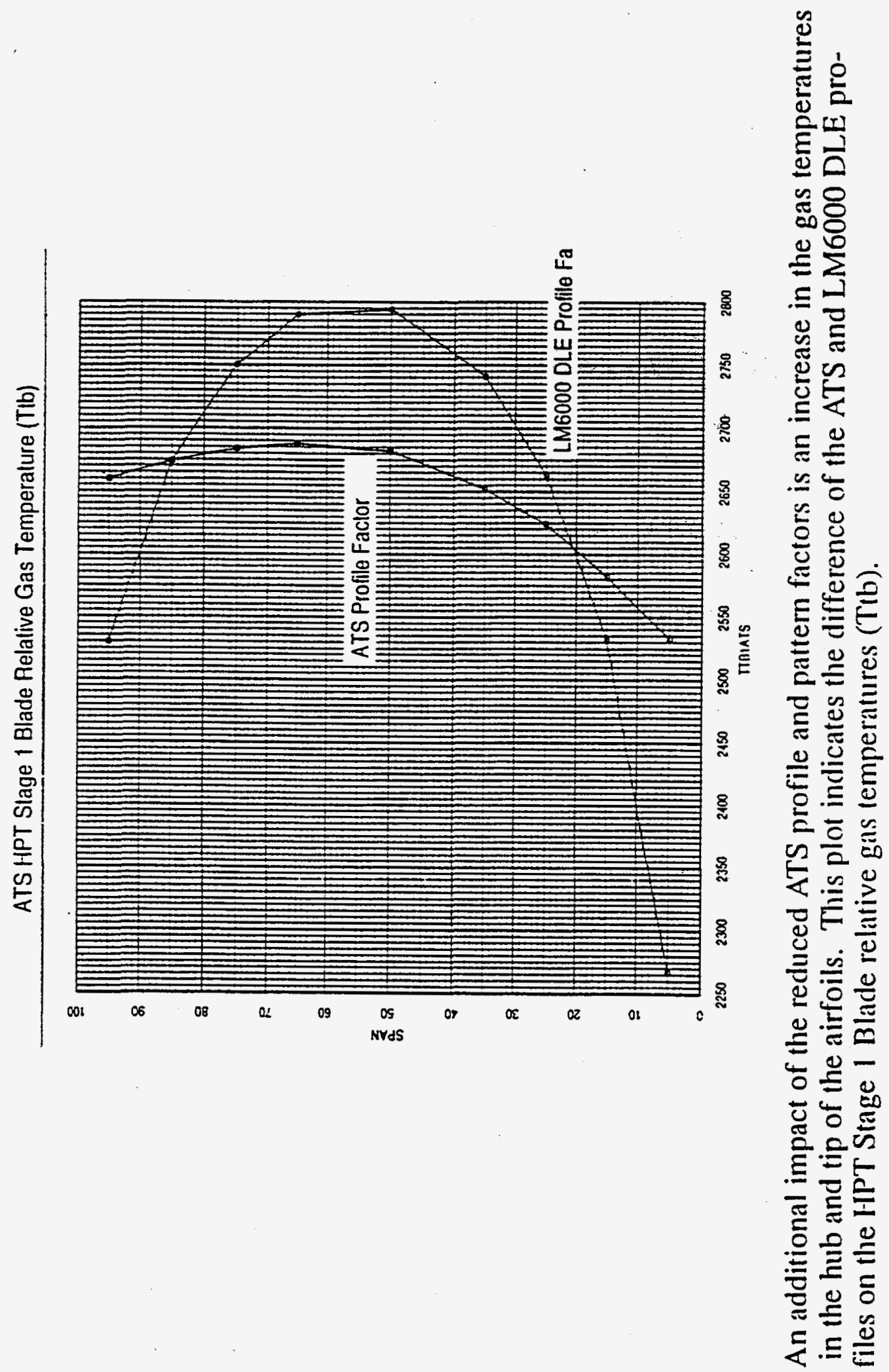

Figure 6.4.4. ATS HPT Stage 1 Gas Temperature 


\section{HP'T Stage 1 Vane}

The design goal for the HPT stage 1 vane is 3000 cycles at the ATS design point with 300F intercooler air. The life limiting location of the N6 airfoil was found to be the trailing edge, which is potentially a repairable location. The next life limiting point was the suction side panel. An optimized thermal design is critical to achieving life.

Cooling flow for the high pressure turbine vane is supplied from the turbocooler at much lower temperatures and higher pressures than the conventional vane coolant supply from CDP air. The HPT vane cooling design includes internal impingement for increased heat transfer. A portion of that flow exhausts through film holes and trailing edge pressure side bleed as in traditional designs, but over half of the flow is captured at the hub of the airfoil and used to cool the combustor inner liner and HPT stage 1 inner bands. The total flow into the HPT vane is $5.73 \% \mathrm{~W} 25$. Of that, $1.38 \% \mathrm{~W} 25$ is used as film at the leading edge and $.98 \% \mathrm{~W} 25$ is pressure side bleed cooling the trailing edge. The remaining $3.37 \% \mathrm{~W} 25$ provides a high impingement heat transfer coefficient on the internal surface of the airfoil, then passes through the vane to cool the inner band, combustor inner liner and forward leaf seal. The ability to reuse the spent vane cooling air is only possible due to the increased pressure and lower cooling temperatures supplied by the turbocooler. Typical impingement/film cooled vane designs are limited by backflow margins (Pcoolant/Pgas) at the leading edge of the vane to prevent gas ingestion. This is not a restriction for the ATS design; only cooling air pressure supplying the combustor inner liner, which is the vane cooling air exhaust pressure, is a design constraint. 


\section{HPT Stage 1 Vane}

Thermal barrier coating is important in achieving the life of the stage 1 vane. TBC outer surface temperatures were limited to $2350^{\circ} \mathrm{F}$ and $\mathrm{TBC}$ bond coat interface temperatures were limited to $1900^{\circ} \mathrm{F}$ in order to minimize the risk of the TBC in sintering and increasing the TBC thermal conductivity. Two TBC thickness designs were analyzed to balance the cooling design of the airfoil. Both configurations used $2.36 \% \mathrm{~W} 25$ in film and $3.66 \% \mathrm{~W} 25$ non-film flow. Both also had a life limiting location at the trailing edge with 3000 cycles nominal N6 material properties and 1500 cycles with minimum properties. This is potentially a repairable location. The first configuration had 10 mils of TBC on the leading edge forward, both pressure and suction side, and 15 mils in the aft cavity. The life of the suction side panel for this design was 3700 cycles for minimum N6 material properties. This is not a repairable location. In order to provide a more balanced temperature distribution, the TBC thickness of the second configuration was modified to 10 mils leading edge, and 10 mils pressure side aft and 20 mils suction side aft. This reduces the aft suction side panel temperature and increases the pressure side aft temperatures which increased the suction side panel life to over 10000 cycles for minimum N6 properties.

In conclusion, an HPT Stage 1 Vane design is dependent on a optimum thermal design which includes thermal barrier coating and N6 properties. The airfoil will be limited at the trailing edge and only achieves 1500 cycles versus the 3000 required. However, this is considered a repairable location. The next limiting location is the suction side panel which will achieve the design goal of 3000 cycles. 


\section{HPT Stage 1 Vane}

\begin{tabular}{|c|c|c|}
\hline Hot Streak Temperature & (F) & 2966 \\
\hline Coolant Temperature & $(\mathrm{F})$ & 300 \\
\hline Pcoolant/Pgas & & 1.10 \\
\hline TBC Thickness & (mils) & $10 / 15$ \\
\hline Wc & (\%W25) & 6.02 \\
\hline Film & & 2.36 \\
\hline Non Film & & 3.66 \\
\hline Life & (cycles) & 3000 \\
\hline TBC Outer Temperature & (F) & 2350 \\
\hline Bond Coat Temperature & (F) & 1700 \\
\hline
\end{tabular}

Figure 6.4.7. ATS HPT Stage 1 Vane - Design Temperature Values 


\section{ATS Stage 1 Vane Estimated Leakage Losses}

\begin{tabular}{|c|c|}
\hline & $\begin{array}{l}\text { ATS } \\
\text { (\%W25) }\end{array}$ \\
\hline \multicolumn{2}{|l|}{ Band Spline Seals } \\
\hline Inner & 0.27 \\
\hline Outer & 0.28 \\
\hline Outer Aft Leaf Seal & 0.35 \\
\hline Inner Mount & 0.25 \\
\hline \multicolumn{2}{|l|}{ Forward Leaf Seals } \\
\hline Inner & 0.95 \\
\hline Outer & 0.85 \\
\hline \multicolumn{2}{|l|}{ Vane (Airfoil) } \\
\hline Forward \& Aft Circuit Film & 1.38 \\
\hline Trailing Edge Film & 0.98 \\
\hline \multicolumn{2}{|l|}{ Bands } \\
\hline Inner & 0.4 \\
\hline Outer & $\underline{0.4}$ \\
\hline & 6.11 \\
\hline
\end{tabular}

Figure 6.4.8. ATS HPT Stage 1 Vane Estimated Leakage Losses 


\section{COOLING AND LEAKAGE FLOWS}

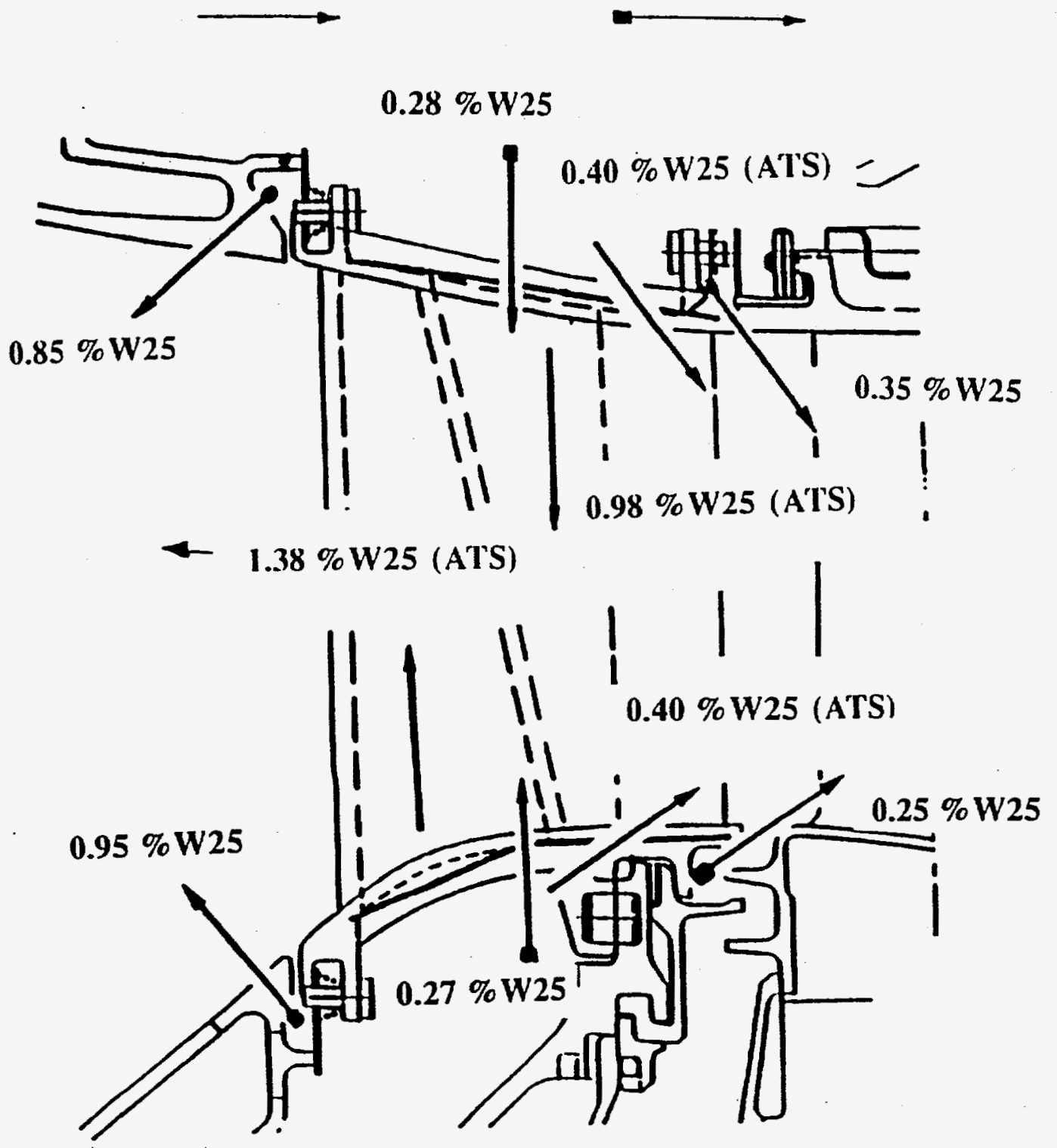

Figure 6.4.9. ATS HPT Stage 1 Vane Cooling and Leakage Flows 


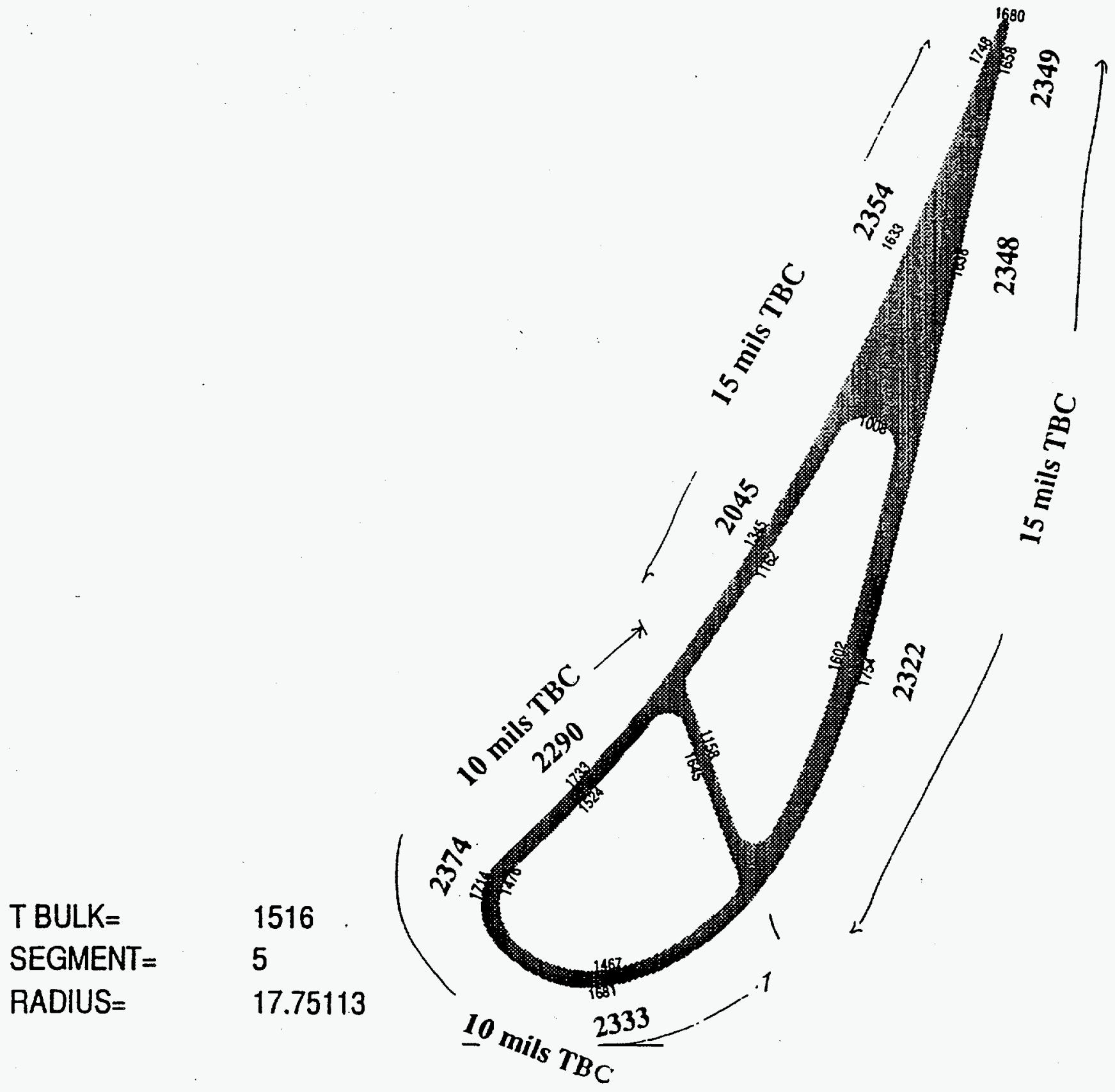

Figure 6.4.10. ATS HPT Stage 1 Vane - Metal Temperatures 
Objective: Determine whether a viable HPT Stage I Vane airfoil design was achievable using the $300 \mathrm{~F}$ intercooler air.

Studies: $\quad$ GE90 HPT Stage I Vane (N5) 3D Model was used to run Ansys thermal \& stress analysis.

\section{1}

$\begin{array}{ll}\text { TBC Thickness } & 10 \text { mils LE fwd/ } 15 \text { mils TE aft } \\ \text { Cooling Flow } & 2.36 \% \text { W } 25 \text { Film;3.66\%W } 25 \text { NonFilm }\end{array}$
2

10 mils LE fwd $/ 10$ mils ps aft $/ 20$ mils ss aft

$2.36 \%$ W25 Film;3.66\%W25 NonFilm

Results: $\square$ Life limiting location occurred at trailing edge:

N5: 1400 cycles nom; 600 cycles min

N6: 3000 cycles nom; 1500 cycles min (scaled)

$\square$ Suction side panel:

Iter 1: $\quad$ N5: 1400 cycles min

N6: 3700 cycles min

Iter 2: $\quad$ Reduce aft suction side panel temperature; Increase pressure side aft temp

N5: 4000 cycles $\min$

N6: $>10000$ cycles $\min$ 


\section{HPT Stage 1 Blade}

The design goal for the HPT stage 1 blade is 25000 hours at the ATS design point.. Due to the flat temperature profile factor from the combustor, the airfoil $10 \%$ span is the life limiting location for this design. Ten mils of thermal barrier coating on the blade is required to achieve life. The ATS design cycle conditions for the IIPT stage 1 blade are shown in Figure 6.32. The
GE90 HPT stage 2 blade cooling circuit will be maintained for the ATS with N6(versus N5) material properties. The circuit consists of a cold bridge leading edge, five pass serpentine and cold bridge trailing edge. The cooling flow has been reduced to $2.66 \% \mathrm{~W} 25$ with $0.84 \%$ in circuit $1,0.82 \%$ in circuit 2 and $1.0 \%$ in circuit 3 . Chambers $2-8$ include the angled turbulators for enhanced heat transfer.

The coolant supply to the ATS HPT stage 1 blade is the same as found in the GE90. Compressor discharge air supplies the blade circuit as shown in Figure 6.33.

As mentioned above,the $10 \%$ span is the blade life limiting location due to the gas temperature profile. Typical metal and thermal barrier coating temperatures are shown in Figure 6.35. 


\section{HPT Stage 1 Blade Pitchline}

Gas Temperature (Ttb)

Coolant Temperature

Pcoolant/Pgas

TBC Thickness

Wc
(F)

(mils)

(\%W25)
2682

972

1.10

5-10

2.66

\section{Life \& Bulk Temperature \\ Requirements}

Span

Life

Tbulk

(hours)

(F)

$10 \%$ * $50 \%$

$25000 \quad 25000$

$1527 \quad 1613$

${ }^{*} 10 \%$ span becomes life limiting location of airfoil due to temperature profile

Figure 6.4.13. ATS HPT Stage 1 Blade Design Conditions 


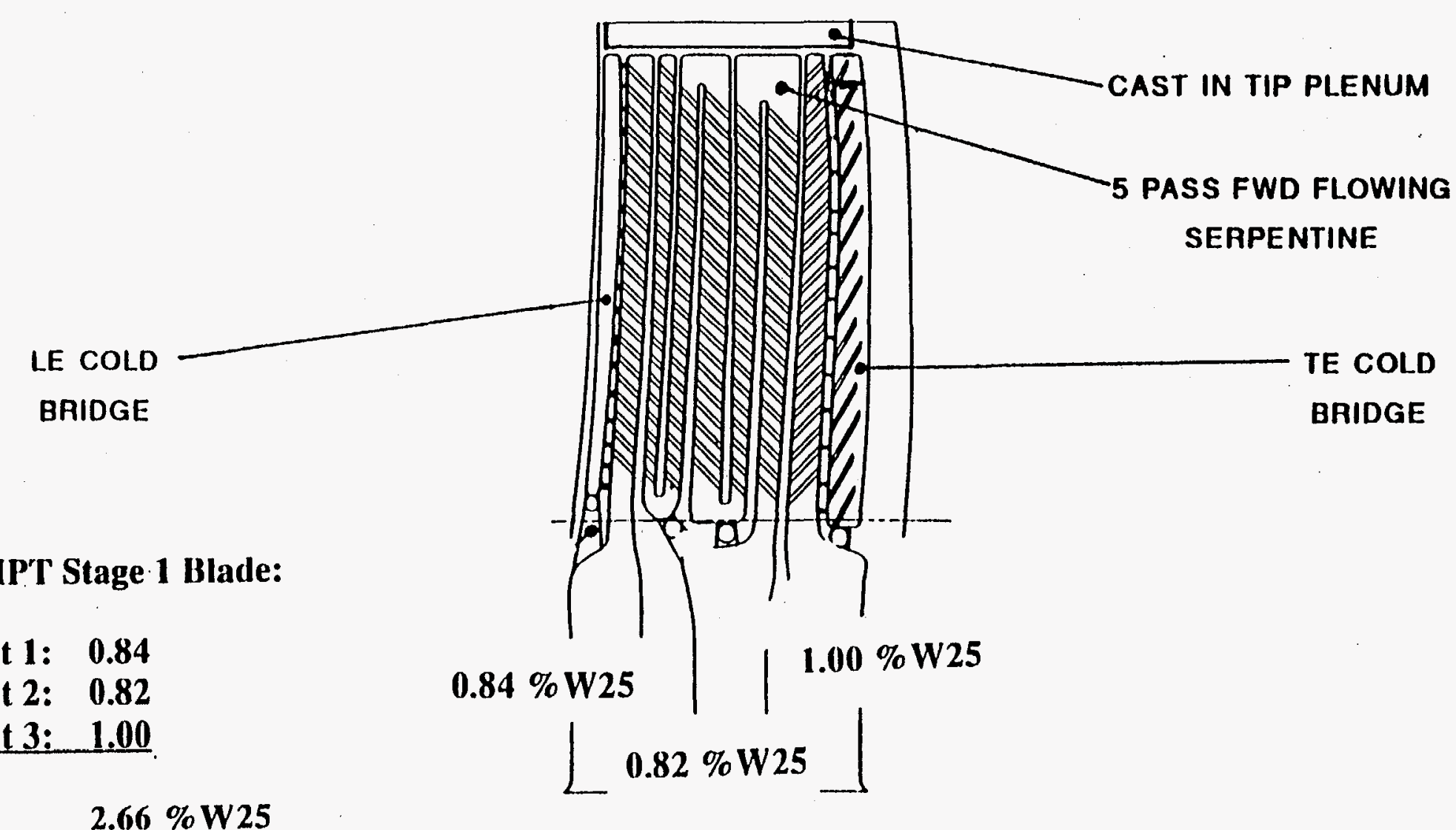




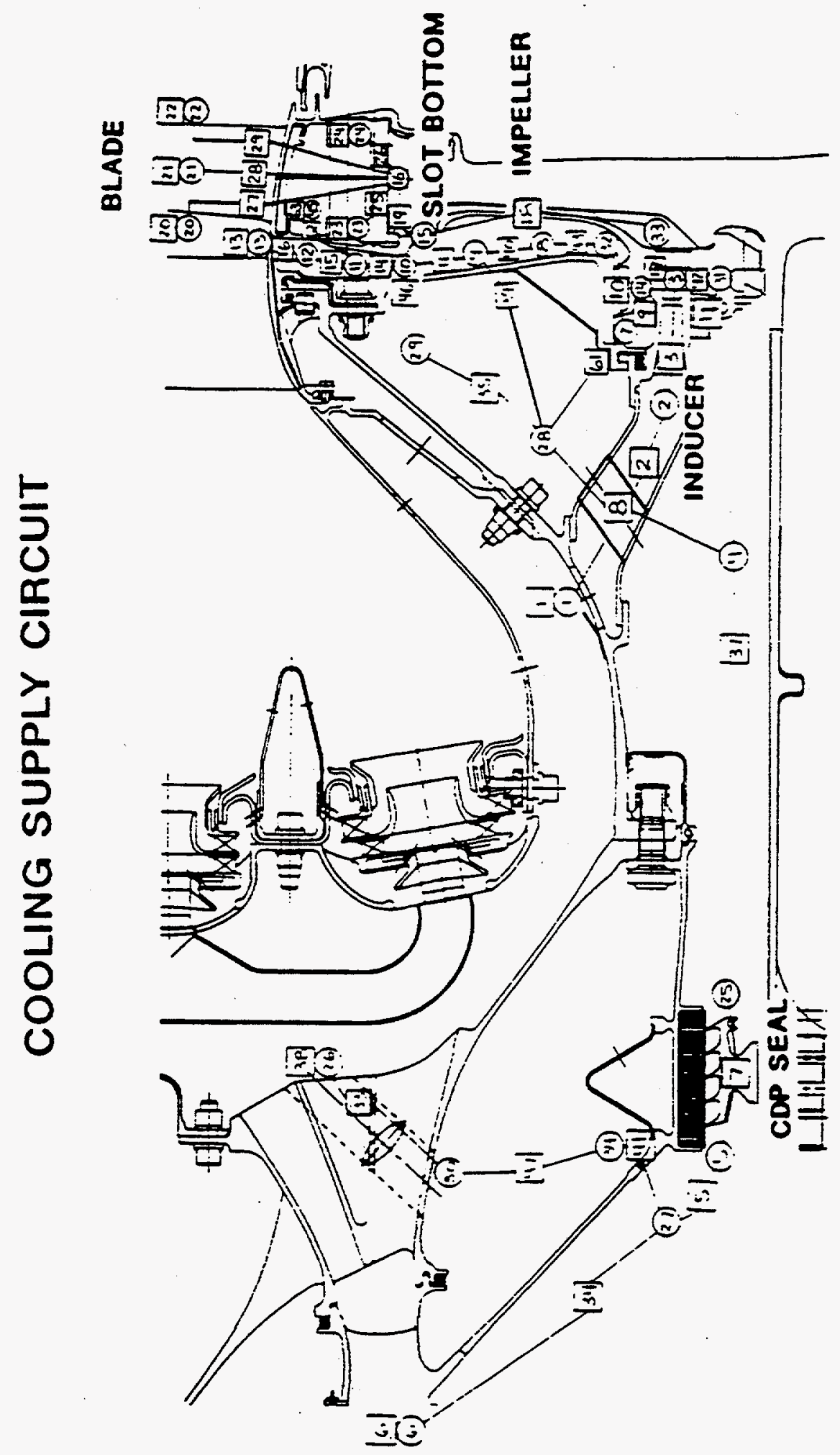

Figure 6.4.15. ATS HPT Cooling Supply Circuit 


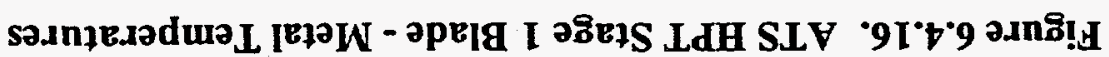

当筧离

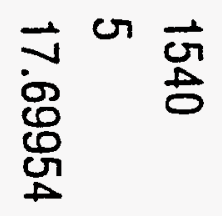

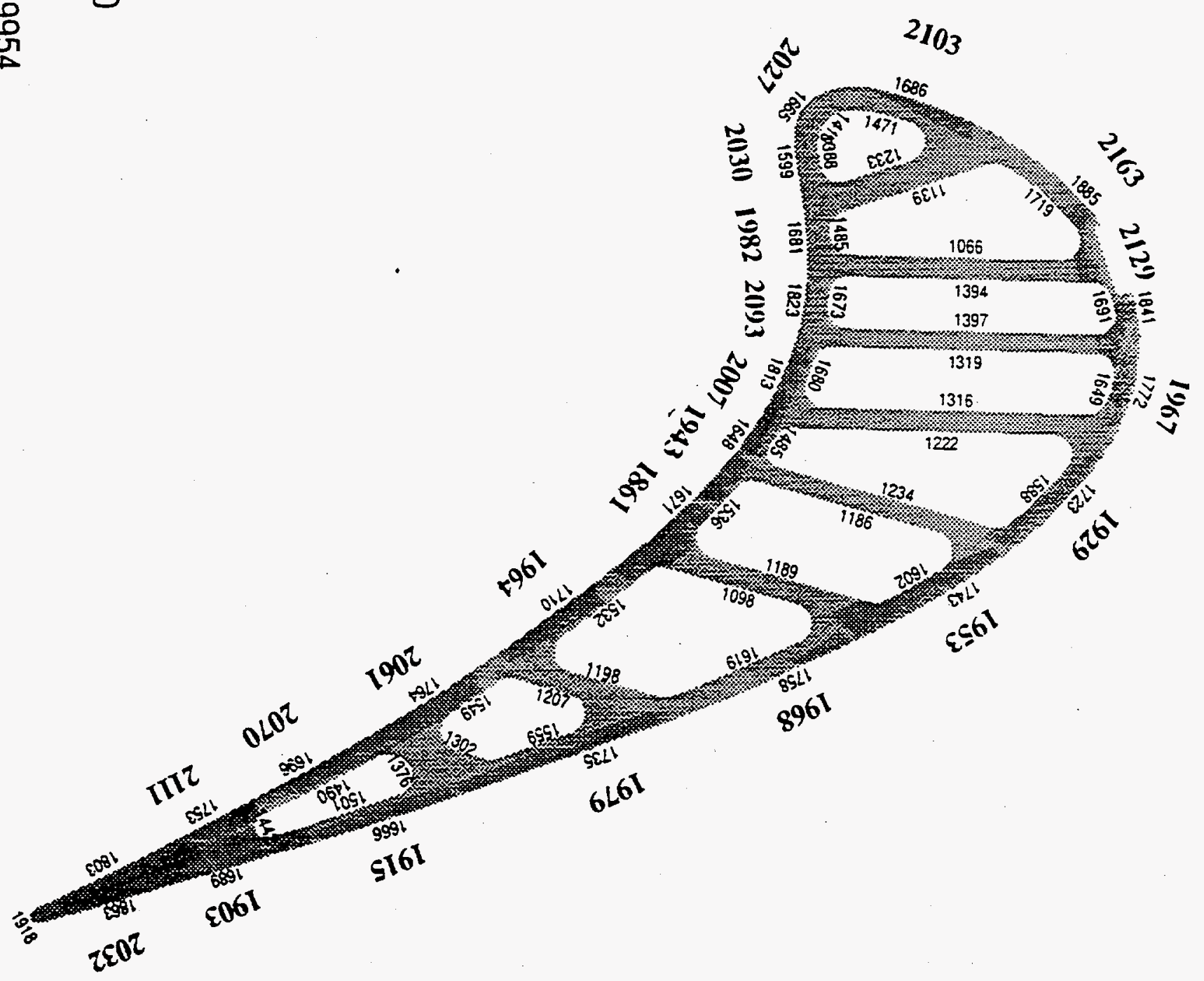




\section{HPT Stage 2 Vane}

The design goal for the HPT stage 2 vane is 3000 cycles at the ATS design point. The GE90 HPT stage 2 vane cooling design will be maintained for the ATS with N6 material properties. The design also includes four to ten mils of thermal barrier conting on the vane to achieve life.

The ATS design cycle conditions for the HPT stage 2 vane are shown in Figure 6.37. The cooling flow is approximately the same as the GE90's at $2.66 \%$ W25 using interstage air. The one concern area in the design is a potential problem of negative backflow margin or local gas ingestion at the pressure side film hole location.

This occurs due to the increase in flow function of the turbine; gas pressures have increased at the stage 2 vane.

To address this, a higher coolant supply pressure will be required. 


\section{ATS HPT Stage 2 Vane}

Hot Streak Temperature

Coolant Temperature

Pcoolant/Pgas

P3

Ps Vane 2 Source

Pt Gas Vane 2 Fwd

Ps Vane 2 Fwd ID

Ps Vane 2 Aft II)

Ps Vane 2 Aft Pitch

TBC Thickness

Wc

I ife

(Required)
2409

719

$1.01^{*}$

(psi)

(psi)

(psi)

(psi)

(psi)

(psi)

(mils)

(\%W25)

(cycles)
760.0

349.2

353.1

334.2

228.7

247.1

4-10

2.23

$3000 * *$

*Gas ingestion pressure side film holes.

holes to achieve life.

** Requires positive backflow margin in pressure side film

Figure 6.4.18. ATS HPT Stage 2 Vane - Temperatures 


\section{HPT Stage 2 Blade}

The design goal for the HPT stage 2 blade is 25000 hours at the ATS design point. Again, due to the flat temperature profile factor from the combustor, the $10 \%$ span of the airfoil is the life limiting location for this design. Ten mils of thermal barrier coating on the blade is required to achieve life.

The ATS design cycle conditions for the IIPT stage 2 blade are shown in Figure 6.39. The GE90 HPT stage 2 blade cooling circuit will be maintained for the ATS with N6(versus N5) material properties. The circuit consists of a single pass leading edge, five pass aft flowing midchord serpentine, and single pass trailing edge. The cooling flow has been increased to $0.86 \% \mathrm{~W} 25$ with $0.2 \%$ in circuit 1 $0.34 \%$ in circuit 2 and $0.32 \%$ in circuit 3 . All seven chambers include the angled turbulators for enhanced heat transfer.

The coolant supply to the ATS FIPT stage 2 blade is the same as found in the GE90. Seventh stage air supplies the blade circuit as shown in Figure 6.40.

As mentioned above, $10 \%$ span is the blade life limiting location due to the gas temperature profile. Typical metal and thermal barrier coating temperatures are shown in Figure 6.42 


\section{HPT Stage 2 Blade}

Pitchline

$\begin{array}{lll}\text { Gas Temperature (Ttb) } & \text { (F) } & 2114 \\ \text { Coolant Temperature } & \text { (F) } & 916 \\ \text { Pcoolant/Pgas } & & 1.43 \\ \text { TBC Thickness } & \text { (mils) } & 10 \\ \text { Wc } & \text { (\%W25) } & 0.86\end{array}$

Life \& Bulk Temperature ATS Requirements

Span

Life

(hours)

$10 \% * 50 \%$

Tbulk

(F)

$25000 \quad 25000$

$1464 \quad 1566$

${ }^{*} 10 \%$ span becomes life limiting location of airfoil due to temperature profile

Figure 6.4.20. ATS HPT Stage 2 Blade - Temperatures 


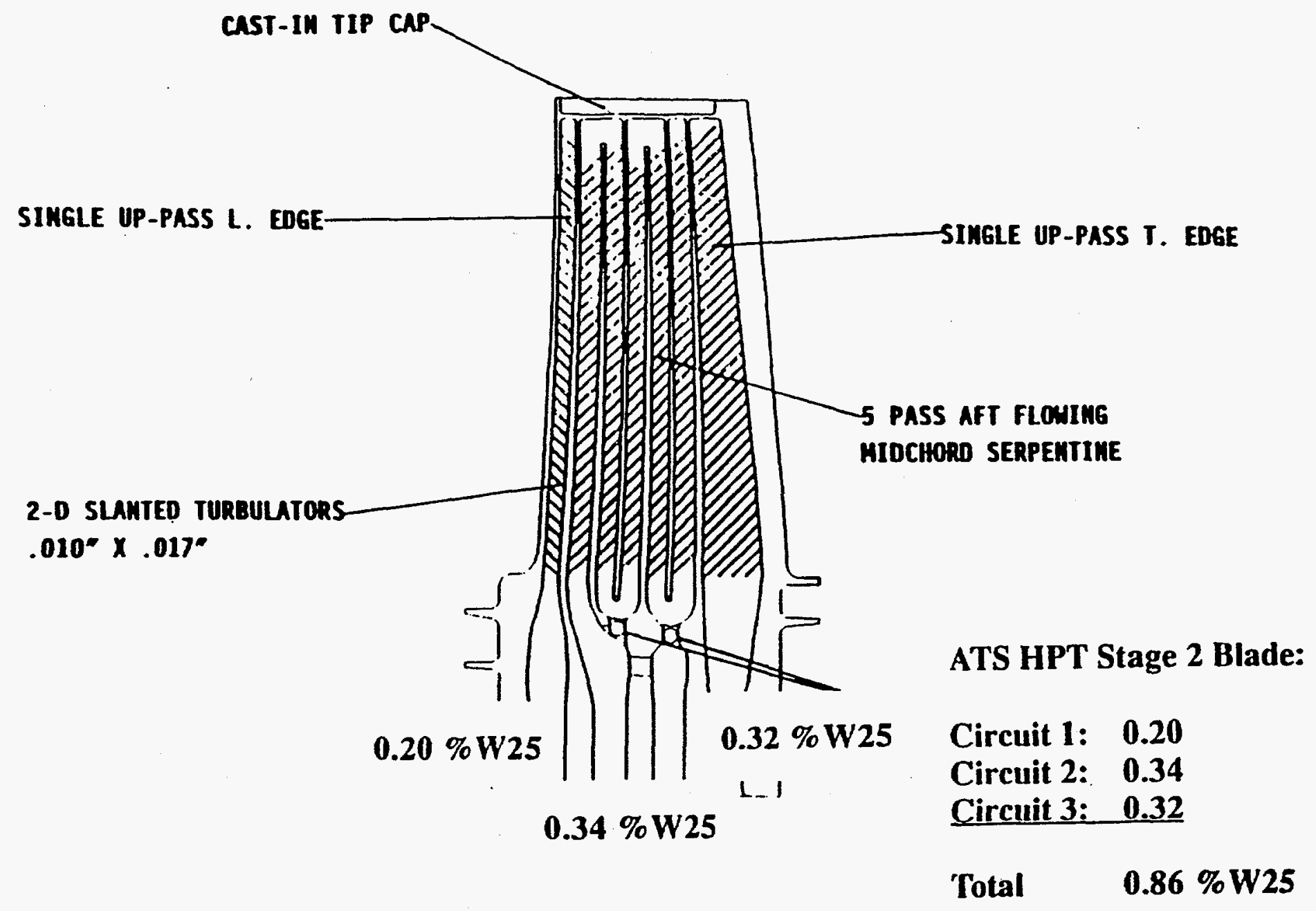

Figure 6.4.21. ATS HPT Stage 2 Blade - Cross-Section 


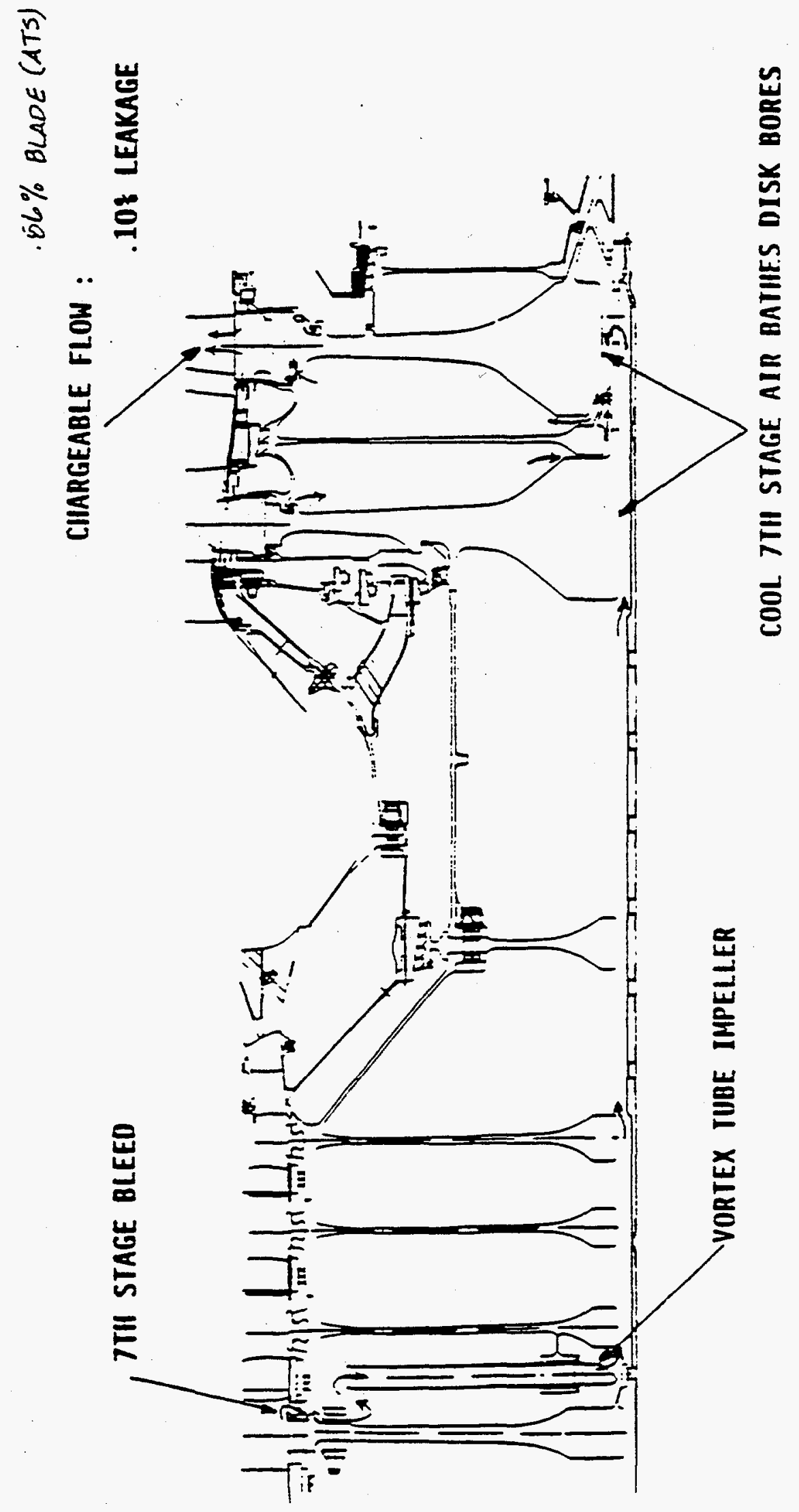

Figure 6.4.22. ATS HPT Stage 2 Blade - Coolant Supply 


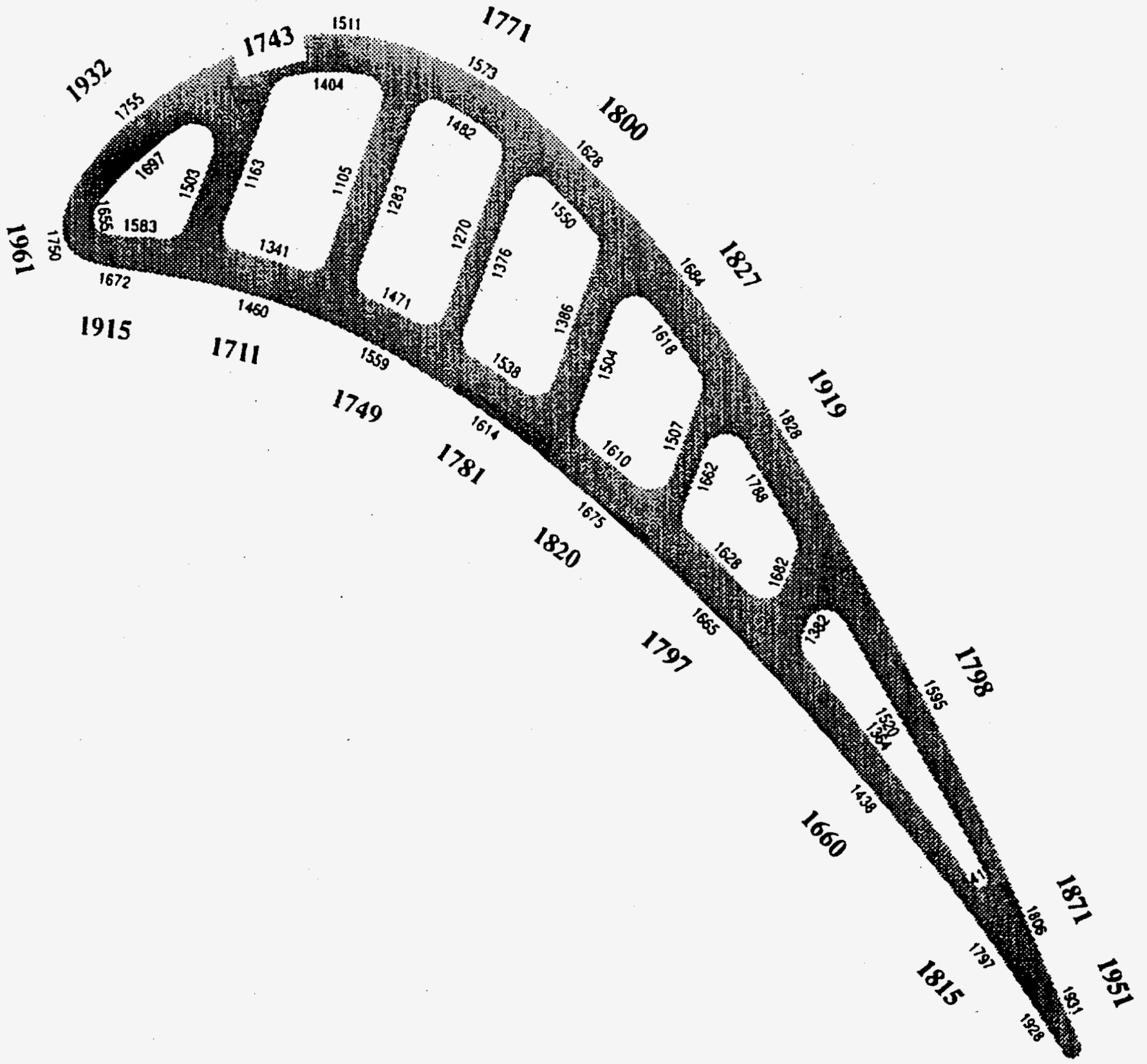

Figure 6.4.23. ATS HPT Stage 2 Blade - Metal Temperatures 


\section{Conclusions}

- The 19\% increase in ATS design flow function relative to the GE90's will require a rotation of the airfoils in the turbine, and may require new airfoils.

- Due to flat combustor profile and pattern factors, the endwall,hub and tip cooling are critical.

- The stage 1 and stage 2 blade life limiting locations are at the 10-20\% span for the ATS design.

- HPT stage 1 vane(N6) achieves life cooled with turbocooler air assuming the trailing edge is repairable. An optimized thermal design is critical to achieving life.

- $\quad$ HPT stage 1 blade achieves rupture life with 10 mils of thermal barrier coating(TBC).

- HPT stage 2 vane indicates there will be gas ingestion with the current interstage coolant supply.

- A higher coolant supply pressure will be required.

- HPT stage 2 blade achieves rupture life with 10 mils of TBC and increased coolant flow.

- Themal Barrier Coating is critical to being able to meet the ATS design goals.

\section{Final Design Studies Needed}

- Evaluste the low engine power settings on gas temperature profiles.

- Include TBC spallation studies for final design acceptance.

- Optimize film and TBC thickness in thermal designs.

- Determine an alternative coolant supply for the HPT stage 2 vane. 


\subsection{ATS TURBOCOOLER SYSTEM}

\subsubsection{PURPOSEJFUNCTION}

The purpose of the turbocooler subsystem is to enhance coolant air extracted at the engine compressor discharge and deployed to cool the HP Stage 1 vane and combustor liner. Enhancement is achieved by cooling and pressurizing the cooling air. Enhancement permits significant reduction in cooling flow and virtual elimination of film cooling of the combustor liner. The latter results in reduced emissions at reduced flame temperature. Fuel heating provides an additional cycle efficiency benefit.

The resulting effect of cooling and compression of the coolant air is a turbocooler exit (engine re-entry) temperature 660 degrees below engine extraction temperature levels. Cooling of this air is achieved by rejecting heat to metered natural gas fuel. The cooling flow requirement and fuel flow available dictate exit fuel temperatures approaching the flammability temperature, well above the fuel temperatures of conventional thermal management systems. Because of the consequent issues of fouling and fire safety, the heat exchange system is probably the principal challenge in ATS development. Enabling technologies are being explored concurrently and are discussed in subsequent sections.

Pressurization of the coolant air is achieved in a compressor operating at a pressure ratio of 1.27. This compensates for losses associated with extraction, cooling, and transport of flow in the system, and provides sufficient pressure upon re-entry to permit convective cooling of the vane and impingement (instead of film) cooling of the combustor liner.

Specifically, the cooling requirements influencing the turbocooler design include: $10.6 \%$ W 25 flow required to cool the vane and combustor liner, vane leakage flow delivered at a pressure $7.2 \%$ above compressor discharge pressure ( $\mathrm{P3}$ ), and at a temperature of $300 \mathrm{~F}$ at the engine manifold for engine full-power operation.

Additional air extraction needed for this cooling enhancement include:

1. W25 extraction at CDP (not included in the flow requirement stated above) to drive the precooled compressor by expansion in a turbine; this air is available at the engine LP turbine for cooling.

2. W25 (included in the coolant flow requirement stated above) is employed, after cooling and compression, to cool the turbomachine air bearing.

\subsubsection{CONFIGURATION}

The turbocooler system consists of a turbocompressor section and a heat exchange section. The turbocompressor consists of a single-stage axial compressor and a single-stage radial inflow turbine mounted on a shaft supported by an air bearing; the bearing is cooled by reverse Pitot extraction at the air cycle compressor diffuser exit. Turbocompressors similar to these have been used in aircraft environmental control systems for decades; the principal differences between their application in environment control system (ECS) packages and their use as turbocoolers for the ATS are the temperature exposure of the turbine and the fact that the 
turbine and compressor are not aerodynamically coupled in the ATS application. For this turbocooler application with precooled compressor and intercooled cycle, the compressor disc is fabricated from aluminum and the turbine disc from Inconel 718 . Precooling the compressor air minimizes the air extraction required to drive the turbine, provides a source of air capable (without further cooling) of cooling the foil bearings, and allows use of conventional lightweight materials for the compressor blades and disc.

The heat exchangers are tube and shell type multipassed on the shell side. The shell side fluid is directed between passes by means of segmented baffles which also provide lateral support for the tubes. Specifically, the fuel heat sink system consists of two heat exchangers with an intermediate water loop. Heat from the air is transferred to water circulating in a closed loop; the water rejects heat to the fuel in the second heat exchanger. A motor-driven circulating pump is located at the water exit of the fuel heat exchanger, and the water circuit pressure level is maintained (assuring required energy exchanges) by means of a pressure amplifier referenced to engine CDP. All fuel wetted surfaces, in the heat exchanger as well as downstream, in the fuel delivery system are coated to retard deposition of gum and formation of coke.

\subsubsection{CONCEPTUAL DESIGN}

The turbocooler system boundary conditions applied to the design of the system are shown schematically in Figure 6.5.3.1. These conditions apply for the intercooled, turbocooled ATS cycle operating at max power. Fuel inlet temperature is assumed to be $77 \mathrm{~F}$, and the cycle intercooler water discharge temperature is assumed to be $200 \mathrm{~F}$.

Compressor flow requirements were established by reference to the engine and air bearing cooling requirements; the flow requirement above was increased by $15 \%$ to provide contingent margin. Compressor operating pressure ratio was determined by accounting for turbocooler system losses, extraction loss, and required supply pressure at the combustor vane/ high pressure vane manifold. The system loss determination at maximum power is summarized in Figure 6.5.3.2.

The supply pressure requirement is predicated upon providing pressure adequate for convective cooling of the vane and combustor liner. The higher supply pressure, on the other hand, increases any existing leakage from the vane outer band.

Compression heat compensation (representing $11 \%$ of the cooling load) depends on the operating pressure ratio, inlet temperature, and compression efficiency. The Allied Signal compressor has a peak adiabatic efficiency of $78 \%$. Compressor inlet temperature is low by virtue of precooling, and the compressor pressure ratio is dictated by turbocooler system losses and required reentry value. The compressor performance map is presented in Figure 6.5.3.3. The motive flow extraction, $2.2 \% \mathrm{~W} 25$, is sufficient for pressurizing the coolant (including $15 \%$ margin in coolant flow levels) and is based on turbine expansion power available with exhaust to the low pressure vane manifold, given the turbine circuit pressure losses of Figure 6.5.3.2. The turbine adiabatic efficiency is $81 \%$. Bearing and windage losses are accounted for in an assumed shaft efficiency of $96 \%$. A representation of the turbine performance is provided in Figures 6.5.3.2 and 6.5.3.5. A summary of the turbocooler design conditions is shown in Figure 6.5.3.6, and a crossection of the turbocooler is presented in Figure 6.5.3.7. 
The fuel sink system design represents Allied Signal's response to the GEAE Statement of Work, dated August 3, 1994. Then, as now, consensus dictates achievement of fire safety by means of complete separation of the fuel and air during heat exchange, the heat energy being transported from air to fuel via an intermediate fluid. Water was selected as the intermediary because of its chemical stability in the operating temperature interval. The Allied Signal design was further influenced by GEAE's preference for relatively modest water circuit operating pressures. The water loop operating pressure chosen was 1600 psia, subcritical, yet higher than the expected fuel system pressure, assuring a positive leakage path in the event of tube failure. Water is evaporated in the air heat exchanger and condensed in the fuel heat exchanger. Compatibility of the temperature profiles in terms of pinch margins limits the available fuel sink and necessitates supplementary cooling of the air to achieve $300 \mathrm{~F}$ re-entry temperature. Supplementary cooling is achieved in a separate heat exchanger, in which a portion of the engine intercooler water discharge is employed as a heat sink.

The resultant Allied Signal heat exchangers were larger and heavier than expected. Direct fuel-toair cores sized internally were on the order of $1 \mathrm{ft}^{3}$ in volume. The two heat exchangers comprising the fuel sink indirect heat transfer system were nearly $27 \mathrm{ft}^{3}$ in volume, significantly larger than would be expected in going from a direct transfer system to an indirect transfer system Furthermore, the tubes carrying fuel exceeded the aspect or spacing ratio felt acceptable for coke barrier coating (CBC) application. The issues of heat exchanger size and configuration are discussed in the next section. The original and new Allied Signal heat exchanger designs are presented in Figure 6.5.3.8.

\subsubsection{CHALLENGES}

\subsubsection{Hot Fuel}

In the Advanced Turbine System, fuel is heated to temperatures well above those in current thermal management systems (300F). Questions of operational safety and fouling of the heat exchanger have been a concern above, and will be addressed more fully below. Fouling is also an issue which must be addressed for the lines downstream of the heat exchanger, such as combustor, the staging valves, the fuel manifold, and injectors. Combustor valve operability at high fuel temperature is a serious concern, since these valves are designed to maintain combustor operation in a narrow band between blowout and burnout.

\subsubsection{Fire Safety}

Preventing a fire in the event of failure of the beat exchanger tubes was a principal concern in the design of the heat exchangers. Separation of fuel and air is felt to provide the best assurance of fire safety. Double-walled tube designs, where leaking fuel is vented away from hot air, are complex and expensive and result in significant reductions in heat exchange capability by imposition of a low conductive vent path between the fluids, requiring large cores to meet the heat transfer requirement. 
Barrier passages in plate-fin heat exchangers are somewhat more producible, the barrier pass representing just another layer in the fin stack, but the GEAE perception is that the ATS system operating pressures seriously compromise the structural integrity (and, therefore, intrinsic safety) of a plate-fin heat exchanger. Again, the barrier passage even with highly conductive fins insulates against efficient heat transfer between the two fluids. Large cores result from increased surface required to compensate for the reduced heat transfer conductance and to accommodate the intervening barrier passages between each active pass.

Intermediate transfer systems provide for positive separation between the potentially reactive fluids, but the intermediate fluid must be selected carefully. Certain forms of Dowtherm remain stable to $700 \mathrm{~F}$, but their deterioration near this temperature can produce reactants as lethal as fuel, relative to fire safety. Heat pipes operating at these temperatures employ liquid metals (potassium, sodium) which are extremely unstable when exposed to either fluid. Water was selected as the intermediary, because it has none of these problems. Subcritical systems will, however, involve phase change, and supercritical systems are characterized by very high water heat capacities, either of which limit utilization of the available fuel heat sink enabled by coke barrier coating.

\subsubsection{Coke Barrier Coating Technology}

At tube temperatures to 650F, fuel reactions occur near the tube surface, producing long chain molecules which may attach loosely to the tube walls in a random skeletal structure. At higher temperatures, these polymers tend to fragment, but metal ions in the wall diffuse to the surface and react with sulfides in the fuel to form coke, which attaches firmly to the tubewall, obstructing flow and reducing heat transfer capability of the unit. GEAE is, independently exploring means of retarding or eliminating these reactions through coating of the fuel wetted surfaces (creating a barrier to the coking reaction and a catalyst to promote fragmentation of the resin molecules). Tests have been conducted on liquid fuel systems (resistance heated single tubes and convectively heated full tube bundles with hot air flowing across the tubes) and natural gas (in heated single tubes) to determine the effectiveness of the barrier coating.

The natural gas tests were conducted in Schenectady by flowing the fuel inside coated tubes heated to $1000 \mathrm{~F}$. After 1,000 hrs. of exposure to these conditions, the tubes showed no coke deposition. Testing of a full tube and shell heat exchanger with liquid fuel flowing inside the tubes and hot air flowing across the tubes was conducted in Evendale last year. These units survived $150 \mathrm{hrs}$ of testing without coke deposition at fuel (exit) temperatures of $850 \mathrm{~F}$. Increasing the fuel flow through the system resulted in full coking of all units within $50 \mathrm{hrs}$. Certain conclusions drawn from this testing (relative significance of residence time and tube temperature in resin formation and deposition; resin deposits may be shed more readily outside the tube than inside) will be the subject of further testing (Phase 2) and repetition of the Phase 1 at a later date. Optimism on the effectiveness of the use of the $\mathrm{CBC}$ with natural gas is well founded in the success of the single-tube tests. 


\subsubsection{Heat Exchanger Size}

The heat exchangers proposed by Allied Signal in response to GEAE SOW are probably typical of configurations intended for industrial use. These units use relatively large, thick tubes $(0.25$ in. OD) in coarse spacing arrangements. The estimated surface density for the feedwater to air unit is $110 \mathrm{ft}^{2} / \mathrm{ft}^{3}$. Surface densities in compact heat exchangers approach $300 \mathrm{ft}^{2} / \mathrm{ft}^{3}$, limited by tube bundle assembly issues.

Studies done within GEAE (without full Allied Signal concurrence to date) suggest significant economies available with respect to volume and weight by using smaller tubes $(0$. 125in. OD).in more dense arrangements ( 30 mils between tube surfaces). These studies were based on flowing fuel over the tubes (rather than inside). This was suggested intuitively by the CBC test in 1994 (following the SOW issuance) and will be the subject of Phase 2 tests later. The GEAE study conclusions follow.

Disk and donut heat exchanger configurations appear to give the greatest reduction in size and weight for the current ATS design conditions. This configuration appeals intuitively to the favorable effect of symmetrical shell temperature distributions on stress.

Liquid water intermediary systems provide for the most efficient heat transfer (relative to multiphase subcritical or steam intermediary systems), but operate above critical pressure ( 3200 psia), requiring that water flow inside the tubes for containment. This is consistent with GEAE's current bias toward external fuel configurations. Minimum core size for the liquid water (supercritical) units is achieved by reducing the system water flow (increasing the water temperature change to approach a constant temperature difference across the tubewall). This tends to reduce the frontal area of the shell; considerations limiting contraction of the shell frontal area include limiting air velocities, (1) over the tubes to prevent vibration, and (2) in the turning paths between passes to limit pressure drop. A typical air-to-water unit is shown in Figure 6.5.3.8.

It should be further noted that, as the water loop design maximum temperature is increased beyond the critical value $(702 \mathrm{~F})$, proportionately more of the heat transfer to the water occurs in the supercritical realm with relatively little change in temperature (high, variable heat capacity) tending to bias the water temperature profile into interference with the air temperature profile. This is analogous to, but not as severe as, the effect of the boiling and condensing regimes in subcritical systems on limiting available temperature variation in the outer (principal) fluids.

Power requirements for circulating the intermediate fluid where the water exists as liquid at some point in the cycle are low; a steam intermediary can probably be operated at pressure levels of 100 psia, but because of the relatively large pressure drops and low density, requires significant power for circulation of the vapor. The principal reason for rejecting low pressure intermediary systems, however, is the adverse leakage path, permitting transport of fuel into the air heat exchanger. 


\subsection{TURBOCOMPRESSOR}

ATS Turbocooler power requirements of 1,300 HP dictate the need for larger load capacity foil bearings. The bearings dictate the design rotational speed $(40,000 \mathrm{rpm}$ at the max power operating condition), which results in some compromise to turbine performance.

The high load bearings proposed for this application have been recently developed by Allied Signal, so their use at this time involves some risk in the absence of performance history. Current production experience is relative to the $\mathrm{F}-22$ and $737 \mathrm{X}$.

\subsection{FAULT DETECTION AND CONTROL}

The turbocooler provides a critical function in its cooling, pressurization and maintenance of vane and bumer coolant flow levels. Any circumstance (fault) interrupting the operation of and/or degrading the expected performance of the system must be detectable and motivate shutdown of the plant; simply bypassing a defective turbocooler will not provide adequate cooling for the hot parts at the rated condition. Reversion to an internal cooling system requires expensive contingent design of alternative cooling paths and probably involves flow and dilution levels which increase emissions well above acceptable levels.

Loss of cooling in the heat exchanger resulting from loss of pressure or charge in the water circuit, fouling of the tubes (including coking of the fuel tubes), or failure of the water pump compromises the structural integrity of the vane and combustor liners (coolant temperature increases and turbocooler flow output is reduced by tendency to spool down) and also threatens the turbocooler compressor.

Although similar to a standard aircraft ECS pack, an engine cooling turbocooler differs in ways that will necessitate a thorough exploration of failure modes and consequences and provision for detection and correction. The former is a bootstrap air cycle with aerodynamic coupling between compressor and turbine, which results in operation in a narrow band on the compressor map; the equipment is well matched over a wide range of operating conditions. The turbocooler, with independent streams to compressor and turbine, is susceptible to overspeed or stall under circumstances which might not affect an ECS pack as seriously.

No attempt has been made in this phase of the study to address failure detection and controllability of the turbocooler system, apart from identifying location of check valves to prevent inadvertent engine extraction via the supply manifolds in the event of a duct failure event.

The larger issues mentioned here will be addressed in the next phase of the ATS study. 


\section{DOE ATS Turbocooler Cycle Conditions}

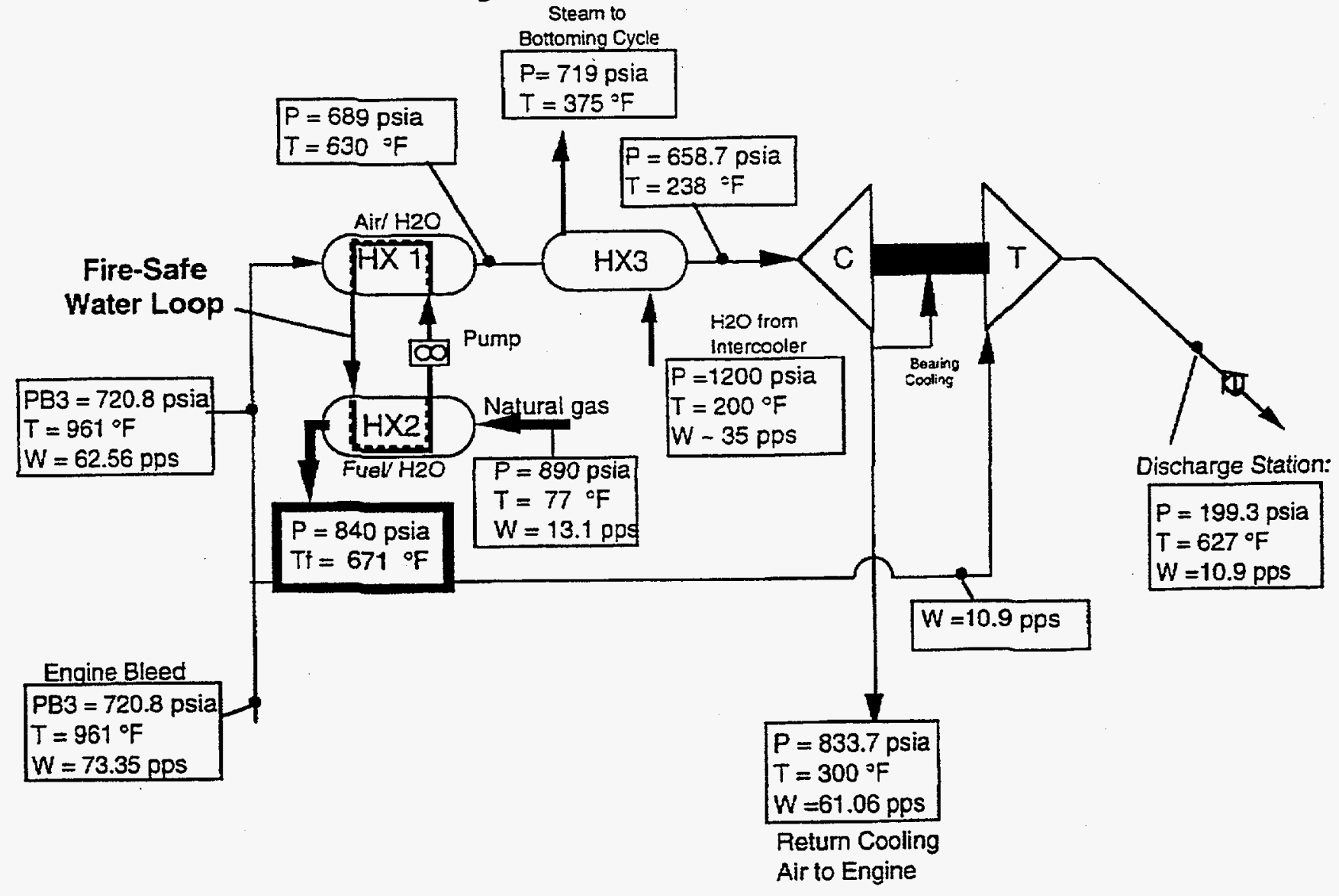

Figure 6.5.3.1. ATS Turbocooler Cycle Conditions 


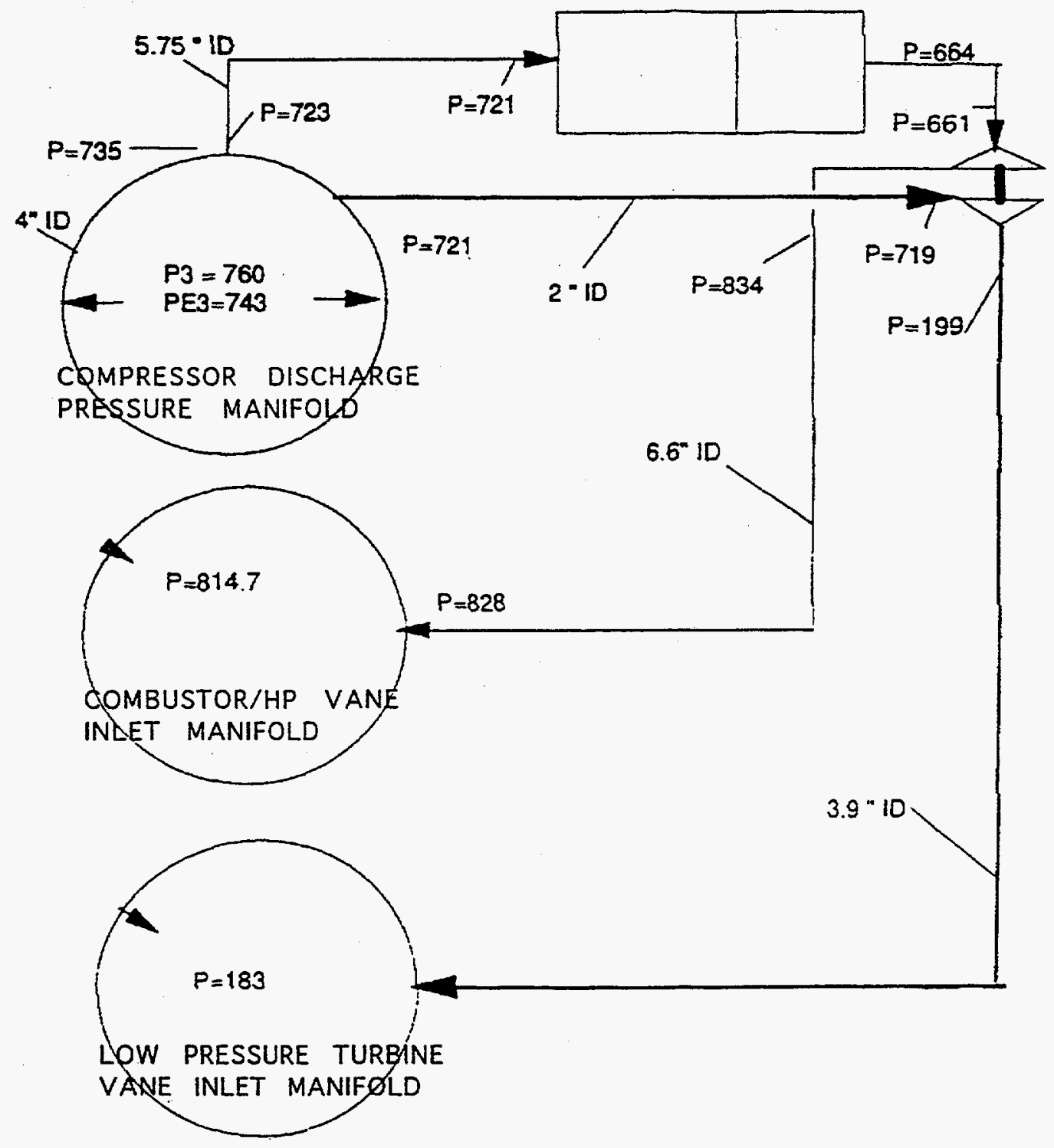

Figure 6.5.3.2. Estimated Pressure Distribution in ATS Turbocooler System 


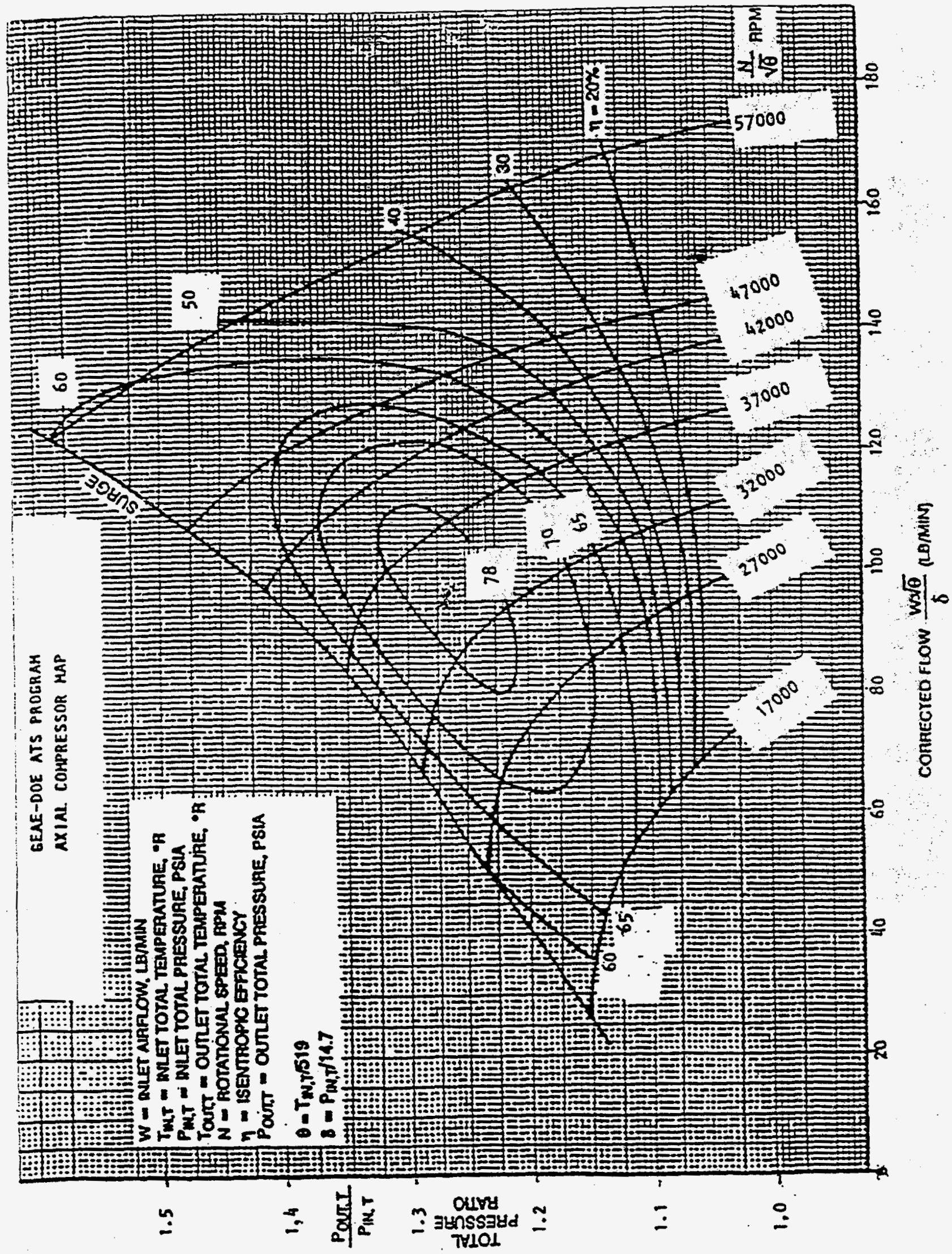

Figure 6.5.3.3. ATS Turbocooler Compressor Performance Map 


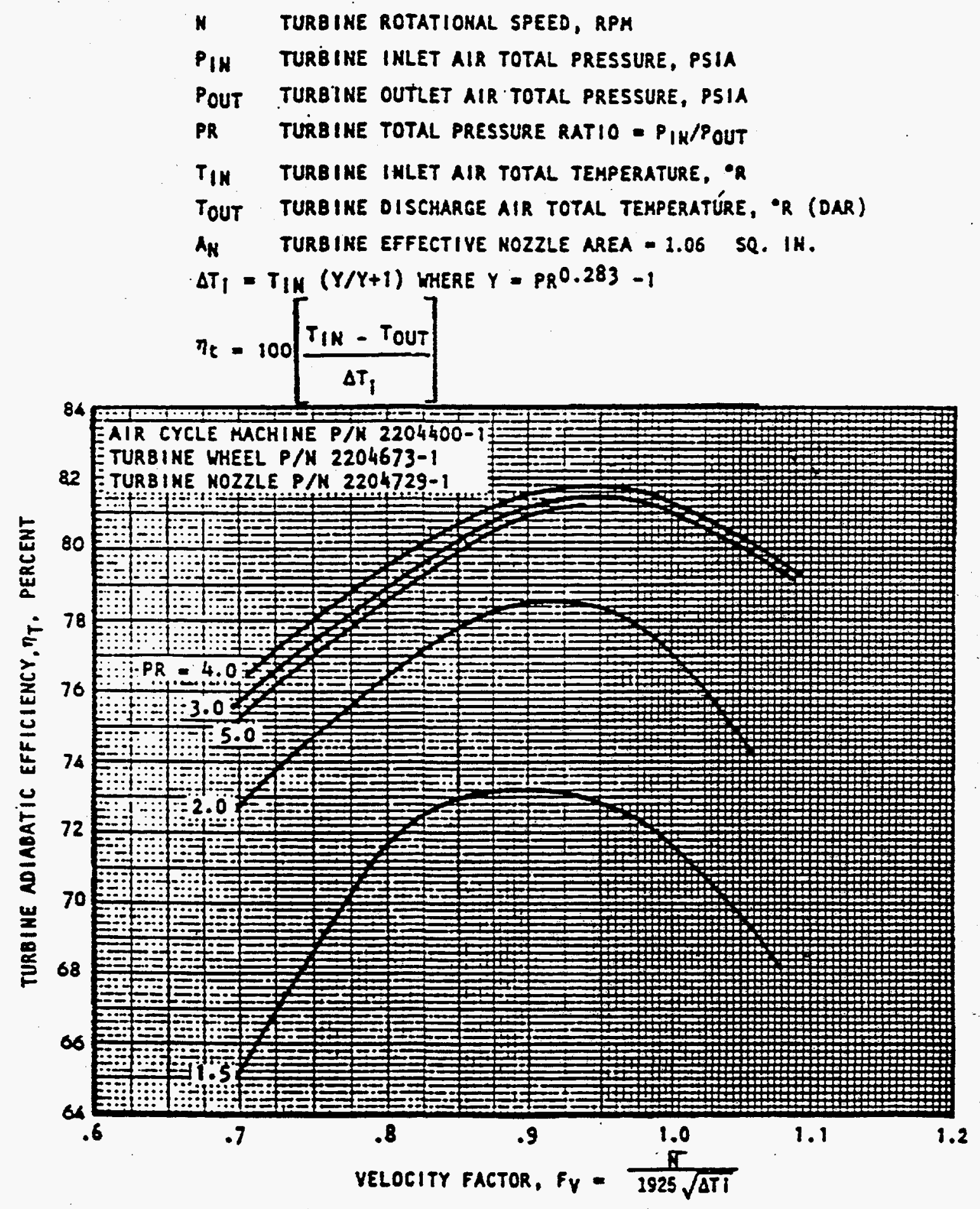

Figure 6.5.3.4. ATS Turbocooler Turbine Performance 


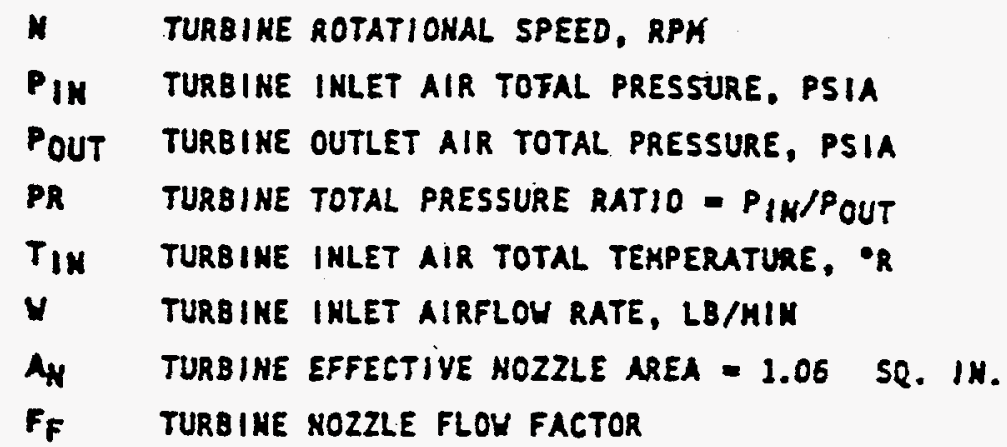

$=\frac{H \sqrt{T}_{I N}}{\left(3(.8)\left(P_{I N}\right)\left(A_{H}\right)\right.}$

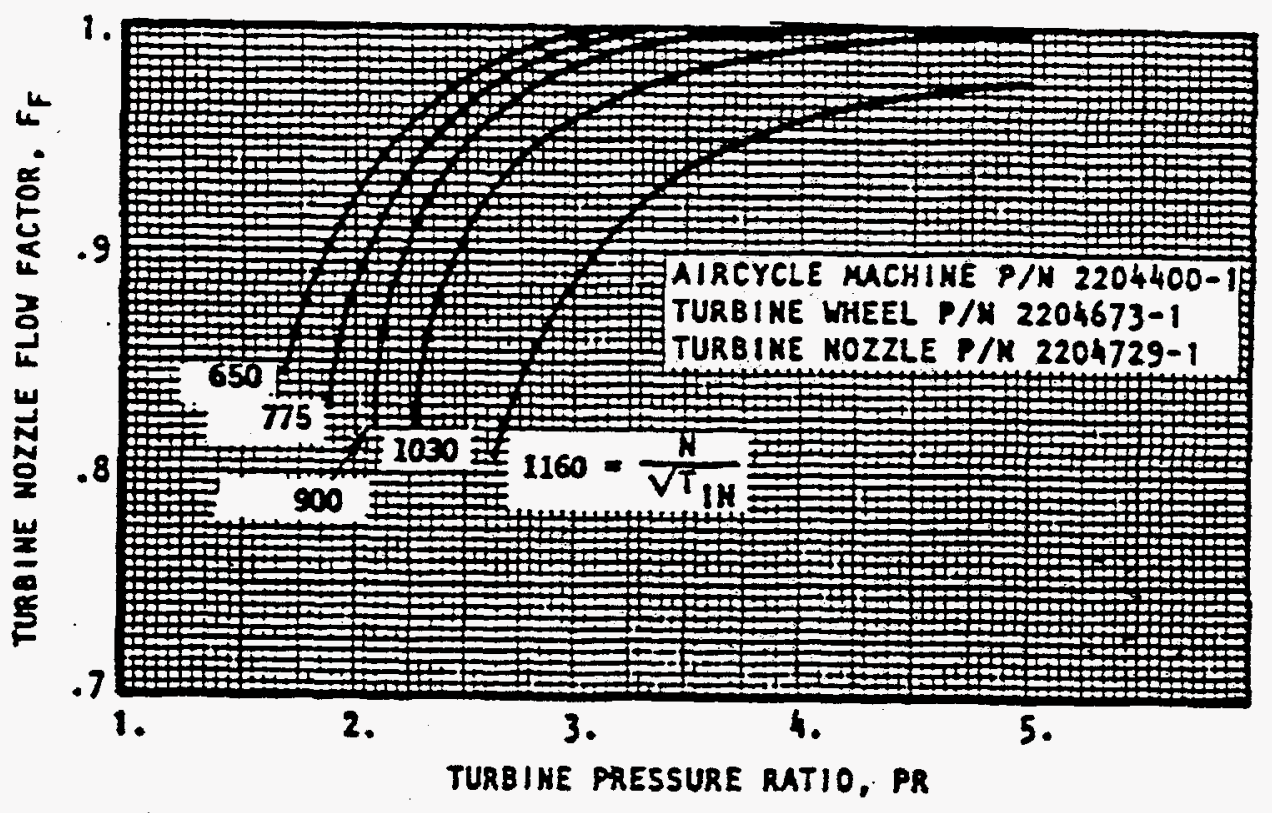

Figure 6.5.3.5. ATS Turbocooler Turbine Performance (cont'd) 


\section{Axial Compressor:}

- Corrected Flow $=97 \mathrm{lb} / \mathrm{min}$

- Pressure Ratio $=1.266$

- Corrected Speed $=34500(60 \%)$

- Blade Tip Diameter $=6$ in.

- Stall Margin $=\mathbf{5 0} \%$

Radial Inflow Turbine:

- Corrected Flow $=0.566 \mathrm{lb} / \mathrm{min}$

- Pressure Ratio $=3.6$

- Corrected Speed $=34500(60 \%)$

- Blade Tip Diameter = 9.3 in.

- Tip Speed $=1625 \mathrm{ft} / \mathrm{sec}$

- $\mathrm{U} / \mathrm{Co}=0.71$

\section{Air Bearings:}

- 1300 Horse Power

- 3 inch Journal

- Operating Speed $=40000 \mathrm{RPM}$

- Operating DN =3,200,000 mm-RPM

- High Load Bearings in limited production on F-22 \& 737X

Figure 6.5.3.6. ATS Turbocooler Design Conditions Summary 


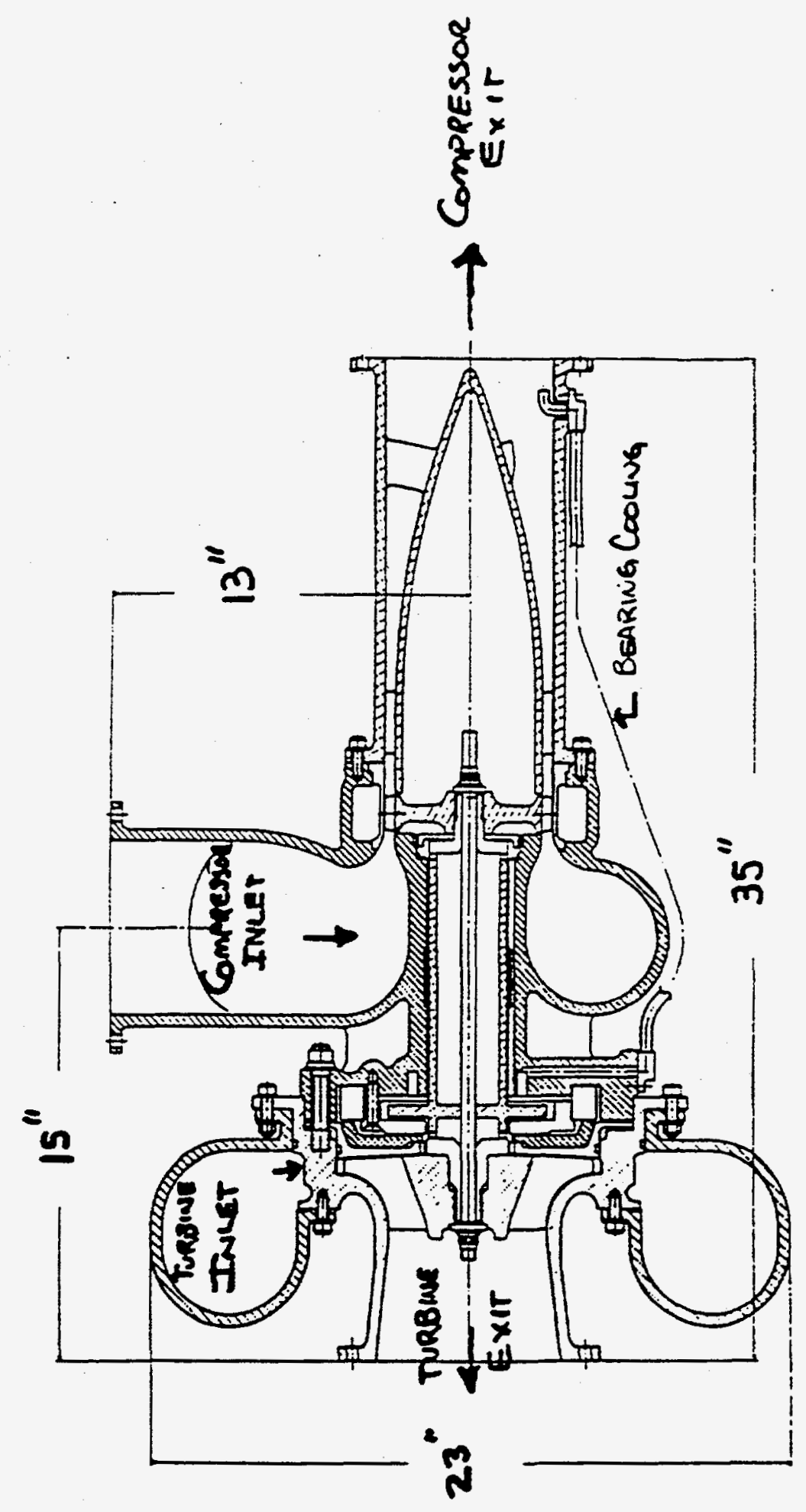

Figure 6.5.3.7. Turbocooler Cross-Section 


\section{Fire Safe Heat Exchangers Schematics}

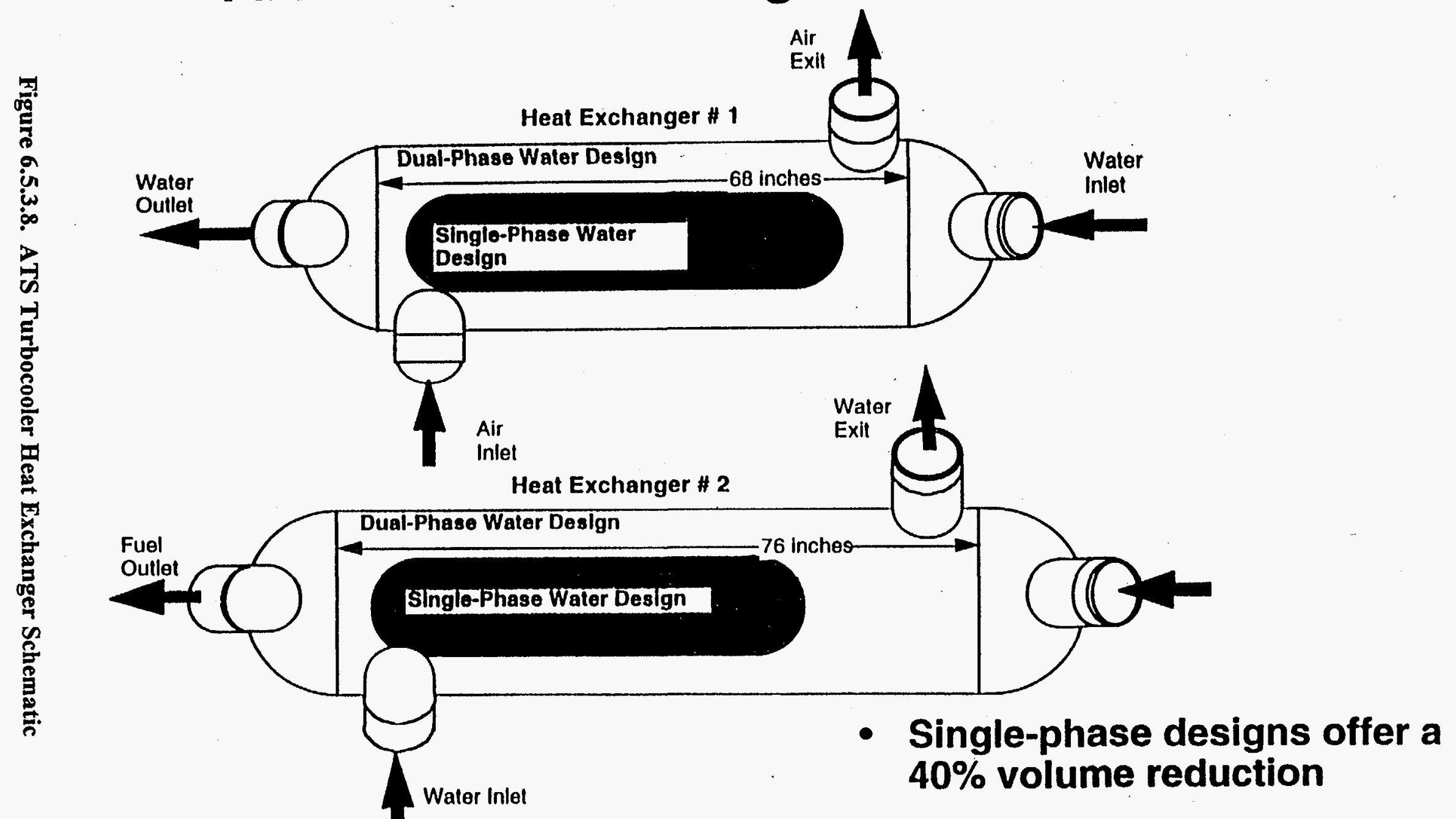




\subsection{ATS LOW PRESSUE POWER TURBINE}

The ATS power turbine is a six-stage design that drives both the low-pressure compressor or booster and the power output shaft. The mechanical design is based on the GE90 low-pressure turbine philosophy. This design utilizes the GE90 type turbine mid frame and case. The power turbine cross section is shown in Figure 6.8.1.

The GE90 LPT secondary flows and temperatures were used for the preliminary estimate of ATS turbine flows and temperatures. These temperatures were used for hardware sizing and are shown in Figure 6.8.2. The hardware has been sized at the ATS operating conditions to meet the following requirements:

Blades:

Disks:

$$
50,000 \text { Hours, } 0.2 \% \text { Creep Life }
$$

$$
100,000 \text { Hours, } 0.2 \% \text { creep life and } 25 \% \text { burst margin }
$$

Shaft and Spline: Low Cycle Fatigue Life of 50,000 Cycles at Max. Torque

Results are summarized in Tables 6.8.1, 6.8.2, and 6.8.3. Figure 6.8.3 shows the recommended materials for this turbine. Due to the high low-pressure turbine inlet temperature and 50,000 hours, $0.2 \%$ creep life requirements, Stages 1 and $2 \mathrm{~N} 6$ blades will require cooling to reduce the metal temperature to $1600 \mathrm{~F}$. Preliminary estimates indicate that a chargeable cooling air flow of approximately $7 \%$ W 25 would be needed to obtain a bulk blade temperature of $1600 \mathrm{~F}$ for the two stages.

To eliminate power turbine blade cooling and the associated complexity, ceramic blades were also evaluated for this application. Due to high rim temperatures, no change in disk material was feasible, but due to lighter ceramic blades, a substantial reduction in disk weight (30\% to $50 \%)$ is possible. Results are summarized in Tables 6.8.4 and 6.8.5.

The turbine mid frame and the rear frame have been adopted from the GE90 design. The forward power turbine bearing and sump design is similar to the GE90 design, whereas the aft sump is based on the proven LM6000 design. For thrust balance, a magnetic thrust compensator is being proposed. 


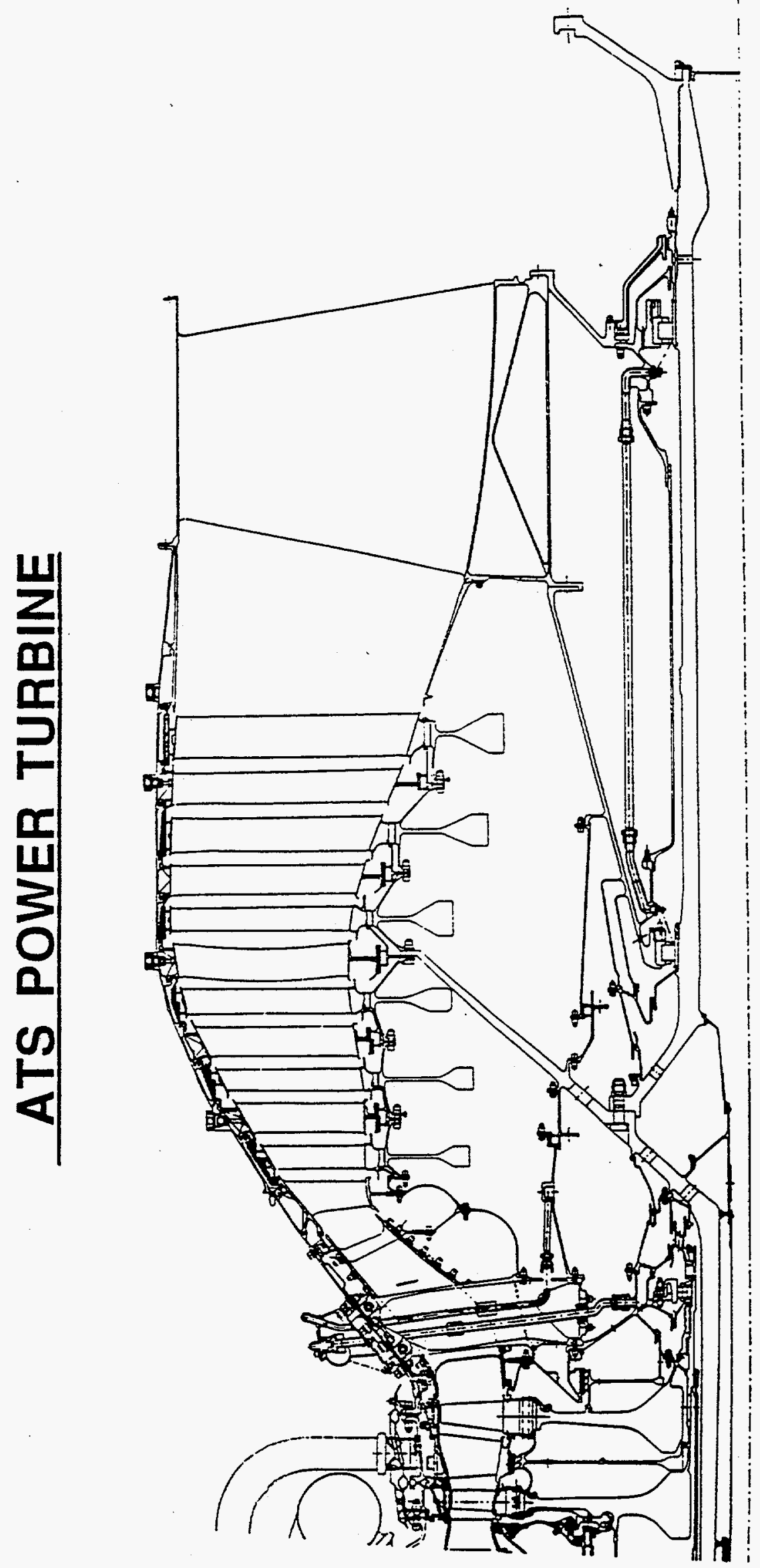

Figure 6.8.1. ATS Power Turbine 


\section{ATS LPT COOLING FLOW TEMPERATURE PRELIMINARY ESTIMATE}



\section{Case \#1023}

$\mathrm{T}_{3}=960^{\circ} \mathrm{F}$

$P_{3}=760$ psia

$\mathrm{T} 48=1900^{\circ} \mathrm{F}$

$P 48=194$ psia

TE $27=480^{\circ} \mathrm{F}$

PE $27=156$ psia

$\mathrm{T}_{48}=1882^{\circ} \mathrm{F}$

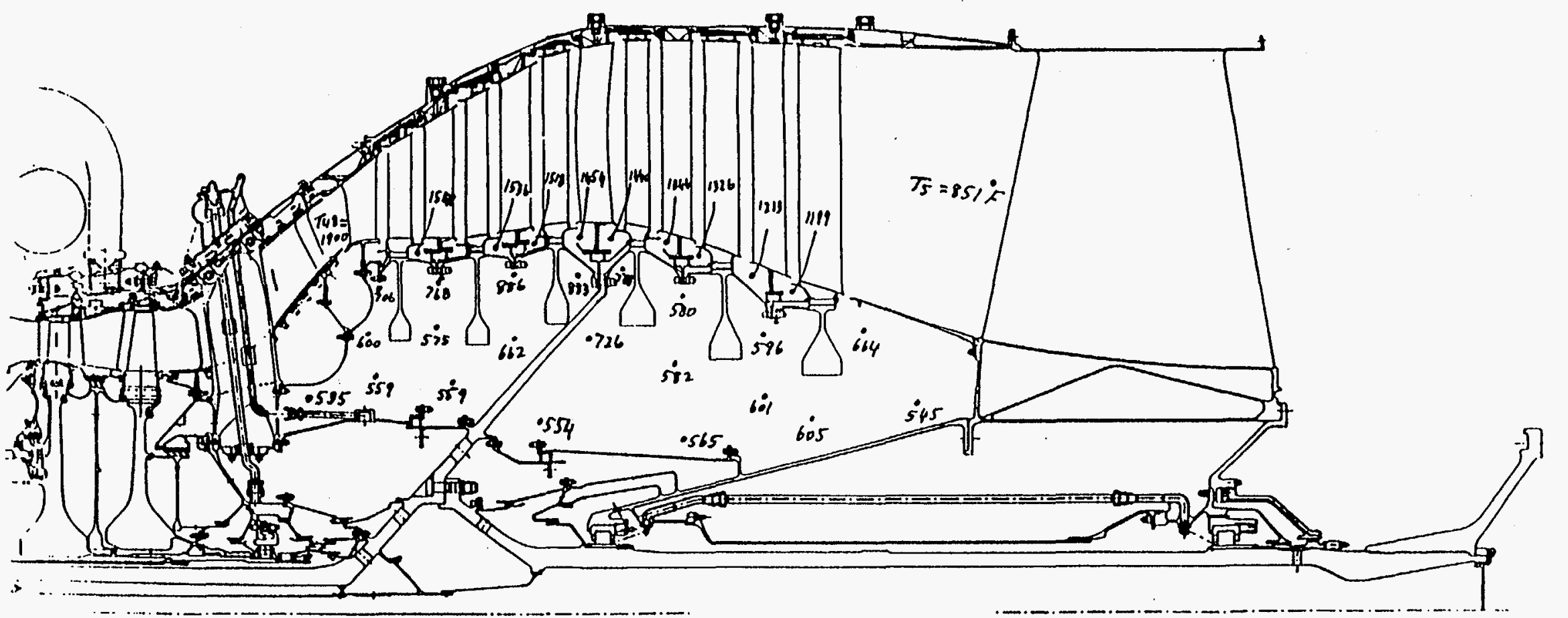




\section{LPT BLADE SIZING}

\begin{tabular}{|c|c|c|c|c|}
\hline \multicolumn{5}{|c|}{ LIFE REQUIREMENTS - 50,000 HOURS, .2\% CREEP } \\
\hline STAGE & TREL ( $\left.{ }^{\circ} \mathrm{F}\right)$ & MATERIAL & $\sigma \mathrm{MAX} .(\mathrm{KSI})$ & REMARKS \\
\hline 1 & 1802 & N6 & 20 & Cooled ${ }^{*}$ to $1600^{\circ} \mathrm{F}$ \\
\hline 2 & 1655 & N6 & 22 & Cooled ${ }^{*}$ to $1600^{\circ} \mathrm{F}$ \\
\hline 3 & 1486 & $\mathrm{~N}_{4}$ & 26 & \\
\hline 4 & 1300 & R125 & 26 & \\
\hline 5 & 1124 & R125 & 38 & \\
\hline 6 & 955 & R125 & 37 & \\
\hline
\end{tabular}

* No prior GE experience (COOled Shrouded blades) WOULd ReQuire DEVELOPMENT OF TECHNOLOGY. 


\section{LPT DISK SIZING}

\begin{tabular}{|c|c|c|c|c|c|c|}
\hline \multicolumn{7}{|c|}{ LIFE REQUIREMENTS - 100,000 HOURS, .2\% CREEP } \\
\hline \multirow[b]{2}{*}{ STAGE } & \multicolumn{3}{|c|}{$\sigma(\mathrm{KSI}) / \mathrm{T}^{\circ} \mathrm{E}$} & \multirow[b]{2}{*}{ MATERIAL } & \multirow{2}{*}{$\begin{array}{c}\text { BURST } \\
\text { MARGIN } \\
\end{array}$} & \multirow{2}{*}{$\begin{array}{l}\text { LCF LIFE } \\
\text { CYCLES }\end{array}$} \\
\hline & POST & L. RIM & BORE & & & \\
\hline 1 & $21 . / 1202$ & $20.0 / 1202$ & $146 / 664$ & R88DT & $25 \%$ & $50 \mathrm{~K}$ \\
\hline 2 & $26 . / 1243$ & $17.0 / 1243$ & $157 / 697$ & & & $50 \mathrm{~K}$ \\
\hline 3 & $26 . / 1269$ & $25.0 / 1269$ & $157 / 655$ & & & $50 \mathrm{~K}$ \\
\hline 4 & $29 . / 1178$ & $41.0 / 1178$ & $111 / 676$ & "Groh" \#6 1718 & & $25 \mathrm{~K}$ \\
\hline 5 & $27 . / 1030$ & $27.0 / 1030$ & $115 / 578$ & & & $25 \mathrm{~K}$ \\
\hline 6 & $27 . / 969$ & $8.0 / 969$ & $111 / 621$ & & & $25 \mathrm{~K}$ \\
\hline
\end{tabular}

POST KT $\approx 1.6$, L. RIM KT $\approx 1.8$

R88DT .2\% CREEP @ 1270 ${ }^{\circ} \mathrm{F}$ (100K HOURS) - OLIMIT $=39 \mathrm{KSI}$

"GROH" \#6 $1718.2 \%$ CREEP @ 1165 $\mathrm{F}$ (100K HOURS) - OLIMIT $=45 \mathrm{KSI}$ 


\section{AFT SHAFT AND SPLINE SIZING}

SPEED - 3000 RPM

MAX TORQUE - 315,220 FT. LB.

ADDERS: OVERSHOOT - $5 \%$

GROWTH - $10 \%$

VIBRATION - $15 \%$

DESIGN TORQUE 418,690 FT. LB.

SHAFT LCF LIFE 50,000 CYCLES

MATERIAL: MARAGE 250 AFT SHAFT

INCO 718 LPT SHAFT 


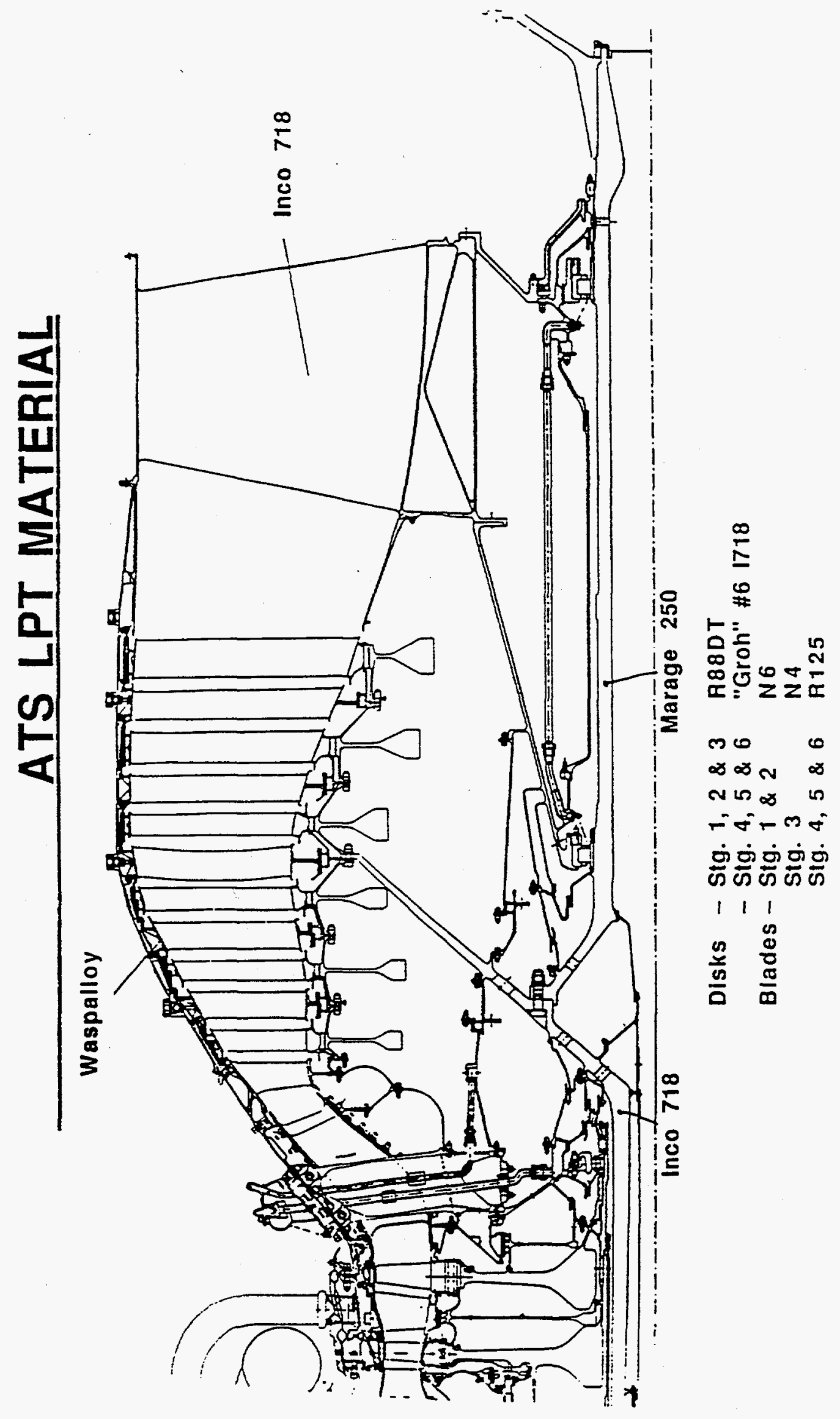

Figure 6.8.3. ATS LPT Materials 


\section{LPT DISK SIZING (CERAMIC BLADES)}

\begin{tabular}{|c|c|c|c|c|c|c|c|}
\hline \multicolumn{7}{|c|}{ LIFE REQUIREMENTS - 100,000 HOURS, .2\% CREEP } & \multirow{3}{*}{$\begin{array}{c}\text { DISK } \\
\Delta W(\%)\end{array}$} \\
\hline & \multicolumn{3}{|c|}{$\sigma(\mathrm{KSI}) / \mathrm{T}^{\circ} \mathrm{E}$} & \multirow[b]{2}{*}{ MATERIAL } & \multirow{2}{*}{$\begin{array}{c}\text { BURST } \\
\text { MARGIN }\end{array}$} & \multirow{2}{*}{$\begin{array}{l}\text { LCF LIFE } \\
\text { CYCLES }\end{array}$} & \\
\hline STAGE & POST & L. RIM & BORE & & & & \\
\hline 1 & $9 . / 1202$ & $17.0 / 1202$ & $138 / 664$ & R88DT & $25 \%$ & $50 \mathrm{~K}$ & -35 \\
\hline 2 & $12 . / 1243$ & $11.0 / 1243$ & $155 / 697$ & & & $50 \mathrm{~K}$ & -43 \\
\hline 3 & 12. / 1269 & $21.0 / 1269$ & $159 / 655$ & & & $50 \mathrm{~K}$ & -43 \\
\hline 4 & $13 . / 1178$ & $37.0 / 1178$ & $117 / 676$ & "Groh" \#6 1718 & & $25 \mathrm{~K}$ & -44 \\
\hline 5 & $15 . / 1030$ & $27.0 / 1030$ & $114 / 578$ & & & $25 K$ & -45 \\
\hline 6 & $13 . / 969$ & $5.0 / 969$ & $114 / 621$ & & & $25 \mathrm{~K}$ & -49 \\
\hline
\end{tabular}

POST KT $\approx 1.6$, L. RIM KT $\approx 1.8$

R88DT .2\% CREEP @ 1270 F (100K HOURS) $-\sigma$ LIMIT $=39 \mathrm{KSI}$

"GROH" \#6 1718 .2\% CREEP@1165F (100K HOURS) - - LLIMIT = $45 \mathrm{KSI}$ 


\section{LPT BLADE SIZING}

\begin{tabular}{|c|c|c|c|c|}
\hline \multicolumn{5}{|c|}{ LIFE REQUIREMENTS - 50,000 HOURS, . $2 \%$ CREEP } \\
\hline STAGE & TREL $\left({ }^{\circ} \mathrm{F}\right)$ & MATERIAL & $\sigma \mathrm{MAX} .(\mathrm{KSI})$ & REMARKS \\
\hline 1 & 1802 & $M I$ & 8.0 & \multirow{6}{*}{$\begin{array}{l}\text { At } 1800^{\circ} \mathrm{F} \text {, for } 50 \mathrm{~K} \\
\text { Hours } .2 \% \text { Creep } \\
\text { Life, } \sigma \mathrm{max} \approx 13.0 \mathrm{KSI}\end{array}$} \\
\hline 2 & 1655 & & 10.0 & \\
\hline 3 & 1486 & & 10.0 & \\
\hline 4 & 1300 & & 12.0 & \\
\hline 5 & 1124 & & 14.0 & \\
\hline 6 & 955 & & 14.0 & \\
\hline
\end{tabular}




\subsection{ENGINE SYSTEM AND PACKAGING}

Using the resulting engine flowpath, as shown in Figure 6.1.1, an engine layout was completed. This engine layout and identification of major engine systems is shown in Figure 6.9.1.

The engine system shown in Figure 6.9.1 was also incorporated in an engine packaging study, and the resulting layout of the engine packing module is shown in Figure 6.9.2.

\subsection{PLANT LAYOUT}

The resulting engine system module was integrated in plant layout arrangements for a combined cycle system and a simple cycle system. Figures 6.10.1 and 6.10.2 show the combined cycle plant layout, and Figures 6.10.3 and 6.10.4 show the simple cycle layout. 


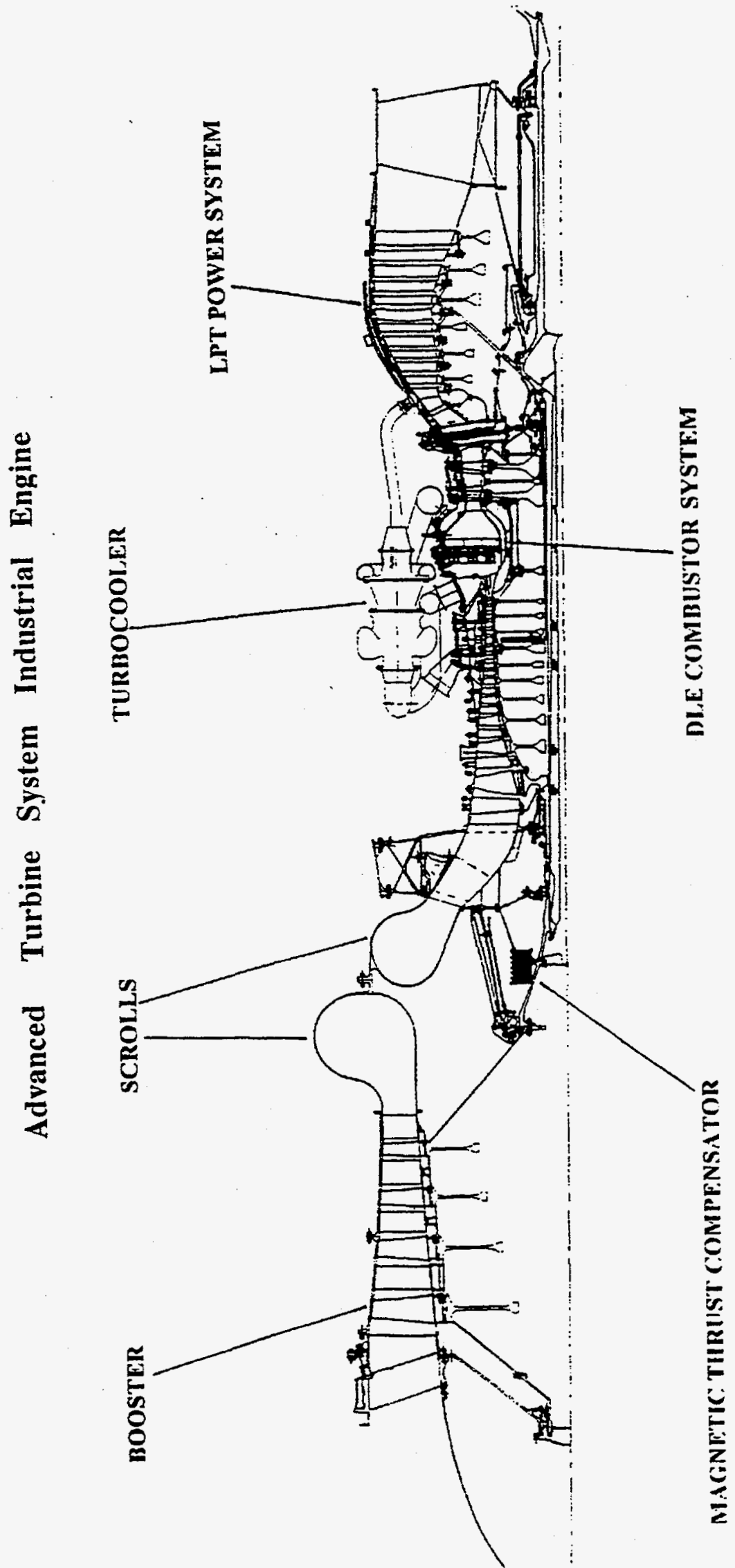

Figure 6.9.1. ATS Industrial Engine Cross-Section 

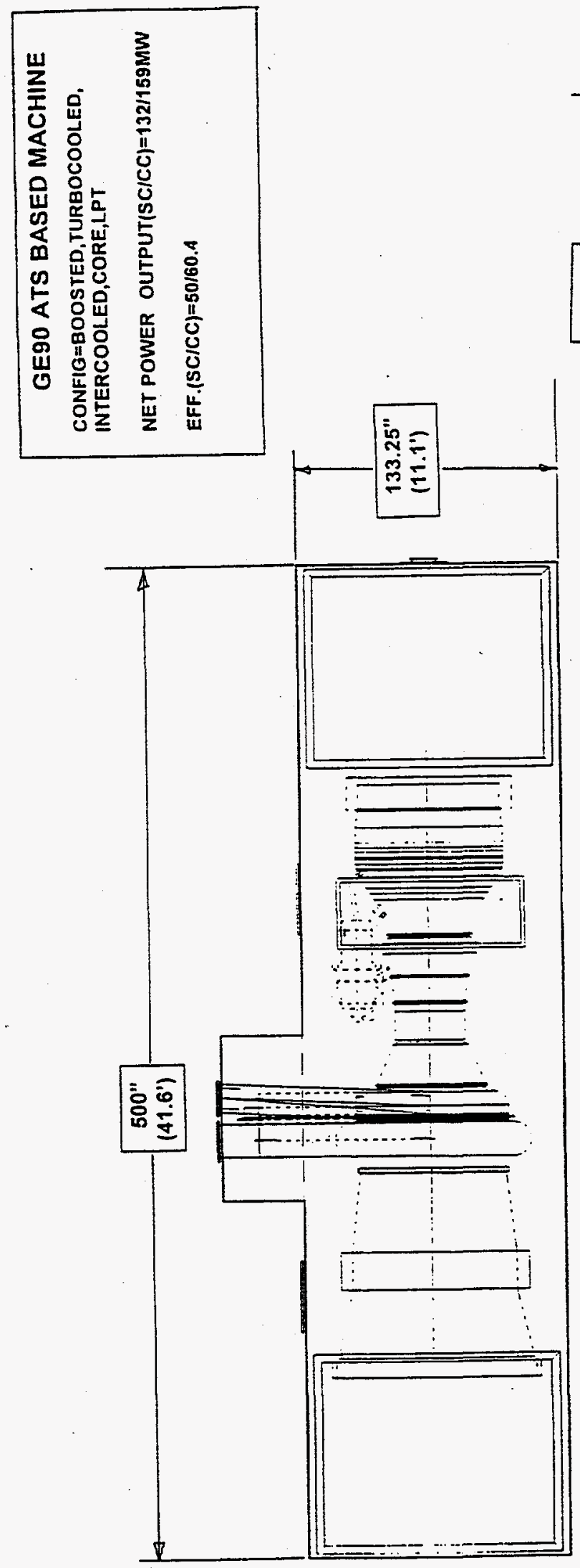
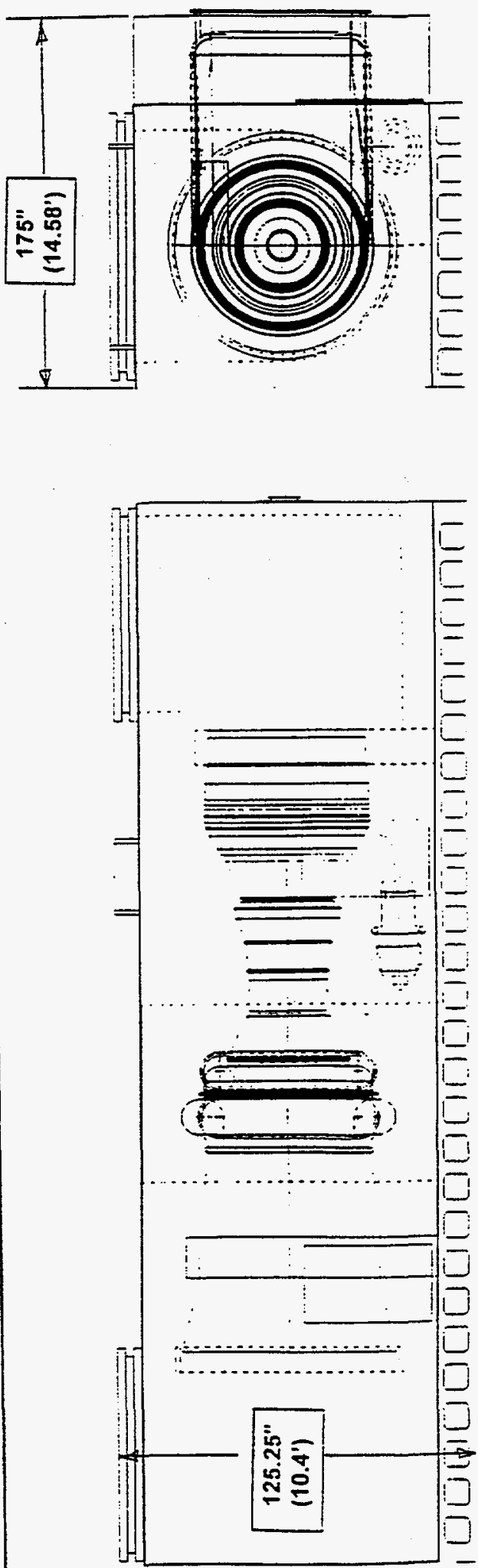

Figure 6.9.2. ATS Packaging Layout 


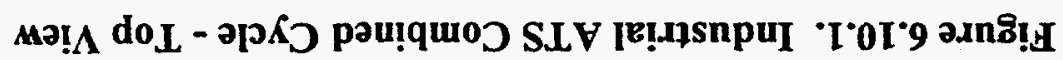

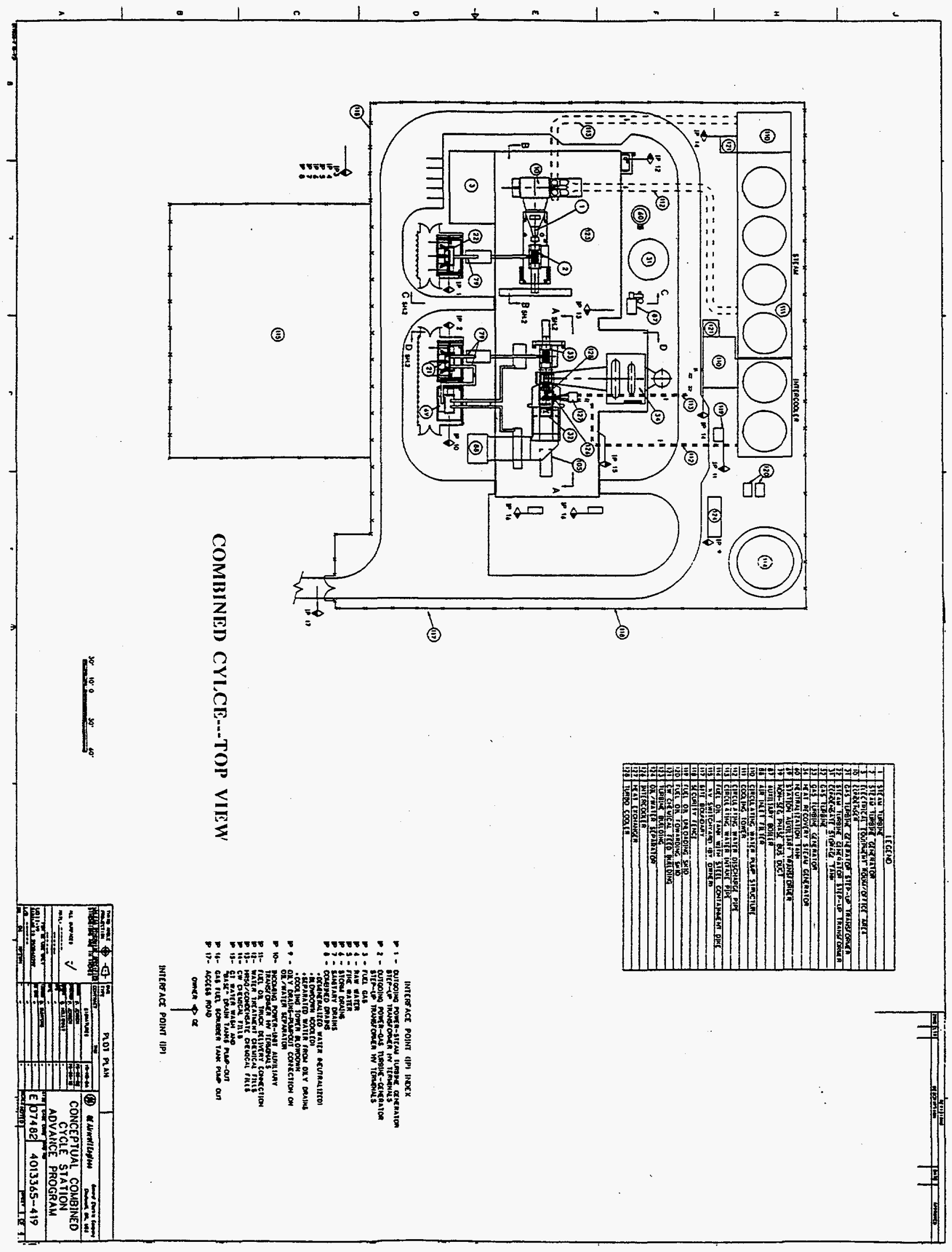




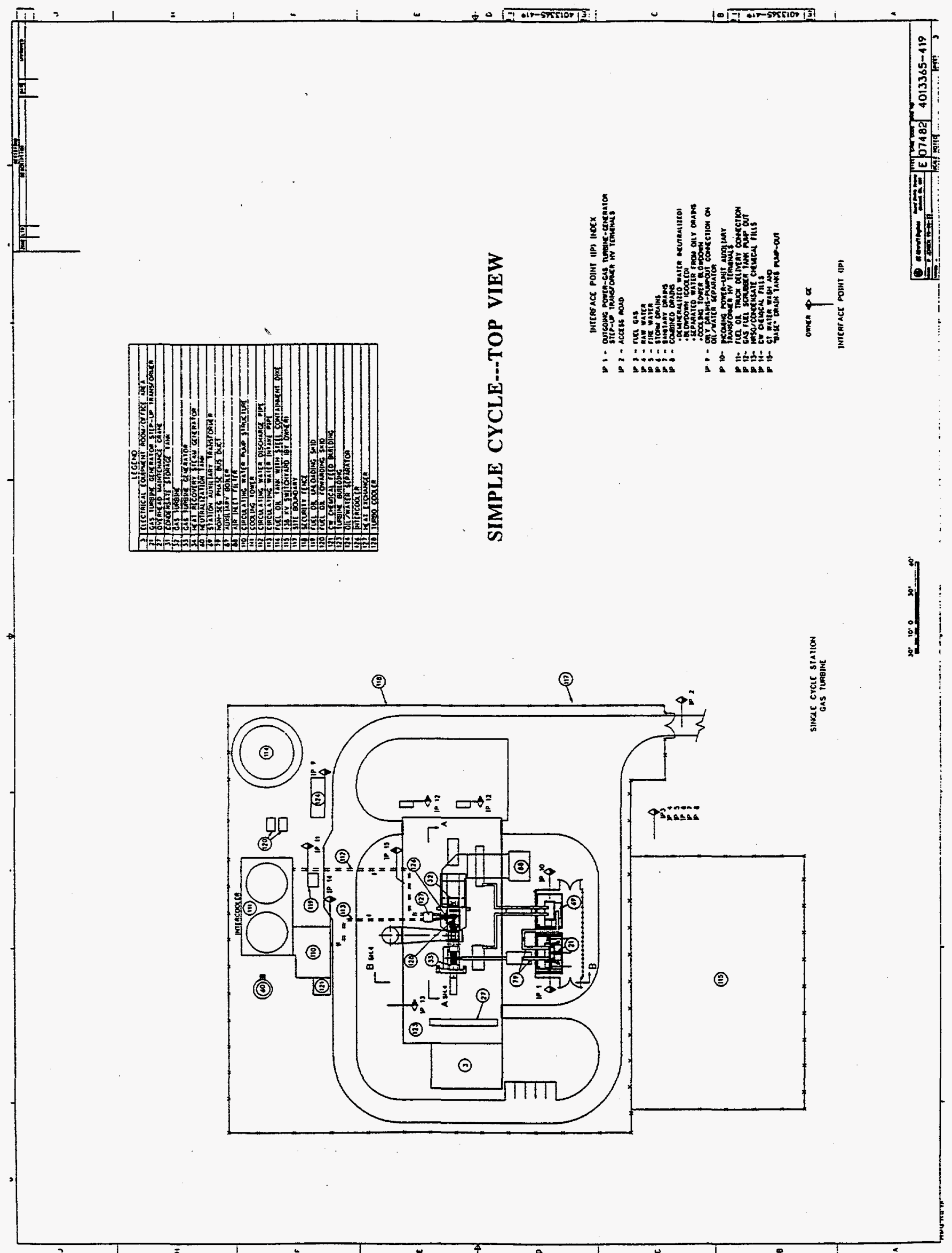

Figure 6.10.3. Industrial ATS - Simple Cycle - Top View 
